FROM FELT TIP TO TECHNOLOGY: THE CHALLENGES OF REPRESENTING TRADITIONAL KNOWLEDGE IN A GIS PLATFORM TO CREATE A KNOWLEDGE SURFACE

\author{
by \\ Julie B. Robertson \\ B.A. Geographic Analysis \\ Ryerson University, 2012 \\ A thesis \\ presented to Ryerson University \\ in partial fulfillment of the \\ requirements of the degree of \\ Master of Applied Science \\ in the Program of \\ Environmental Applied Science and Management
}

Toronto, Ontario, Canada, 2017

CJulie B. Robertson, 2017 


\section{Author's Declaration}

I hereby declare that I am the sole author of this thesis. This is a true copy of the thesis, including any required final revisions, as accepted by my examiners.

I authorize Ryerson University to lend this thesis to other institutions or individuals for the purpose of scholarly research.

I further authorize Ryerson University to reproduce this thesis by photocopying or by other means, in total or in part, at the request of other institutions or individuals for the purpose of scholarly research.

I understand that my thesis may be made electronically available to the public. 


\title{
Abstract \\ FROM FELT TIP TO TECHNOLOGY: THE CHALLENGES OF REPRESENTING TRADITIONAL INUIT KNOWLEDGE IN A GIS PLATFORM TO CREATE A KNOWLEDGE SURFACE.
}

\author{
MASc, 2017 \\ Julie B. Robertson \\ Environmental Applied Science and Management \\ Ryerson University
}

Traditional knowledge (TK) has been the keystone to survival in the Arctic for thousands of years. Caribou are integral to the society, health and culture of the Inuit, the Indigenous peoples of the Arctic. There is a lack of research regarding caribou on King William Island (KWI), Nunavut. Through a project in Gjoa Haven, located on KWI, Inuit Elders and hunters used maps to help represent their knowledge of caribou in the region. These 32 maps were processed in a GIS to explore the spatial dimensions of TK, and different forms of knowledge representation. Using vector data the features drawn were separated into lines and polygons to show hotspots of caribou knowledge. Using a fuzzy raster methodology, all caribou data was summed to create a collective knowledge surface of the caribou features. These maps refine the data from the vector maps and create a continuous surface that aims to better reflect the collective nature of TK. This research explores the challenges of representing TK using western technologies, and application of fuzzy methodologies for improving the representation.

Key words: Traditional knowledge, fuzzy methodology, caribou, GIS, vector data, Gjoa Haven, King William Island, Inuit, Nunavut 


\section{Acknowledgements}

This thesis would not be possible without the generosity of the Inuit Elders and hunters of Gjoa Haven, Nunavut who permitted the use of the features drawn in their 32 maps, representing Inuit knowledge of caribou. Thank you to Dr. Gita Ljubicic, Department of Geography, Carleton University for facilitating access to these maps, the map digitization completed at Carleton, and ongoing feedback through this research process. Thank you to Dr. David Atkinson for your technical knowledge as I explored different options for representing and interpreting these maps drawn by Inuit Elders and hunters. 


\section{Dedication}

This thesis is dedicated to several very important people in my life:

My father Ron Robertson who believed in me as I embarked on this long journey in 2008. Although he is not with us to see me finish, he has guided me along the way.

A special thank you to my Mom, sister Kimberly and son Drew. Without this team, I would not have faced the challenges head-on and persevered. The three of you believed I would return to complete this dream on days when I did not think it was possible. Thank you for allowing me to grow and helping set my sights high. 


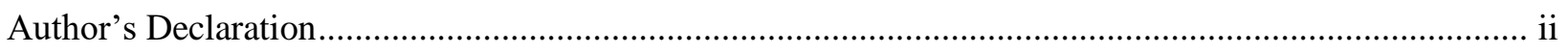

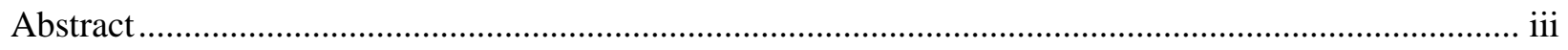

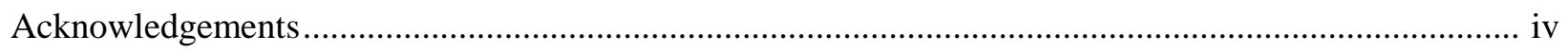

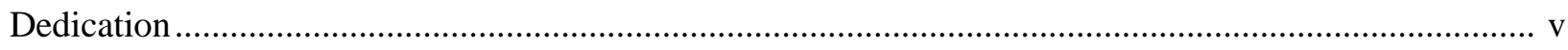

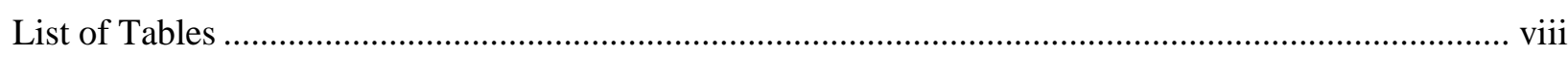

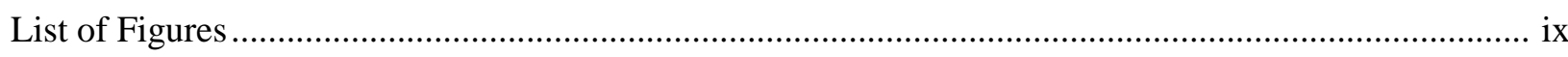

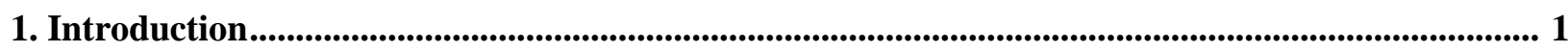

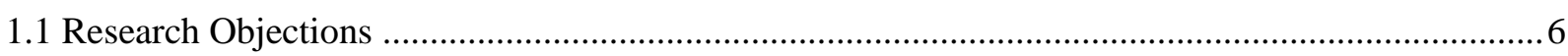

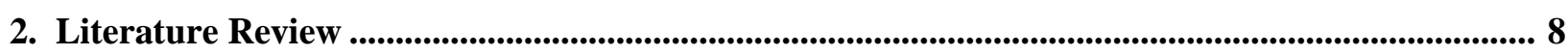

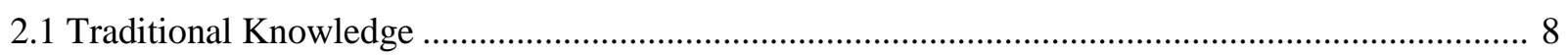

2.1.1 Traditional Knowledge and Western Science....................................................... 11

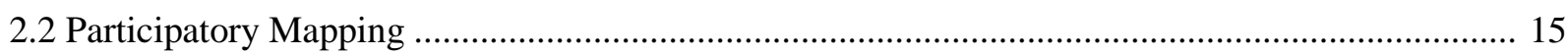

2.3 Geographic Information Systems and Traditional Knowledge ............................................... 18

3. Methodology ............................................................................................................................................................... 22

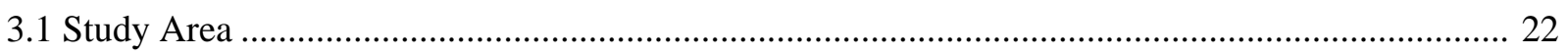

3.2 Caribou in the King William Island Region of Nunavut ........................................................ 26

3.3 Barren Ground Caribou Habitat in the Study Area ..................................................................... 30

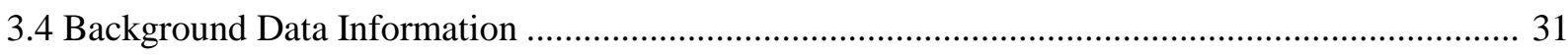

3.4.1 The Role of this Research within the Larger Project.................................................. 32

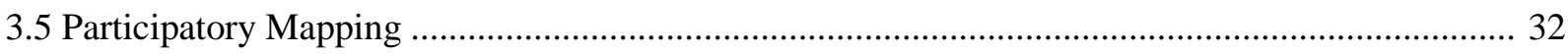

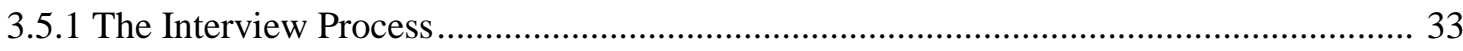

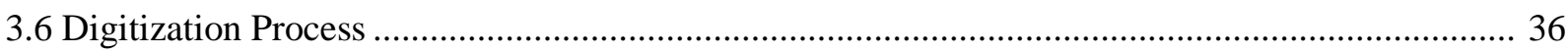

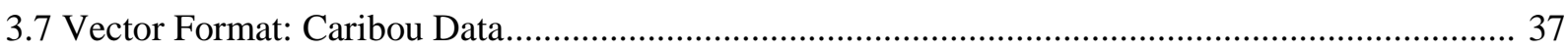

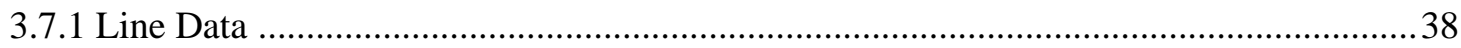

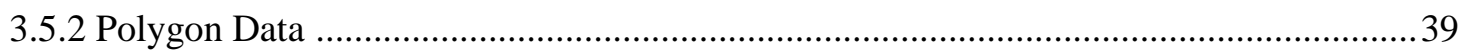

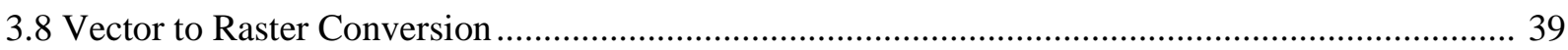

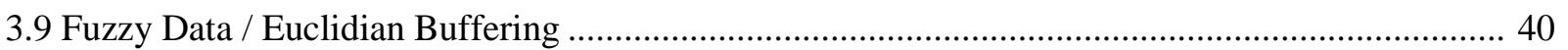

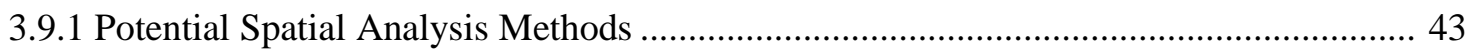

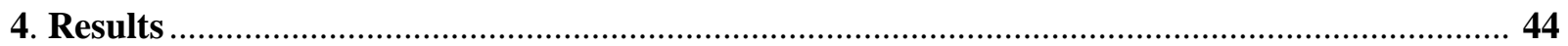

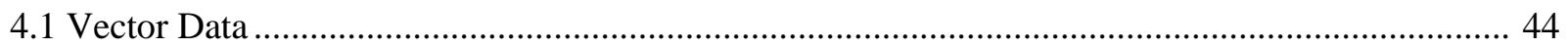

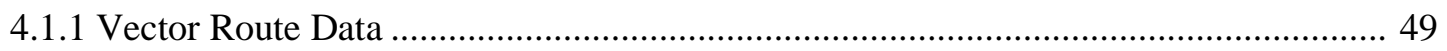




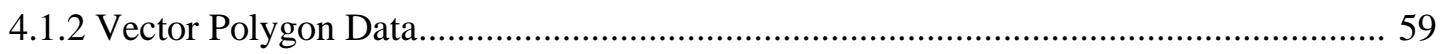

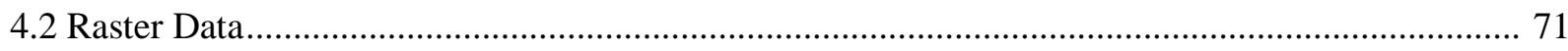

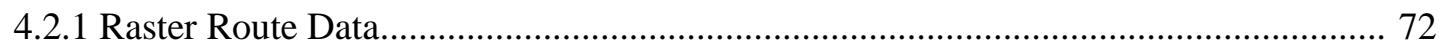

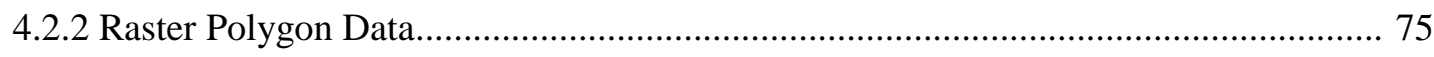

4.3 Comparative Analysis of Hunting Data in Vector and Raster Fuzzy Format ............................... 78

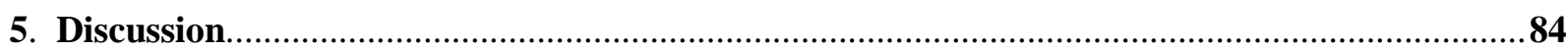

5.1 Successes and Challenges of Vector Data Maps........................................................................ 85

5.2 Successes and Challenges of Raster Data Fuzzy Method Maps ................................................. 87

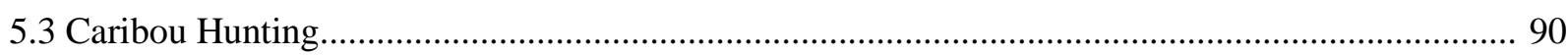

5.4 Observed Differences between Caribou TK in Maps and Caribou Management........................... 91

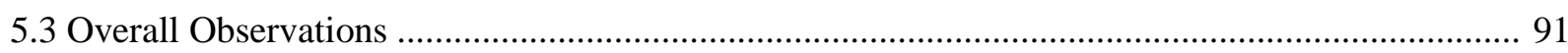

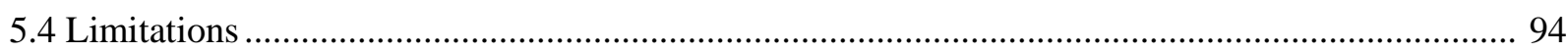

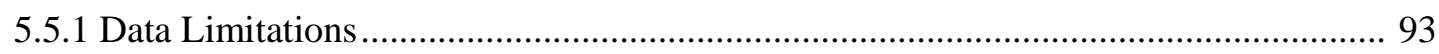

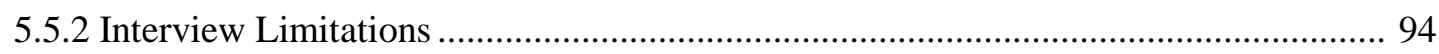

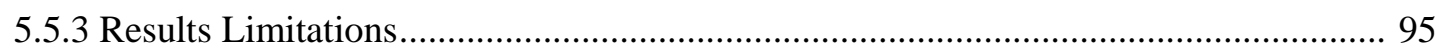

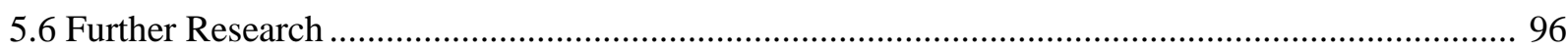

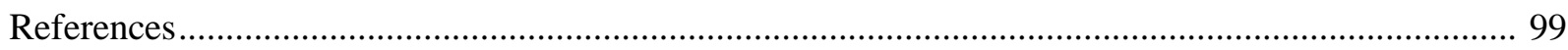




\section{List of Tables}

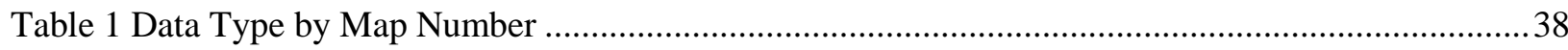

Table 2 Recommendation for Improving the Translation of TK to a GIS Platform ................................96 


\section{List of Figures}

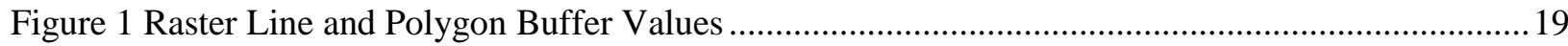

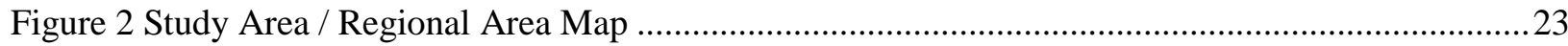

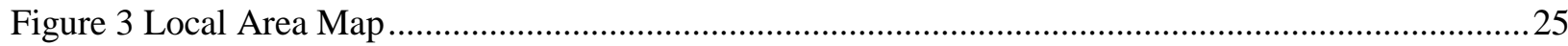

Figure 4 Geographic Populations of Caribou and Reindeer in Nunavut ..............................................22

Figure 5 Gjoa Haven Traditional Knowledge Map Number N5, July 22, 2013 .....................................35

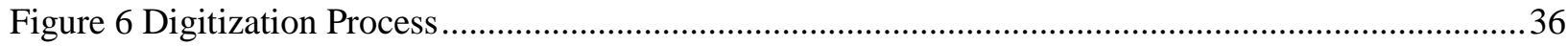

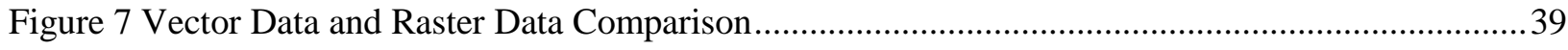

Figure 8 Vector to Raster Conversion Process …................................................................................... 41

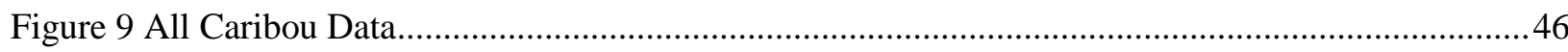

Figure10 Layering Effect of Vector Data with Similar Coordinates ...................................................47

Figure 11 All Caribou Route and Area Knowledge on 32 TK Maps, Gjoa Haven, NU..........................49

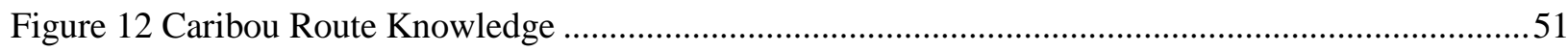

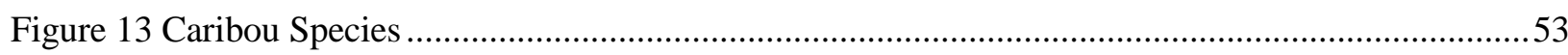

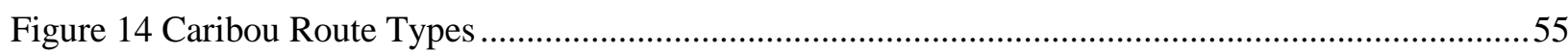

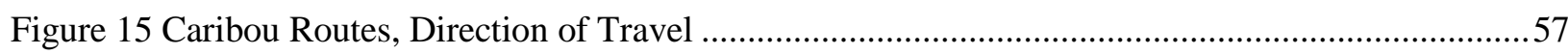

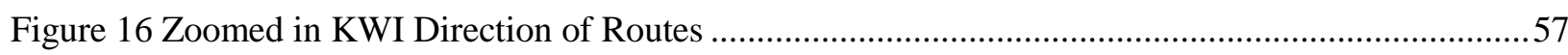

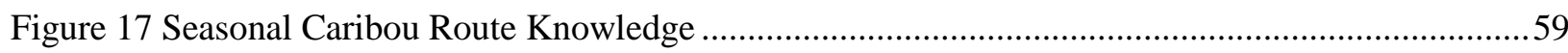

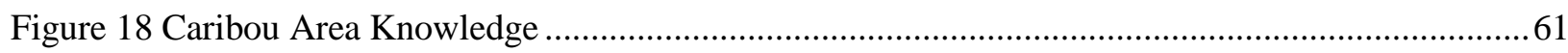

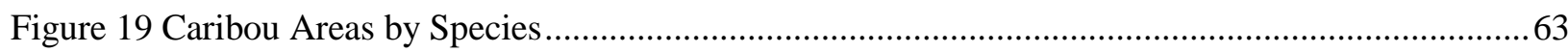

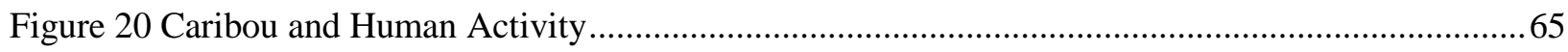

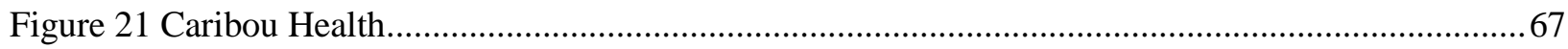

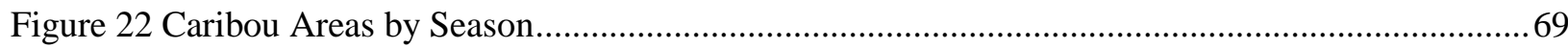

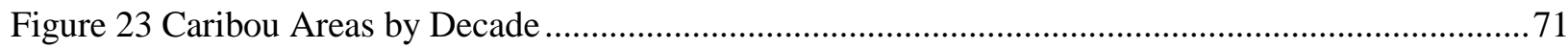

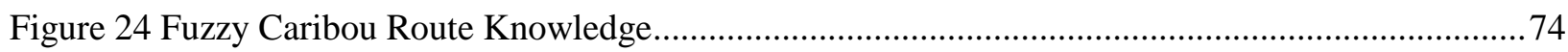

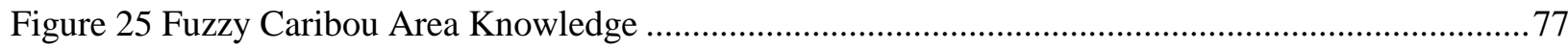

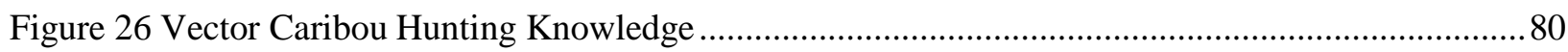

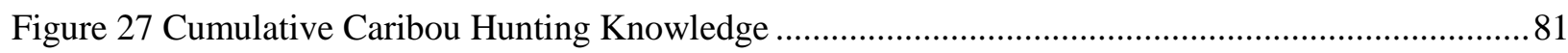

Figure 28 Caribou Hunting area and routes with 20 KM Buffer .........................................................83 


\subsection{Introduction}

Traditional knowledge (TK) is the key to survival for Inuit in the Canadian Arctic (Duerden, et al., 1996; Engler, et al., 2013; Freeman, et al., 2005; McGregor, 2004). This survival is nested in the relationship the Inuit have with the environment; the wildlife, land, sea, and ice and is the basis of TK (Engler, et al., 2013; Freeman, et al., 2005; Pearce, et al., 2011; McGregor, 2004; Duerden, et al., 1996; Berkes and Berkes, 2007). There is a myriad of definitions of traditional knowledge, but there are common threads to define TK in an Inuit context. There is consensus among scholars that TK is an oral tradition, historically fundamental to the survival of hunter - gatherer societies (McGregor, 2004; Duerden, et al., 1996). Through an oral manner, the knowledge is passed from Elders to the younger generation and from community to community. Furthermore, human interaction and long-term direct experience are the fundamental processes that are the building blocks of TK (Engler, et al., 2013; Pulsifer, et al., 2011; Freeman, et al., 2000; Pearce, et al., 2011). This intimate knowledge of the landscape creates mental maps that are the crucial to understanding the environment (Freeman, et al., 2000, Pearce 2011). Traditional knowledge is also an aspect of social processes that are critical to life in the Arctic (Engler, et al., 2013, Pulsifer, et al., 2011, Leduc, 2006). TK is spiritual in nature as well as pertaining to all aspect of the ecosystems (McGregor, 2004; Duerden, et al., 1996; Pearce, et al., 2011; Martin, 2009). Additionally, ecosystems are difficult to separate and define as they are nested within each other creating a continuous borderless system which aligns with Inuit view of their environment (Berkes and Berkes., 2009).

A cautionary note by The World Intellectual Property Organization stated in 2002 that TK is the process of interactions between members of the community and is a continuum of knowledge. Caquard states in a 2011 paper that there is a growing interest in the relationship between the Inuit TK narrative and maps. Yet, mapping of such knowledge creates a snapshot in time while TK is difficult to capture in a singular moment as it is constantly changing and every knowledge holder has a personal perspective of the knowledge (WIPO, 2002). Partnerships with the Inuit have been evolving since the 1970's and are shaping the way the they are included in environmental governance (Berkes, et al., 2007). In 1992, the 
then Minister of Environment Ellen Bielawski suggested that Arctic scientists recognize the worth of TK and understand the value in Inuit "ways of knowing" (Martin, 2009). However, the value of traditional knowledge is not in a qualitative function but, is the value of understanding the environment, a person's relationship within the environment, how to interpret and understand that environment (Berkes, et al., 2009).

Caribou are vital to the culture, health and social aspects of Inuit societies and are an integral part of the complex ecological systems in the Canadian Arctic (Kendrick, 2003; Miller, et al., 2009; Russell, et al., 2000). Inuit are dependent on caribou as a food source that is shared amongst the community as required by cultural norms (Mason, et al., 2012). During the 1980's the Canadian Government established caribou co-management boards to provide management of the complex herd systems (Kendrick, 2003; Russell, et al., 2000). The collection of caribou data is costly and difficult, and as such is collected on an average of six year intervals (Kendrick, et al., 2008; Russell, et al., 2000). Based on this cost and challenges with timing, weather and environmental factors herd range maps of Barren-Ground caribou such as those produced by the Beverly and Qamanirjuaq Caribou Management Board (BQCMB) and the Nunavut Wildlife Management Board (NWMB) are often qualified as being partial, based on available data and not necessarily the complete picture.

The cultural significance of caribou to the Inuit was one of the catalysts for the larger research initiative in Gjoa Haven, Nunavut, located on King William Island (KWI), and led by Dr. Gita Ljubicic in the Department of Geography and Environmental Studies, at Carleton University. A group of community representatives, including Elders and hunters, participated in planning workshops where caribou was the dominant theme of their initial discussions (Laidler and Grimwood, 2010). They highlighted the importance of sharing their knowledge of caribou with wildlife managers and caribou researchers, to ensure more representation of Inuit knowledge in decision-making as they rely on caribou hunting yearround. Through follow-up research, a discrepancy was noted between the caribou Inuit described on KWI and in the region, and the caribou range maps put out by the Government of Nunavut and co-management board range maps (Ljubicic et al., 2017). For example, the NWNB recorded on a 2011 map that King 
William Island is under-represented in most maps regarding caribou, notably the Nunavut Caribou Strategy report 2011 where the island is noted as "an area of uncertainty" (NWMB, 2011). The TK used in this analysis was recorded through participatory mapping in interviews, with 32 Inuit Elders and hunters in Gjoa Haven, to help express their knowledge of caribou. These interviews were conducted by a Postdoctoral fellow and a Master's student in Dr. Ljubicic's research group. These maps help to begin addressing the gap in knowledge of caribou on KWI, based on caribou range maps available from the Government of Nunavut and caribou co-management boards.

Participatory mapping has been widely used for the expression of TK as it aides in the representation of communication between the knowledge holder, the cartographer, and the end user (Crampton, 2001). Participatory mapping is complex and extensive including action-oriented intentions, partnerships and collaborative partnerships that are equal, respectful, and shared (Grimwood, et al., 2012; Parlee, et al., 2005). Participatory mapping is aimed at reducing power imbalances and social differences between western science and Indigenous driven approaches to environmental issues (Robinson, 2016).

Participatory mapping aligns the power of knowledge to provide a common ground for all parties. In a 2001 paper Crampton suggests that the Map Communication Model (MCM) provides a basis to understand that a hand drawn map by an Elder has equal merit to the complex map created in GIS. The map is the means of communication between the two parties with the power of the knowledge shared between the knowledge holder and the end user (Crampton, 2001). The spirit of participatory mapping is to combine sound methods of scientific inquiry with community based strategies which foster team work and require mutual understanding and respect from all members to formulate research queries that are relevant to the community (Parlee. et al., 2005; Cutts, et al., 2011).

Traditional knowledge and western science are similar in that they both are ways of knowing, both based on observations and the accumulation of knowledge. Both systems aim to create order out of disorder (Berkes, et al., 2009). Yet, they are dissimilar in their transfer of knowledge and the rationale of qualitative versus quantitative analysis. Indigenous knowledge systems are not quantitative in nature as 
western science is, they are developed to understand and relate complex systems (Berkes, et al., 2009). The use of TK in the management of resources and wildlife is now mandated in the Nunavut Land Claims Agreement, 1993 as well as Nunavut Bill 33 with Co-management boards such as The Nunavut Wildlife Management Board (Nunavut Land Claims Agreement, Section 5, 1993).

The visualization of TK is an issue that has been long debated as how to best represent it and retain the richness and distinct qualities it contains (Pulsifer, et al., Kendrick, et al., 2008, Freeman, 1976, Freeman, et al., 1992, Thorpe, et al., 2002; Middleton, 2010; Feirizadeh, et al. 2014; Robbins, 2003). It is standard protocol to employ the use of a GIS to convey map data, perform statistical and spatial analysis tests (Goodchild, 2000). GIS was developed to meet the needs of a planners, geographers, engineers, and cartographers. It is common practice to recreate the landscape to fit the demands of a particular use of the technology (Robbins, 2003). Paul Robbins suggests in a 2003 paper that GIS can also breakdown political and societal boundaries to allow researchers to broadly explore and record ecological knowledge without borders to create a continuous surface. However, not all maps are created equally and are embedded with power and influence based on the origin of the map (Pulsifer, et al., 2011; Middleton, 2010). Power and privilege embedded in the Colonial relationships can impose representations of space that influence the power balance (Middleton, 2010). The boundaries between local and scientific knowledge are permeable and the distinction between the two are often arbitrary and historical in context (Agrawal, 1995; Robbins, 2000; Robbins, 2003). Maps are created and situated in a set of interests which may be cultural, historical, political, or environmental (Middleton, 2010). Additionally, maps inherently embody political and social power by what is and is not depicted in the data (Crampton, 2001; Engler, et al., 2013). The knowledge may not contain precise geographic coordinates or spatial information but it may be anchored in a place through historical or spiritual ties (Engler, et al. 2013). These barriers do not exist in Inuit culture as people, wildlife, and earth are one dynamic system each interacting and influencing the other. (Engler, et al., 2013; Freeman, et al., 2005; Pearce, et al., 2011; Duerden, et al., 1996). Scientific knowledge is inter-woven in TK in respects to plant phenology, wildlife, and climate and it is this dichotomy that creates unique experiences with TK representation. TK can include 
knowledge about flora and fauna, stories may contain wildlife as characters, and knowledge of wind direction, ice conditions, weather based on cloud formations (Engler, et al., 2013).

Geographic visualization of data is the ability of the cartographer to use the data to visualize spatial relationships. One of the primary objectives of map data analysis is to interpret spatial patterns in the data (Crampton, 2001). There are challenges in maintaining the integrity and depth of information while moving to a geo-spatial paradigm as the use of GIS to visualize traditional ecological knowledge tends to homogenize the data to fit the information into a GIS format (Store, et al., 2001; Robbins, 2003). The use of GIS to meld TK and science methodologies may be a tool to assist in bridging the gap in knowledge systems (Forsyth, 1996). This research will address the issues of ambiguity in TK and the challenges of recreating TK in a GIS through the use of varied technical methods.

Common mathematical processes in GIS are based on Boolean logic with crisp hard lines, the data is either true or false (Jaing, et al, 2000; Sui, 1992). Classic Boolean logic is based on the Greek philosopher Aristotle's "law of the excluded middle" which states every proposition is either true of false. Western science tends to evaluate data in this bivariate true - false logic (Berkes, et al., 2009). Fuzzy logic aligns with the school of thought held by scholars such as Plato who believed beyond true - false there was a middle ground where a breadth of data is valid (Berkes, et al., 2009). Traditional knowledge is precise in the knowledge and is inherently geographic as it pertains to place and the relationship with the land (Engler, et al., 2013; Dunn, 2007). Yet, there are questions as to how this knowledge can be effectively represented using mapping techniques, as it does not necessarily contain discrete locations such as geographic coordinates. The knowledge may also convey information regarding the land, culture, history and spiritual beliefs, this creates an uncertain context to the data (Engler, et al., 2013). Fuzzy logic in GIS was developed to deal in imprecise location data (Dunn,2007). It is a mathematical approach to dealing with complex systems with undefined boundaries and uncertainty. This uncertainty does not suggest the data lacks accuracy, but encompasses data that is not bounded in a true / false paradigm. (Berkes, et al., 2009; Engler, et al., 2013, Sui, 1992; Bojorquez-Tapia, et al., 2002; Matsakis, et al., Tong, et al., 2012; Hou, et al., 2007; Vahidnia, et al., 2010). Fuzzy logic aligns with the intricacies of TK and 
may be the key to how Indigenous systems deal with the overall complexity of large nested ecosystems (Berkes, et al., 2009; Dunn, 2007). Key elements of human thinking are linguistic cues with a varying range between member and non-member of a set (Berkes, et al., 2009). Fuzzy models relay on these language cues which is well suited to cues in traditional knowledge (Berkes, et al., 2009). A fuzzy model allows for the variation, of presence and non-presence of caribou. A polygon has defined spatial edges yet, a caribou hunting ground or calving ground would not have a discrete boundary as drawn. The concentration of caribou would be clustered in an area and have a distant decay effect from that area of the herd to the edges. A fuzzy model allows for the gradual decline in membership to the outer edge of the specified distance as explained previously.

\subsection{Research Objectives}

The objectives of this thesis are to:

1. Examine the effectiveness of GIS procession using vector data to recreate maps of traditional caribou knowledge to maintain the context of how they were drawn by individuals in interviews.

2. Explore the untility of fuzzy membership to produce maps that more closely represent the intention of traditional knowledge shared, through a continuous surface.

The first objective of the research is, through the use GIS tools, to create maps of caribou data that are an accurate depiction of the information that is respectful of the knowledge in maintaining the integrity through as few alterations as possible. With the vector based maps there is an assumption that the volume of caribou data in the maps will create images that are not defined. The data will require separation into specific categories to produced maps that have a clear visual perspective of the data (Forsyth, 1996).

Through the use of GIS tools the data is separated by attribute type to distinguish patterns and clusters of knowledge within the group of participants. The separation of data will allow for deeper analysis. The separation of information may also create strong spatial patterns which will highlight hotspots of collective knowledge. These hotspots can increase the justification for the inclusion of traditional 
knowledge as base data where appropriate providing a link between western science and TK (Middleton, 2010).

The second object is the use of a fuzzy methodology to produce continuous knowledge surfaces that best approximate the combined data of the participants. Furthermore, the fuzzy methodology requires a mathematical process that takes the data from qualitative to quantitative, creating a formula that is repeatable and where data can be measured. The use of a fuzzy methodology, will display the data as a continuous surface with consideration for the lack of specific spatial references and ambiguity which affect the data (Tong, et al., 2012). The ability to use a cumulative process provides for a data surface that visualizes definitive knowledge hotspots that synthesize the collective knowledge of the participants of the research study.

This method will display the data without bias and under an inclusionary lens as all data is assessed by its degree of membership to the set as a whole. The fuzzy approach provides the use of data which falls in the "excluded middle" between the true and false or yes and no operators of Boolean logic (Berkes, et al., 2009; Engler, et al., 2013, Sui, 1992; Bojorquez-Tapia, et al., 2002; Matsakis, et al., Tong, et al., 2012; Hou, et al., 2007; Vahidnia, et al., 2010).

Finally, a comparative analysis of hunting data in vector Boolean and Fuzzy methodology maps will provide the rationale for the preference of one method over the other. This analysis will highlight the advantages and disadvantages of both analytical approaches.

This thesis will begin with a literature review of traditional knowledge, participatory mapping, challenges representing traditional knowledge, the melding of traditional knowledge and western science and the challenges, and fuzzy methodology. The methodology used to analyze the data contained in the maps will follow the literature review. The results will be deliberated followed by the discussion, limitations, further research and conclusion. This research will produce two sets of maps based on the attribute type for caribou in the 32 maps using vector based and fuzzy methods. 


\section{Chapter 2 Literature review}

The literature review will focus of the key elements of the research: traditional knowledge and the definition that best suits this context, participatory mapping in an Indigenous context, caribou in the King William Island Region of Nunavut, the use of TK in a GIS system and the use fuzzy methodology in a GIS.

\subsection{Traditional knowledge}

Traditional knowledge is complex and unique to each culture (McGregor, 2004). A single definition cannot express the complex holistic system that encompasses TK (WIPO, 2002; Berkes, et al., 2007; McGregor, 2004). Therefore, to define TK can be problematic to the knowledge holders as it suggests that knowledge uniformity across all Indigenous people (McGregor ,2004). Additionally, researchers concede that the knowledge and knowledge holder are one in the same and it cannot be separated into a single definition (Wenzel, 1991; McGregor ,2004; Berkes, 2009). In a universal framework, traditional knowledge is a way of life, it requires an action, doing, living with constant fluidity, knowledge is a continuum that interacts with every aspect of life (McGregor, 2004). There are Indigenous groups that use practices that suggest a sophisticated understanding of ecological relationships and dynamic view that human is an equal portion of the ecosystem based on a relationship of respect for the land and all living things (Berkes and Berkes, 2009, Berkes, et al., 2007; McGregor, 2004; Pulsifer, et al., 2011; Martin, 2009; Wenzel, 1999) There is no consensus of a general definition yet, there are common threads to define TK.

The common threads that will enable a meaning that is appropriate in the context of Inuit TK is the oral transfer of information that is imperative to survival in hunter-gathered societies, it is an aspect of social processes that are critical to life in the Arctic (Engler, et al., 2013; Pulsifer, et al., 2011; Leduc, 2006). A very strong common thread is the holistic view where the connection to the land is as strong as the connection to other community members (Berkes, et al., 2009; Pearce, et al., 2011). TK is an interregnal part of the culture with explicit social contexts including rules about the processes of 
"knowing”, or how the knowledge is transferred (Berkes, et al., 2009; Pearce, et al., 2011). Human interaction and long-term direct experience are the fundamental processes that are the building blocks of Traditional knowledge. TK is communicated through stories, folklore, cultural values in the oral sharing of knowledge passed from Elders to the younger generation and from community to community

(Freeman, et al., 2000; Pearce, et al., 2011; Eisner, et al., 2012; Pulsifer, et al., 2011; Leduc, 2006; Dunn, 2007). It is imperative to understand that TK is not static, it is an iterative process that includes recent events with those of a distant past (Jardine, et al., 2010). Traditional knowledge encompasses several spatial components; land use, way-finding skills, wildlife habitat, and places of cultural importance such as burial sites, gathering and trading sites (Duerden, et al., 1996; Engler, et al., 2013). TK is rich with the history and migration of the people and the wildlife they hunt as it relates to the land and sea (Laidler G., 2003). TK is also a cumulative body of knowledge that is distinct and unique to the society that evolves through adaptive processes and hands-on living on the land, it is the cultural transmission of living beings about relationships between all living things and the environment (Berkes and Berkes, 2009; Berkes, 1999; Dunn, 2007). TK and land based knowledge facilitates the adaptive capacity of Inuit communities through knowledge transfer about personal experiences, inherent dangers of hunting, and the evaluations of risk (Ford, et al., 2008) The passing on of TK is imperative to the inter-generational connections that ensure the cultural norms are carried forward (Engler, et al., 2013).

Traditional knowledge is the melding of local, social and cultural society as a blend of spiritual values, authority, practice, and knowledge. (Turnbull, 1997). There are aspects of self-determination and social processes that are interwoven into the TK that are the underpinnings of the people's view of the world around them (Engler, et al., 2013; Duerden, et al., 1996; Berkes, et al., 2007). It is an intimate connection between culture and nature where the knowledge is rooted in the local culture and belief system. TK provides the guide for life and as such it entails instructions for the appropriate conduct to all creations as they are all interconnected (Pulsifer, et al., 2011). This knowledge is gained through experience, on-the-lands interaction with the environment where living and learning are not mutually exclusive but are one in the same (Pulsifer, et al., 2011). Traditional knowledge promotes self-learning, 
preservation of language, hunting skills and culture, all of which are critical to survival in the Arctic (Engler, et al., 2013). The representation of Arctic animals is woven through the language, personal names, place names, memories, stories, emotions, wisdom and the lessons of life. This is combined to provide the spiritual awareness and strength as humans within a larger natural and interconnected world. It is a holistic view of life (Kendrick, 2013).

Levels of ecological knowledge overlap and are interwoven in to life, they change over time in response to changes in the physical environment and who they interact with (Berkes and Berkes, 2009; Engler, et al., 2013). The sharing of detailed knowledge about the ecological aspects of the environment, changes in the space due to climate change are key aspect of the ways of knowing and the oneness with the lands (Leduc, 2006; Pearce, et al, 2011). This spatial knowledge is based on generations of astute observations about their environment and the ecosystems that are within the environment (McGregor, 2004; Leduc, 2006, Pulsifer, et al., 2011). The value of TK is not in a quantitative number but, in the value of understanding the environment, how to read and interpret the environment and in the relationship with it (Berkes, et al., 2009). The Inuit management of resources is integral to their survival and an important aspect of their cultural identity (Duerden, et al., 1996; Engler, et al., 2013). Knowledge is critical to existence, the way of knowing that is provided by the Elders is rife with detailed ecological information that enables them to have insight into both local and regional impacts as well as historical knowledge (Leduc, 2006).

Traditional knowledge and traditional ecological knowledge (TEK) are often used synonymously. Berkes (2009) defines TEK as a subset to TK. Berkes suggested it is nested within the system. Traditional knowledge is the term used in the planning portion of this research. Although the dataset is ecological in nature the term TK has been used to ensure continuity throughout the project. For this research, the definition of traditional knowledge has been synthesized from all the literature to one that is best suited for this purpose as a body of knowledge that is passed on from generation to generation through an oral transmission that is unique to the knowledge holders and society. It is more than knowledge, it is a way of 
being, a oneness with the earth with a holistic view of the world as they know it. It is a collective and an adaptive process that is a view of living.

\subsubsection{Traditional Knowledge and Western science}

Historically traditional knowledge has been included when it can be incorporated into western science models with the information being transformed to fit the technology (Forsyth, 1996; Kendrick et al., 2008). The use of traditional knowledge in decision making has been evolving in Inuit communities since the 1970's and has been encompassed in a wide variety of research areas including resource management, and a range of environmental issues (Berkes, at al., 2007; Duerden, 1996; McGregor, 2004; Pulsifer, et al., 2011). The Northwest Territories and what is now Nunavut have fostered the growth of cooperative / co-managements boards since the 1980 's to provide autonomy in communities in regard to wildlife quotas (Wenzel, 2004). In 1992 Ellen Bielaswki, then Minister of the Environment suggested that Arctic scientists resolve the conflict between different "way of knowing" by recognizing the intrinsic value of traditional knowledge (Martin, 2009; Kendrick, 2013). Western scientific methods are the standard in which traditional knowledge is evaluated, in many cases it is not regarded to be on par (McGregor, 2004). Additionally, without participation of the Inuit from the onset of a research study there is a paring down of data which is rich and multi-dimensional (Kendrick, et al., 2008). The removal of data that does not fit a western science paradigm results in weak data sets that do not represent the true nature in way the information was shared (Kendrick, et al., 2008). This pairing down of the TK results in issues of trust as Traditional knowledge is a cumulative body of knowledge where all aspects are interrelated (Berkes, 1999; McGregor, 2004; Kendrick, et al., 2008).

The inclusion of traditional knowledge is mandatory in Nunavut requiring Inuit representation on wildlife co-management boards as stipulated in the Nunavut Land Claims Agreement, 1993. The Agreement Article 5.1.3 states that the creation of a wildlife management system that fully acknowledges that primary role of Inuit in wildlife harvesting through the creation of the Nunavut Wildlife Management Board (Nunavut Lands Claims Agreement, 1993). These agreements stipulate environmental assessments, 
land use regulations and management of land and resources (Berkes, et al., 2007). There is an expectation that with greater involvement in research and the environment that local TK will be acknowledged as scientific and have merit in research in the north (Russell, et al, 2000). The Inuit have furthered the use of TK in decisions regarding wildlife by advocating for the use of their knowledge in the management of Arctic species through co-management boards, establishing priorities and guiding the development of science-based studies. (Nunavut Land Claims Agreement Article 5). Through the collaboration of Inuit and scientists the TK must go beyond simply supplementing or verifying scientific knowledge. The process must allow for true collaboration and an equal understanding of Arctic ecosystems (Ford, et al., 2010; Kendrick, 2013). This participatory based research model is collaborative in its approach where the societal outcomes are improved when there is a balanced approach to research with community members having meaningful input to research that is relevant to their community (Cutts, et al., 2011). The active involvement of communities in the process is ethically important and central to fostering cooperation and trust with the community (Ford, et al., 2008). Participatory research provides a structure that sets the tone and provides a basis for respectful and meaningful communication between the groups which is respectful, relevant, and responsible (Windsor, et al., 2013; Peters, 2013). Additionally, the collection of traditional knowledge must be culturally appropriate and may be in the form of text, drawings and oral stories, video, audio recordings, and interviews, which must be viewed as reliable, credible data (Pulsifer, et al., 2011). Western science focuses on the written transmission of knowledge which is commonly used in analysis (Pulsifer, et al., 2011). However, the use of TK requires one to think beyond the standard processes of data collection and written knowledge. It requires understand that the value of knowledge in a different format holds the same value as western science processes (Kendrick, et al., 2008, Pulsifer, et al., 2011). Inuit and scientists agree that there is need for collaboration that is critical to the successful achievement of common goals (Laidler, 2007). This co-management approach provides communities with a powerful instrument to establish their influence over decision making that impact their lands and lives (McGregor, 2004; Berkes, et al., 2007). The use of TK and the perspectives of the Inuit must be upheld in the decision-making process without compromising their aboriginal right to self-determination (Kendrick, 
2003). Furthermore, Martin suggests in a 2009 paper that researchers in the Arctic must work towards resolving conflicts with the Inuit through recognizing their ways of knowing and place the same value on their knowledge as with western science.

Traditional knowledge and western science have different strengths and can work in a complementary manner (Berkes, et al., 2007; Berkes and Berkes, 2009; Laidler, 2007). Science based analysis tends to focus on a single variable and one analytical process at a time while TK focuses on a large number of a holistic suite of information to understand the environment (Berkes, et al., 2007; Berkes and Berkes, 2009; Laidler, 2007). As Berkes suggests in a 2009 paper there is an inverse relationship between the complexity of a system and the degree of precision that can describe it in a succinct manner. The data contained in complex systems are at times beyond comprehension of conventional science and it is through a holistic simplified view that the systems as a whole is better understood (Berkes, et al., 2009). Western science often relies on well-defined linear cause and effect connections where change and observation are empirically connected while TK is a holistic interconnected system (Berkes, et al, 2007). Berkes suggests in a 2009 paper that logical positivism is the dominant science paradigm. With reductionism, it breaks down systems into discrete components, analyzing each component and making predictions based in the single analysis while TK considers the environment as meld of knowledge practice, authority, trust, spiritual values, social and cultural organization and knowledge of space (Berkes and Berkes, 2009). Traditional knowledge is a continuous system that cannot be separated from the knowledge holder, this dichotomy is the challenge of melding the two systems (Pulsifer, et al., 2011; Berkes, et al., 2009). TK in conjunction with western science can provide a perspective that has a clearer understanding of changes occurring in the Arctic as TK focuses in the holistic understanding of the environment while western since focuses on the physical processes. (Laidler, 2007). Increasingly traditional knowledge is accepted as scientific and the boundaries between them are blurred and porous with an understanding that TK captured and applied to western science is merely a snapshot in time (Berkes, et al., 2009). 
There are several issues that may arise with the meld of TK and western science. Trust between parties involved is a key factor (Wenzel, 2004; Robins, 2003; Russell, et al.,2000; Kendrick,2003). The life of the Inuit has changed drastically since colonization with the forced move to settlements, European religion and the loss of language, and culture due to residential schools (Kendrick, 2003; Martin, 2009). This historical mistrust by Inuit and the complexities of Inuit society suggests that community based research is required to manage the science -policy intersection to improve societal outcomes (Middleton, et al., 2010; Caquard, 2011). Trust is multi-faceted and must be a mechanism to building the bridge between the Inuit and western science (Kendrick, 2003; Wenzel, 2004; Robins, 2003; Russell, et al.,2000). There are social and ethical consequences of the use of TK combined with western science that must be addresses to the satisfaction of all parties involved (Eisner, et al., 2012). Co-management boards set in place to satisfy the Nunavut Land Claims agreement and as attempts to meld TK and science often fail due to political reasons related to wildlife as it can cross several levels of government and jurisdictions (Pulsifer, et al., 2011; Engler, et al., 2013; Robinson, et al., 2016). Therefore, there is a need for innovative co-management of resources that integrates traditional knowledge and western science to adapt to environmental changes (Ford, et al., 2010) Additionally, the use of hard boundaries to define specific political areas such as Territories and Provinces can be historic and static, whereas the Inuit view the area and the wildlife as fluid, flexible and without boundaries (Eisner, et al., 2012; Pulsifer, et al., 2011).

Historically, environmental concerns are under the control of policy makers, government, and the research scientists (Cutts, et al., 2011). TK is laden with temporal knowledge that can provide western science a view to Inuit resource management practices as well as insight into the interconnection between the culture and the environment (Freeman, et al., 2002, Stewart, et al., 2001). The holders of TK understand the nuances of the wildlife, environmental, and seasonal changes as well as natural fluctuations that occur in ranges, herds, and health of herds (Kendrick, et al., 2008).

TK is cumulative, long term knowledge is an asset to the scientific community as it provides the historical trends that are not otherwise available (Eisner, et al., 2012). As the impacts of climate change 
emerge there is a growing understanding that the historical knowledge rooted in TK is imperative to understand the depth and breadth of the changes (Cutts, et al., 2011). It is through a combination of traditional knowledge and GIS based modelling that it is possible to produce maps that are informative with a content base that is rich with knowledge (Crampton, 2001). Maps created in a GIS system have the capability to handle traditional knowledge (Store, et al., 2003). Current trends are the use of hybrid data that includes and values TK as facts that are as relevant and sound as scientific data (Kendrick, et al., 2008). Inuit communities endeavor to ensure that their knowledge regarding local hunting and herd trends and conditions are documented and used appropriately (Kendrick, et al., 2008).

\subsection{Participatory Mapping}

Participatory mapping emerged in the 1990's with the onset of GIS as a tool to engage Indigenous communities in the processes of recording TK and is a collaborative effort between science and community advocates (Engler, et al., 2013). The early maps were used as an aide on behalf of Indigenous communities to establish land claims, and reclaim sovereignty of native lands (Olson, et al., 2016; Engler, et al., 20131; Bryon, 2011). There is a strong relationship between the Inuit and the land that grounds the TK in a geographic space, therefore, the map is an appropriate use for the recording of historical and current TK (Engler, et al., 2013). Maps are of particular importance in the recording and preservation of the TK and the relationships with the land. Furthermore, it requires the understanding of mapping elements that traditionally have not been mapped (Engler, et al., 2013). Participatory mapping provides a realm to record the identities of the Inuit in relation to the physical environment of time and space as well as the inclusion of the spiritual and culture influences over the land (Engler, et al., 2013; Dunn, 2007)

However, the cartographer must be cognizant of the possible power imbalance created through maps as the knowledge holder is vulnerable to exploitation of natural resources and wildlife as it pertains to harvesting, and herd counts (Crampton, 2001; Byron, 2011; Sletto, 2009). Since the 1980's with the development of critical cartography hidden narratives and agendas embedded in maps have been exposed (Caquard, 2011). Maps are a social construct of power, communication and visualization set in specific 
interests which can be cultural, historical, and political (Crampton, 2001). Crampton also suggests that data which is not included may be the agenda of the map where the political narrative is evident. Maps are embedded with social and political power by what is and is not displayed in the data (Crampton, 2001; Robbins, 2003; Engler, et al., 2013; Caquard, 2011; Dunn, 2007). Participatory mapping can reinforce colonial relationships as maps are a representation of space that may not be created equally with some maps representing power and influence based on the agenda of the cartographer (Middleton, et al., 2010; Dunn, 2011). There can be social, political and ethical consequences of incorporation TK and GIS as the use of the GIS has the potential to distort and devalue TK and Indigenous cultures (Eisner, et al., 2012). The hard boundaries used in GIS can reinforce political and social boundaries that are not recognized in TK (Eisner, et al., 2012). The use and codification of ecological knowledge can be political as it has the ability to alter the power relations between Indigenous groups and the dominant society (Robbins, 2003; Verland, et al., 2014). Middleton states in a 2010 paper that maps can create injustice where credibility is aligned with the social power. Those in power are assigned as the credible knower and set the criteria creating an imbalance where power and privilege impose on the representation of space (Middleton, et al., 2010; Byron, 2011).

Participatory mapping is complex and substantial including action-oriented intentions and collaborative partnerships that have the possibility of creating equality (Grimwood, et al., 2012; Parlee, et al., 2005). There is a growing interest in participatory maps and the narrative that accompanies them as they have the potential to foster long-standing relationships in the community (Caquard, 2011; Dunn, 2007; Vaijhala, 2005). Caquard, 2011 suggests that geo-spatial story-telling creates a narrative between the person and the map. While Dunn suggests that the participation in mapping provides a resource for people to control their lands and resources (Dunn, 2007). Maps created in a participatory research method bridge the power of knowledge and provide possibilities for collaborative, united work for a common goal with the knowledge and skillset of each of the participants (Crampton, 2001; Middleton, et al., 2010; Robbins, et al., 2016). When the collaboration is respectful, the methodology is aimed at reducing power imbalances, and is based in reciprocity the outcome is one that is meaningful to all 
players (Middleton, et al., 2010; Robbins, et al., 2016; Engler, 2013). The use of participatory methodologies will result in inclusion and provide the knowledge holder with free, and prior consent of the research agendas (Robinson, et al., 2016).

The spirit of participatory mapping is to combine sound methods of scientific inquiry with communal based strategies (Grimwood, et al., 2012; Robinson, et al., 2016). It fosters team work and requires mutual understanding and respect from all members to formulate research queries that are relative to the community (Windsor, 2013). When the community is engaged, the data collection is enhanced, the quality of the data is improved and there is clearer understanding of the interpretation of the information and the outcomes (Windsor, 2013; Ford, et al, 2008). The efficacy of maps is in the ability to produce ones that are understandable, meaningful and true to the TK captured in the renderings (Bryan, 2011). During community based data collection activities, the participants plot spatial information on the maps provided. This creates a powerful method to portray TK and the perceived spatial realities of the participants (Gaillard, et al., 2010). Elders have a long-term knowledge base that enables them to understand the impacts of climate change as it relates to their environment, seasonal migration routes, the changes in the relationship between the people and the land, traditional travel routes and way-finding skills. (Ford, et al., 2008; Eisner, et al., 2012; Engler, 2013). The ability for community members to illustrate changes and document the effects is a tool that enables cooperation and autonomy in their communities (Middleton, et al., 2010; Cutts, et al., 2011). Sharing long term traditional knowledge about the built as well as the natural environments are critical to the preservation of Inuit culture and their identity (Engler, et al., 2013). The cartographer must ensure that the knowledge holder maintains control of the TK throughout the process and that maps created are representative without distortion of the data (Engler, 2013).

An aspect of the relationship between the Inuit culture and the land is grounded in geography, it is the connection to space. TK is particularly geographic when the knowledge system is with the bearer's relationship with the land (Engler, et al., 2013; Dunn, 2007). TK is embedded in the environment and spatial associations in relation to resources, spatial correlations between groups and resources and 
environmental hazards (Dunn, 2007). The map is a form of recording that when framed in an appropriate context for historical, current environmental and cultural data when it is respectful and cognizant of political and power imbalances (Engler, et al., 2013). Maps created through participatory mapping can recreate place and space for Indigenous people that preserves traditional knowledge (Verland, at al., 2014).

A cartographer's goal is to define visual spatial relationships and describe patterns in the data. GIS enhances the ability to create visual images of data through tools and techniques which create maps that all parties agree is the best depiction of the data for its intended use (Crampton, 2001). Western science requires quantitative validation, focuses on themes and laws, separates nature and culture. The system is reduced to parts for analysis before linking it back to a whole. The qualitative aspect of traditional knowledge enhances the quantitative aspect of western science. The dataset can be complimentary as each brings a unique advantage that can assist when assessing the multi-dimensional data in TK (Berkes, et al., 2009).

\subsection{Geographic Information Systems and Traditional Knowledge}

Geographic information systems (GIS) were developed in the 1960 in the aero-space engineering and comupting industries (Verland, et al., 2014). Since the 1990's GIS has been used to map human geography (Verland, et al., 2014). What to map and how to represent it are the broad concerns for Indigenous peoples in respect to the representation of place and space (Verland, et al., 2014). However, the meld of TK and GIS may also expunge political and jurisdictional boundaries to visualize space as a continuum which is a more accurate representation of TK (Crampton, 2001; Robbins, 2003).

The use of a GIS aides in the collaboration of traditional knowledge and empirical science based research (Robbins, 2003). Additionally, GIS can assistant in the separation of local knowledge into categories that are measurable (Forsyth, 1996). Forsyth suggests that there is a gap between how local knowledge holders and science experts view an area, using GIS and the melding of the knowledge can align the view can be expressed which satisfies both players (Forsyth, 1996). 
TK relies on environmental information and resources that are spatial, but not be exact. They may be situated on recollection and recall, they have a spatially fuzzy context (Dunn, 2007). Additionally, Indigenous knowledge systems are not based on the quantitative techniques of western science and are a means of dealing with complex inter-connected nested systems (Berkes, et al., 2009). Ecological data inherently lacks precision as it has varying degrees of correctness between true and false (Dunn, 2007; Jiang, et al., 2000; Berkes and Berkes, 2009; Berkes, et al., 2009). The use of a fuzzy methodology is well suited to the indistinctness in the parameters of TK as they compensate for uncertainty and imprecise information since it deviates from the standard true / false binary tradition of most sciences (Atkinson, et al, 2005; Berkes and Berkes, 2009; Tong, et al., 2012; Sui, 1992; Vahidnia, et al., 2010; Jiang, et al., 2000; Shad, et al., 2009). A fuzzy membership is not the probability that an attribute is part of a set but the possibility that is part of the set (Burrough, et al., 1998). A fuzzy membership is a continuum from 0 to 1 where 1 equals full membership and 0 equals complete non-member (Atkinson, et al., 2005; Sui, 1992). The closer the number is to 1 the greater the possibility that the attribute has membership to the sets (Burrough, et al., 1998). Figure 1 Illustrates the possibility that the area noted as B has a relationship with A.

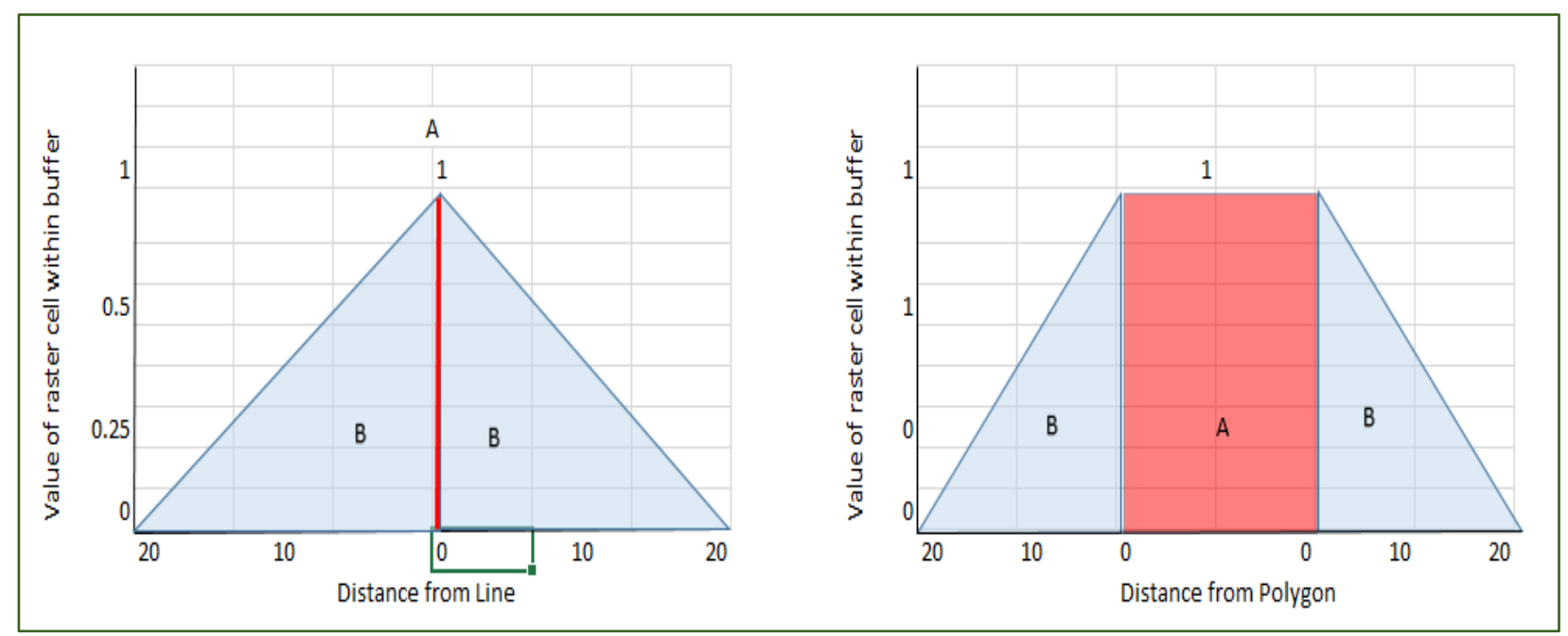

Figure 1 Raster Line and Polygon Buffer Values

The diagrams illustrate the degree of membership of a line and a polygon with a $20 \mathrm{KM}$ buffer surrounding the attribute. Directly adjacent to the attribute the value of a raster cell would 0.999 , at the 10 
KM point the value would be 0.500 and at the full $20 \mathrm{KM}$ distance the value of a cell is 0.001 , beyond this point all cells have a value of 0 .

A fuzzy approach may aide in the understanding of how Indigenous societies cope with large complex ecosystem management (Berkes and Berkes, 2009). A summary of data is by nature an approximation of the information. Per Zadeh, in a 1973 paper the approximation of a data set is characteristic of the function of human brains that group data as it is understood and reduce to an approximation (Zadeh, 1973). The brain allows for degrees of tolerance in decision-relevant data, furthermore, the ability to manipulate data and summarize is a fundamental characteristic of human intelligence (Zadeh, 1973). As suggested by Fikret Berkes in a 2009 paper, ecosystems are nested within each other making it difficult to apply discrete boundaries whereas western science tends to apply these boundaries to simplify the management of systems. This oversimplification understates the impact of the overall system reducing the variability and impeding long-term effects (Berkes, et al., 2009). Fuzzy memberships were developed to represent imprecise information (Berkes, et al., 2009). The fuzzy image is three parts with a core, the zone between the core and the boundary and beyond the boundary as seen in Figure 2 (Shad, et al., 2009) The rationale of the decreasing value is the relationship between the data and the degree of membership to the attribute. As noted previously the numbers assigned to the membership represent the membership to the attribute from 0 to 1 with 1 as the attribute. The greater the relationship to the attribute the greater the number or the closer it is spatially to the attribute.

Much of the data in daily life is indefinite as in the length of time for a pedestrian to cross a street There is no set exact amount of time (Berkes and Berkes, 2009). It depends on the width of the street as well as the stride and pace of the person. A fuzzy suggestion is given as a guideline: Only cross if the hand is flashing safe and you feel there is enough time to safely cross. GIS uses fuzzy methods to deal with this type of data that is not precise or fits into a Boolean true or false scenario (Sui, 1992; Shad, et al., 2009; Feizizadeh, et al., 2014; Tong, et al,2009; Berkes and Berkes, 2009; Saati, et al., 2013; Bojorquez-Tapia, et al., 2002). 
Fuzzy logic methodology fits the needs of complex systems that have a variable database with fluctuating degrees of fit. As stated by Berkes in a 2009 paper, western logic is based on Aristotle's "law of the excluded middle" the law states that every everything is true or false. The tendency with western science is to be bi-variant: Yes, or No. With fuzzy logic, the need of this type of precision is absent. Data does not need to be quantified precisely. Fuzzy logic includes and quantifies the fuzzy middle between Yes and No (Berkes, et al., 2009). Fuzzy logic uses the most common operator in mathematics: intersection, union and compliment, it allows for propositions to be partially true and partially false (Vahidnia, et al., 2010). Fuzzy membership is a logical process of standardization; it represents a specific relationship between the criterion and the decision set. It makes it possible to encapsulate information about the uncertainty in the spatial extent of physical elements (Matsakis, et al.; Jaing, et al., 2000). Fuzzy models relay on linguistic identifiers that cover a range between true and false or member and nonmember (Berkes, et al., 2009).

The data used may be interval, ordinal or categorical attributes members as long as all data is in a raster format (Atkinson, et al., 2005; Sui, 1992). Each cell of the raster has a value between 0 and 1 to indicate the degree to which it belongs to the data set (Sui, 1992). These fuzzy sets of data provide mathematical structure to data that can be very complex with nested systems that do not have crisp edges (Atkinson, et al, 2005, Berkes and Berkes, 2009).

The use of a fuzzy methodology in GIS to create a collective knowledge surface of traditional knowledge is the process that will be used to create maps of the TK in the 32 maps drawn. TK has been defined as a body of knowledge that is passed on from generation to generation through an oral transmission that is unique to the knowledge holders and society. It is more than knowledge, it is a way of being, a oneness with the earth with a holistic view of the world as they know it. It is a collective and an adaptive process that is a view of living. Participatory mapping can provide all parties with a method of data collection that has a balance of power and is based on respect of the knowledge when approached as a collaborative effort. The power of these maps is in the collective knowledge of the Elders. Participatory mapping can ensure their knowledge is recorded in a manner that is understood by all parties 


\section{Chapter 3 Methodology}

\subsection{Study Area}

The study area in the Kitikmeot region of Nunavut includes King William Island (KWI), a portion of the Boothia Peninsula and mainland Nunavut and south to Baker Lake, east to Repulse Bay and west to Cambridge Bay as illustrated in Figure 2. The scale of the map used in the participatory mapping as a base map was at 1:250,000 and occupies 729,061.9 square kilometres. The base maps used in the creation of the traditional knowledge maps and the base maps in the GIS are the GCS North American 1983 Coordinate system and Lambert Conformal Conic projection. This project reflects an area that is a broad regional extent of caribou knowledge based on common practices of caribou hunting by the participants. 


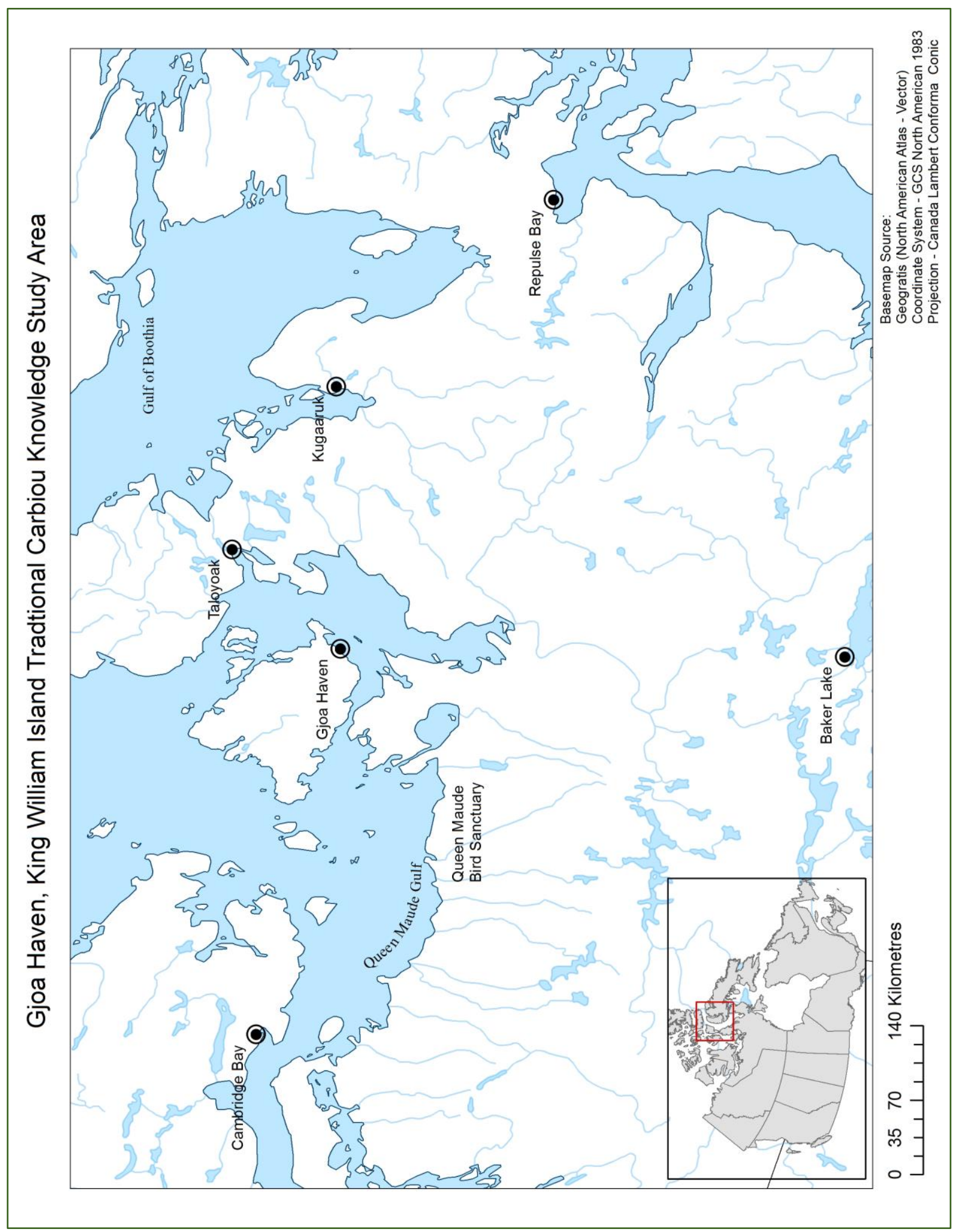

Figure 2 Study Area / Regional Area Map 
The community of Gjoa Haven is located on the southeastern shore of King William Island in the Kitikmeot Region of Nunavut. The Hamlet is in a small protected bay seen in Figure 3. In 1903, the Norwegian explorer Roald Amundsen set anchor on his ship the "Gjoa" in the harbour during his quest to find the Northwest Passage. Amundsen began to conduct research and wintered over two years in the harbour. The nomadic Inuit from the surrounding area began to trade furs, hides and food for metal products with the Amundsen crew (Gjoa Haven, 2010). The harbour became known as Gjoa Haven and when Amundsen continued his exploration the Inuit stayed in the area and the community was formed. The Hudson's Bay Company set up a fur trading post in 1927. The Netsilik Inuit continued to live a nomadic lifestyle well into the $20^{\text {th }}$ century where they traveled to the post on a regular basis to trade (Gjoa Haven, 2010). The population has grown from 110 in 1961 to 1079 in 2011 with 995 of the residents being of Inuit descent (Statistics Canada, 2011).

One Elder drew their knowledge on a map that was at a larger scale and encompassed less territory at a scale of 1:200,000 as seen in Figure 3. This view of the region includes the KWI with the farthest distance from the Hamlet of Gjoa Haven, south at 187,000 metres, east to 178,000 metres, north 163,000 metres and 250,000 metres to the west. There was a regional and a local scale map available for use in each interview, but after the first few interviews most people preferred the regional map, and thus it was most consistently used throughout interviews. 


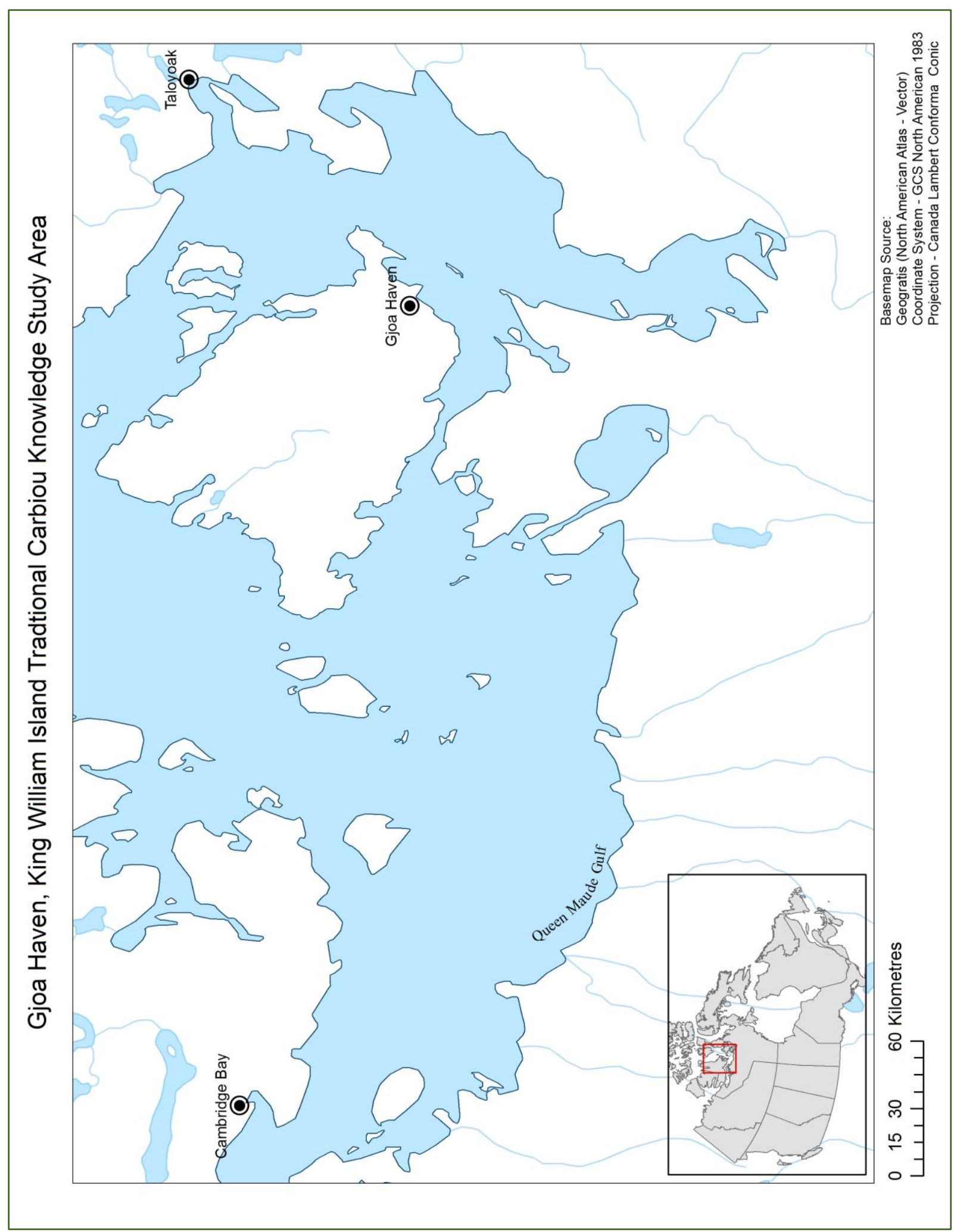

Figure 3 Local Area Map 


\subsection{Caribou in the King William Island Region of Nunavut.}

Dr. Gita Ljubicic conducted meetings in Gjoa Haven in 2010 to learn about local research priorities and to explore possibilities for collaborative projects to address community needs. At these meetings caribou were identified as a research priority as they unified the residents through health, culture, and lifestyle (Laidler and Grimwood, 2010). The relationship between the Inuit and caribou is paramount to their society, health and culture, with significant archaeological evidence that dates back over 25,000 years (Kendrick, 2003; Kendrick, 2013; Miller, et al., 2009; Russell, et al., 2000; Johnson, et al., 2014). Yet, research of journal articles, caribou co-management board reports and government reports indicate a lack of presence of caribou in the King William Island region (Ljubicic, et al., 2017). A map of caribou populations produced for the Nunavut Caribou Strategy 2011 in Figure 4 indicates that King William Island and the northern Boothia Peninsula are areas of uncertainty. The inset map notes "Exact delineation unknown". This highlights the need to more effectively include TK in the management of caribou in the region to fully understand caribou populations and ranges. 


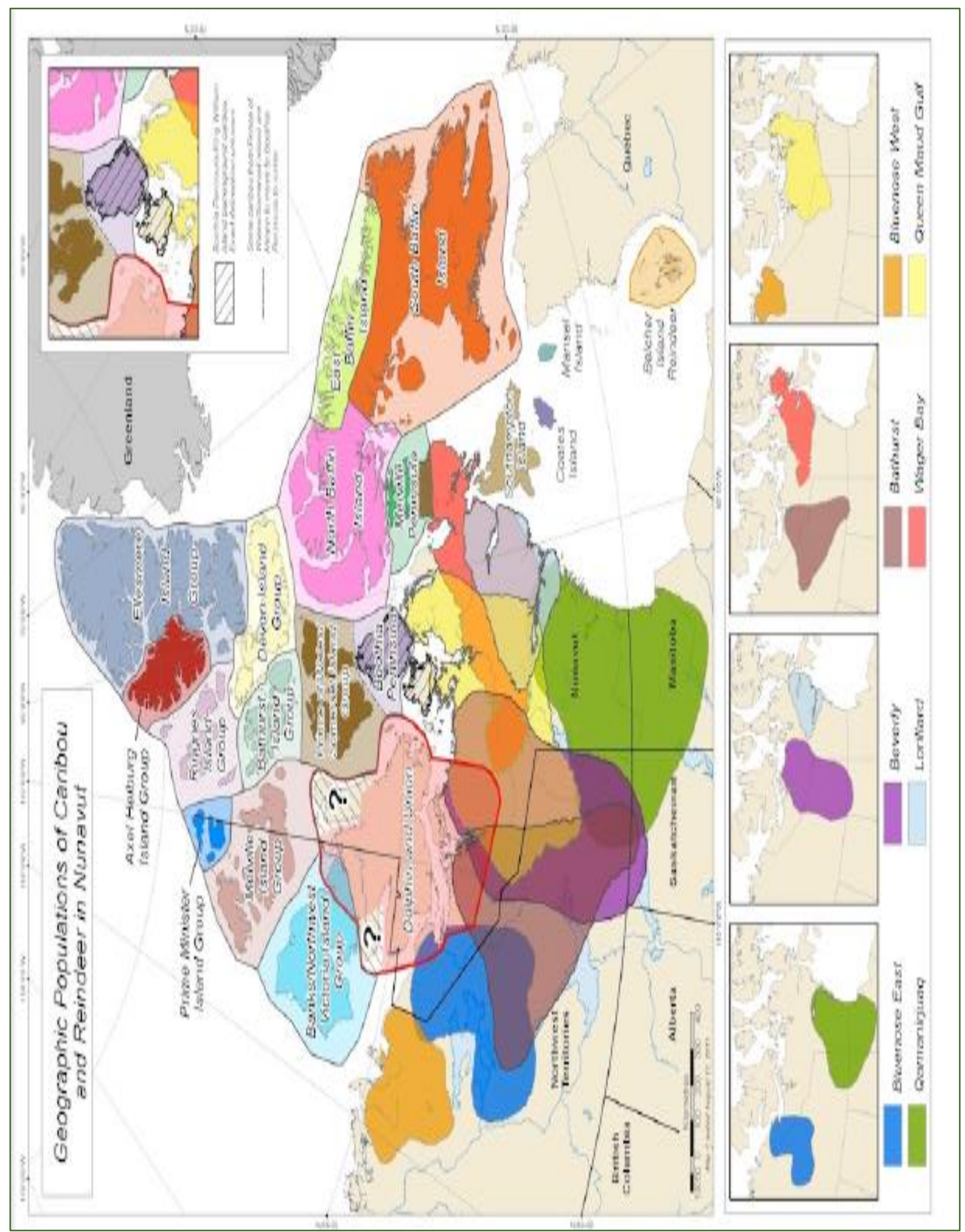

Figure 4 Geographic Populations of Caribou and Reindeer in Nunavut (Source: Working Together for Caribou, Nunavut Caribou Strategy 2011) 
The map in Figure 4 was well as reports and research conducted by Ljubicic, Kendrick and Dunn indicate that barren-ground herds are relevant to King William Island. These specific herds are identified as the Ahiak, Beverly and Bathurst, yet island is overlooked in the majority of research (Ljubicic, et al., 2017).

The management of the Barren-ground caribou herds is complex as herds overlap range distributions in the winter months as illustrated in Figure 4 These herds cross thousands of miles, are harvested by several Indigenous groups, are under the jurisdiction of several boards and multiple levels of government and Land Claims agreements in Nunavut and The Northwest Territories as well as northern Alberta, Saskatchewan and Manitoba (Kendrick, et al., 2008). There is a lack of scientific information about the dynamics between the different herd populations or the characteristics of large and small herds over both long and short periods of time (Kendrick, et al., 2008; Gunn, et al., 2011; Russell, 2000, Sharma, et al., 2009; Lenart, et al., 2002). Furthermore, Barren ground caribou travel the furthest distance of all caribou, their migrations is timed with abundance of a food sources and seasonal locations vary with changing numbers in the herd. Their range extents vary based on these variables as well as snow condition and disturbances (Kendrick, 2003). Additionally, Inuit have a different knowledge base to make judgements and do not feel comfortable making decision about herds based on aerial surveys which are common methods to evaluate the health and population of a herd (Kendrick, et al., 2008; Kendrick, 2003). Inuit communities are dependent on caribou to maintain health, tradtional economies and their culture. There is a mistmatch in indentifying caribou species between the Inuit who majorally consider Barrenground as a single breed and refer to them as Big caribou, whereas, western science they are classified into distinct herds that can only be identified through DNA (Kendrick, 2003). The issue arises when specific herds have restrictions or bans, yet without DNA testing the herd a caribou is associated with is unknown. The specific herd structure also poses a logistical problem as herds overlap at times of the year (Kendrick, 2003).

Caribou co-managements boards where established in the 1980's to reduce this conflict between the Canadian government and Inuit communities well as to provide a suitable management approach to a complex system (Kendrick, 2003; Russel, et al., 2000). The Beverly and Qamanirjuaq Caribou 
Management Board (BQCMB) and the Nunavut Wildlife Management Board (NWMB) provide representation from the Inuit hunters, government, scientists. These herd ranges also the include several land claim and treaty lands of Inuit and First Nations people. In the context of this paper the lands in the study area are subject to the Nunavut Land Claims Agreement, 1993. Inuit communities and management boards agree that they must work together to understand how and when anthropogenic influences effect caribou herds and how to manage the changes as herd dynamics are altered (Dunn, et al., 2010).

Prior to the inclusion of traditional knowledge biologists used harvesting levels to manipulate caribou populations (Russell, et al., 2000). These methods used to control herds created uncertainty among the Inuit as they did not allow for input of traditional knowledge, or consider the importance of cultural perspective of TK (Russell, et al., 2000). The short and long term fluctuations of caribou populations support the need for long-term historical knowledge to better understand these dynamics (Lenart, et al., 2002). Scientists believe that Barren-ground caribou may be on a major decline due to an increase in human population in the Arctic, changes in plant and insect phonologies, spatial -temporal changes in species overlap due to climate change and extreme weather events both in frequency and intensity (Vors, et al., 2009 Gunn, et al., 2010). In a 2007 report on caribou management noted that the size of the Beverly herd was unknown and calf survival had not been tracked since 1994 (The Valued Component -Caribou Final draft report, 2007). The Nunavut Caribou Strategy is based on the need and desire for healthy, sustainable herds that will support the needs of the people. The spirit of the strategy aligns with that of the Nunavut Lands Claims Agreement, 1993 which protects that harvesting rights of the Inuit (Draft Nunavut Caribou Strategy Framework, March 2010). Research and developments have been taken to improve the understanding of caribou fluctuations and estimates of specific Barron-ground herds, yet there is still a level of uncertainty that currently exists. Traditional knowledge plays a key role in understanding the historical fluxes in caribou that can help predict the future (Ostrom, et al., 1994). Inuit hunters respond to varying ice conditions, and climate conditions with adjustments of their timing, modes of transportation and travel routes to reach caribou herds (Pearce, et al., 2015). Yet, there is a 
sense of uncertainty about Barron-ground herd populations and how this effects access to the herds (Ostrom, et al., 1994).

Inuit and scientists agree that Barren-ground caribou herds experience fluctuations in population that are normal but are not systematic in pattern (Gunn, et al., 2011). Through the input from comanagement boards there were decisions made in the 1980s and 1990s regarding herd numbers that were based on local ecological knowledge, historical shifts in caribou migration patterns and the decline of the health of herds based on body condition, behaviour, herd size and composition and the direction of their movement (Kendrick, 2013; Parlee, et al., 2005).

To fully understand the presence of caribou on KWI the system must be analyzed on both a local and regional scale. Traditional knowledge provides an in-depth local level understanding about the condition of the herd, migrations numbers, changes in timing and while western science can complement the TK with global knowledge tracking range fluctuations, and deviations in herd numbers (Berkes, et al., 2009; Kendrick, 2003).

\subsection{Barren Ground Caribou Habitat in the Study Area}

Habitat is an interrelated suite of characteristics of resources and conditions that are multidimensional (Mayor, et al., 2009). The study area is comprised of metamorphic and sedimentary rock with an elevation that ranges from sea level to 40 metres. The area has numerous clusters of eskers which are raised linear glacial features comprised of silt, gravel, and sand because of retreating glaciers that appear as ridges in the Arctic landscape (De Angles and Kleman, 2005). Caribou travel along eskers as

they are dry and predators such as the Arctic wolf can be spotted from the vantage point. Barren-ground caribou in the region are migratory, therefore, the habitats are weather dependent and varied from the southern reaches of a herds range in the winter to the northern portion in the summer months (Gunn, et al. 2010; Gunn, et al., 2013; Kendrick, 2013; Lenart, et al., 2002). In the winter months, they forage on lichen beneath the snow. The herds migrate north in the spring to the calving grounds on the tundra. In the study the calving ground is the Queen Maude area south of the Adelaide Peninsula. The timing of the 
migration is dependent on snow melt and the greening of the land (Gunn, et al., 2013; Fryxell and Sinclair., 1988). In the spring and summer months the quality and quantity of plants to forage is a direction correlation to the health of herds (Barrett and Gray, 2011). The ability of a female to forage on nutrient rich food affects the lactation, antler development and health of the calves (Fryxell and Sinclair, 1988). A change in quality of food, temporal changes to snow melt, and human disturbance as some of the factors result in changes in caribou migration, calving and grazing locations.

\subsection{Background Data Information}

The research in Gjoa Haven, Nunavut was led by Dr. Gita Ljubicic and spanned several years beginning with a planning meeting in February 2010 and concluding with a meeting in February 2016. During the summers of 2012 and 2013, 39 semi-directed interviews were conducted with 27 males and 12 females from the community. This larger project aimed to work within the Indigenous research paradigm where the researcher: accepts and advocates Indigenous knowledge systems, where the community determines the research agenda, the community is an equal partner in the collaboration of the research, and there is reciprocal sharing of knowledge (Louis, 2012; Wilson, 2007). The broader project had a number of diverse facets, and it is important to note that within this thesis the maps drawn in interviews are the focus (see Section 3.4.1). This thesis engages in exploratory research around spatial representation of TK. Therefore, it is acknowledged that this thesis works within this specific scope, and is unable to address the full extent of knowledge and relationships shared through the larger project.

The prominent theme in the findings of the February 2010 Research Planning Workshop in Gjoa Haven was caribou (Laidler and Grimwood, 2010). The participants noted that caribou health, connections to climate change in relation to timing of migration, Inuit health related to the importance of country food in local diets, vegetation changes for caribou foraging, habitat changes, appropriate research methods and increase of predators were important to them (Laidler and Grimwood, 2010). As noted in the literature review there is a general lack of knowledge regarding caribou presence in the KWI area. This 
lack of knowledge is the basis for the use of the TK of the 32 maps to better understand the collective knowledge of the participants.

Caribou are also the dominant theme in the maps drawn by the participants which reinforces the literature that suggests caribou are vital to the social, cultural and physical health of the Inuit. There is a deep understanding, rich with information about types of caribou, specific herds, fluctuations in herd sizes, migrations routes, health, knowledge of hunting grounds, calving grounds and detailed body conditions of individual caribou (Pulsifer, et al., 2011, Kendrick, et al., 2008, Freeman, et al. 2000). The information is both very specific and broad-based information with aspects of ecological management and environmental insights. It also includes evidence that is not ecological but necessary to communicate the information.

\subsubsection{The Role of this Research within the Larger Project}

The GIS research in this study is a portion of the larger project led by Dr. Ljubicic. The original Mylar maps along with the digitized data were provided by Dr. Ljubicic (additional details provided on page 36 - 37). Additionally, an overview document was provided to ensure there was an understanding of the scope, direction and methodology of the project. The scope of this research is through the use of a GIS platform to recreate vector data maps that aim to visualize an accurate representation of the data. Further analysis consists of a conversion to raster data and the use of a fuzzy methodology to produce maps that aim to more effectively represent the collective knowledge of the participants.

\subsection{Participatory Mapping}

Participatory mapping was an integral portion of the interviews as TK has a spatial aspect as the knowledge is related to the land (Duerden, et al., Engler, et al., 2013). The interviews and mapping took place on various dates during July and August 2012 and July and August 2013 at the various locations in 
Gjoa Haven, Nunavut. To facilitate the participatory mapping during the interview a clear piece of Mylar was securely taped down on all four corners of the table over the base maps in front of the individual who was in the interview. Each of the interviewees had access to markers of varying thickness from fine to medium point and in a variety of colours. In most cases the person being interviewed drew on the maps as they were describing the answers to the questions the interviewer was asking. There were instances when the eye sight or person's comfort with drawing that the interpreter or interviewer would draw what the person was explaining (Laidler, Personal Communication) This was only done after clarification that attribute the person was drawing and where it was represented was exactly as the interviewee intended it to be represented on the map (Laidler, Personal Communication ). The map in Figure 6 is identified as map N5 drawn by one of the Elders on July 22, 2013.

\subsubsection{The Interview Process}

The interview mapping sessions were conducted by Sean Robertson (Postdoctoral Fellow at the time, now Associate Professor at the University of Alberta) and /or Rebecca Mearns (MA student working with Gita Ljubicic). Simon Okpakok was the local project coordinator in Gjoa Haven, and he also often acted as interpreter, or Leonie Aaluk also did interpretation when needed during interviews (i.e. Inuktitut/English translations). The interviews were conducted with one participant at a time, with an interpreter as needed, and individual maps were drawn except map one which was a compilation drawn by three participants during a verification workshop. The participants drew the information as they were speaking about it, helping to illustrate the conversation. Interviews covered a broad range of topics, facilitated by an interview guide prepared ahead of time, but also following the direction of the individual being interviewed at the time, including:

- Introductions and personal context related to place of birth, where they grew up, where they travelled and hunted, when they moved to Gjoa Haven and family connections 
- The importance of caribou, caribou herds and herd names, the presence of caribou on King William Island, caribou health, changes in caribou over time, caribou range and migration routes, uses of caribou and disturbances to caribou

- Cultural learning, inter-generational learning, role of land-based skills and now they have changed in the context of life in a community, cultural values related to caribou and otherwise, and the ways to integrate land-based and school-based learning.

- Caribou management practices with respect to experience with wildlife management boards, Hunters and Trappers groups, co-management boards, traditional management practices and ways the TK and western science can work in unison.

- The meaning of Inuit Qaujimajatuqangit (IQ) in the community context.

- Efforts were made to ask relevant questions about timeframes, seasonality of information, and traditional Inuktitut terminology (Ljubicic, Personal Communication)

Discussions and information drawn on the maps about caribou were a significant portion of most interviews, and these are the focus of this thesis. Analysis and publications on the other aspects of caribou knowledge and interactions will be shared through the work of others in the project. Therefore, the data used in the research pertains only to the maps drawn, it does not reflect the information in the dialog portion of the interview. Through a meeting at Carleton with Gita Ljubicic, David Atkinson, and I in May, 2014, I was provided with a copy of the available verified data at the time, and the associated digitized shape files ready for use in GIS analysis. Maps were shared in accordance with individual consent forms, and under Carleton ethics approval. The caribou data is the only data that was included in the study. 


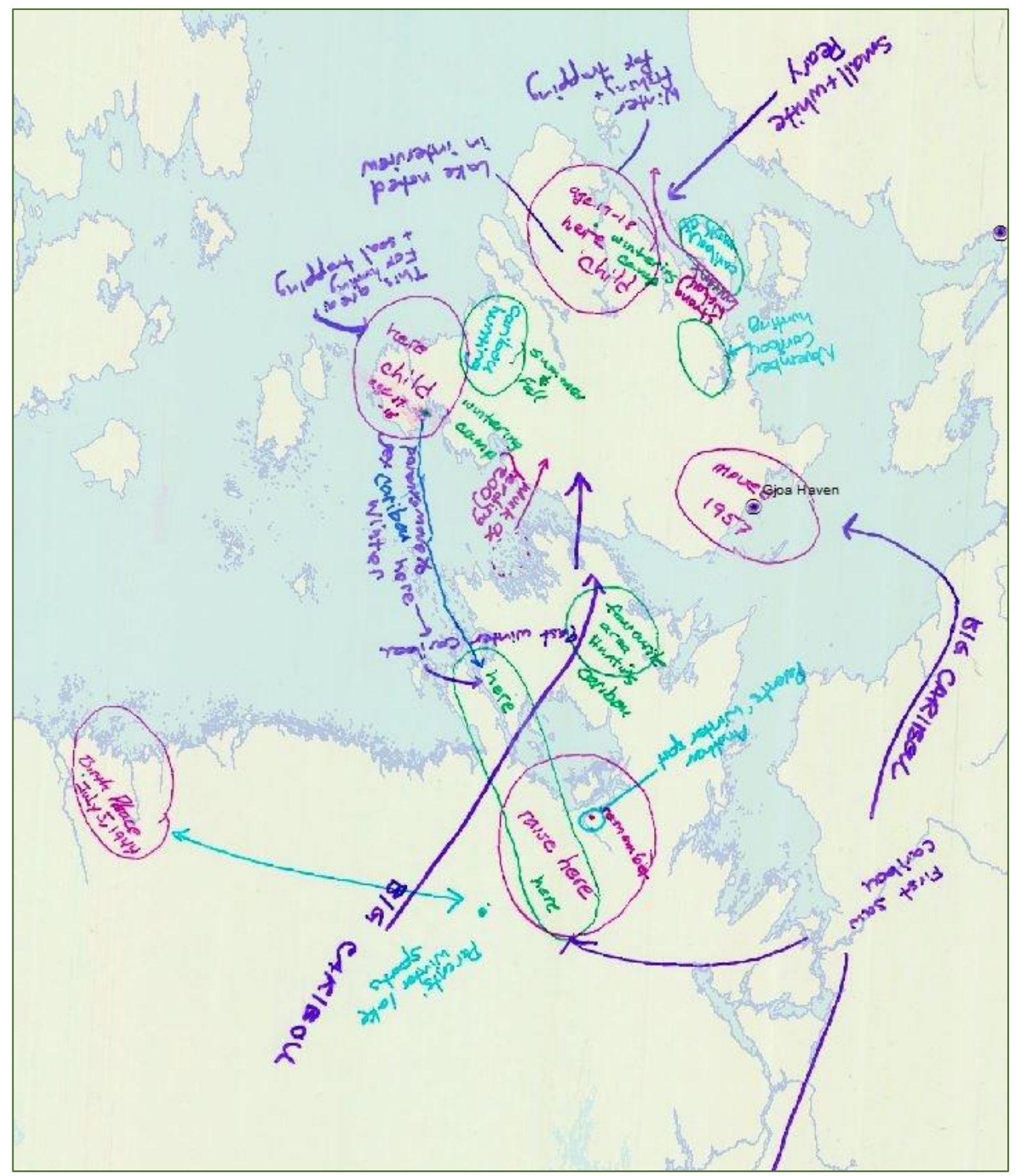

Figure 5 Gjoa Haven Traditional Knowledge Map Number N5, July 22, 2013

There were four verification workshops in 2013 in an effort to ensure that the data that was digitized aligned with the context in which the map author had intended. This iterative process is imperative to ensure respect of the knowledge being shared, and that it is representing the original 
intentions in how it was shared. Each map was scrutinized for inconsistencies in data such as both a point, line and polygon indicating caribou. Questions that remained were taken back to the contributor for verification.

Each person's knowledge contains their personal perspective on life in their community. Many maps encompass temporal data regarding the abundance of caribou throughout their lifetime, health of caribou, types of caribou, climate observations, notes pertaining to caribou calving and grazing areas as well as areas of sick caribou. Many of these attributes are noted in Map N5 shown in Figure 5, as an example. Numerous maps contain life stories beginning with approximate location of birth, historical burial grounds, fishing locations, historical sites, data pertaining to musk ox, seal, polar bear, whale, and Arctic fox.

The map in Figure 6 illustrates the plethora of data using points, lines and polygons. Caribou are noted on maps as text, point, line and polygon. The various types of symbology representing one attribute "caribou" requires in-depth understanding of the data to represent it as the author has intended.

\subsection{Digitization Process}

The digitization process of the original maps into a GIS was completed by Glenda Smith, at Research Assistant on the project from 2012 - 2014, at Carleton University in Ottawa, Ontario, Canada. The process outlined in Figure 7 highlights the procedure followed to ensure consistency, accuracy and inclusion of all verified data. Each Mylar map was scanned as a TIFF file with settlements as control points to assure each map was aligned in the same position. 


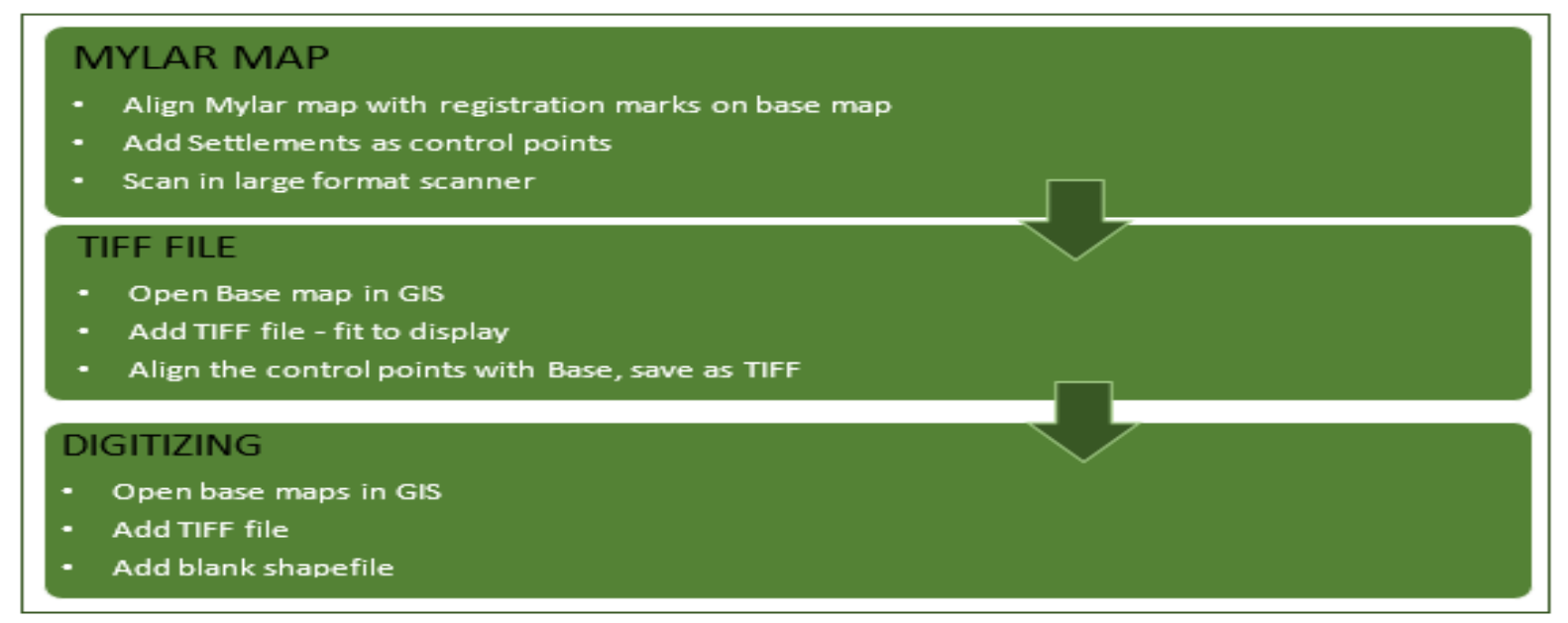

Figure 6 Digitizing Process

The digitized versions of the maps resulted in 32 shape files in a vector format that were duplicates of the original hand drawn maps. All information on each map was digitized however, this paper will analysis data that pertains to caribou.

\subsection{Vector Format: Caribou Data}

The 32 map files created in the digitizing process were combined at Carleton into one map with the original map number as the identifier. To perform analysis on the data by the attribute type: point, line and polygon the data required further dissemination. The separation of caribou data is essential; therefore, the data was extracted from the main file into three files by attribute type: polygon, line and point. Table 1 lists the data by the original map number for consistency with the number of lines, polygons and points on each map. There is a total of 189 attributes in the maps of which 173 are used in the analysis. The point data was not used as the data set is very small and points are not conducive to the fuzzy methods used for analysis. Polygons where drawn on a total of 29 maps and line data was drawn on 19 of the 32 maps that were used for the analysis. There are three maps where the author had drawn polygons within another polygon. The data in two of these three maps simply noted both polygons as caribou presence. The third map noted that one of the polygons indicated sick caribou. The data in these three maps were split into two files with the map number A and map number B. This allows for the conversion of the data to raster 
while maintaining all of the relevant polygons, in an effort to ensure appropriate representation of all details shared.

\begin{tabular}{|c|c|c|c|}
\hline \multicolumn{4}{|c|}{ Data Type and Frequancy by Map Number } \\
\hline \multicolumn{2}{|c|}{$\begin{array}{c}\text { Caribou Polygon } \\
\text { Frequency }\end{array}$} & \multirow[t]{2}{*}{$\begin{array}{l}\text { Caribou Line } \\
\text { Frequency }\end{array}$} & \multirow[t]{2}{*}{$\begin{array}{c}\text { Caribou Point } \\
\text { Frequency }\end{array}$} \\
\hline L3 & 2 & & \\
\hline N1 & 2 & 6 & \\
\hline $\mathrm{N} 2 \mathrm{~A}$ & 2 & 4 & \\
\hline N2B & 1 & & \\
\hline N3A & 4 & 3 & \\
\hline N3B & 1 & & \\
\hline N4 & 4 & 5 & \\
\hline N5 & 4 & & \\
\hline N6 & 1 & 4 & 3 \\
\hline N7 & 3 & & \\
\hline N9 & & 10 & \\
\hline R1.11 & 4 & 5 & 2 \\
\hline R1.14 & & 8 & \\
\hline R1.15 & & 1 & \\
\hline R1.16 & & 7 & \\
\hline R1.19 & 7 & & \\
\hline R1.2 & 1 & 3 & \\
\hline $\mathrm{R} 1.3$ & & 8 & \\
\hline R1.4 & 2 & 6 & 2 \\
\hline R1.5 & 6 & 12 & 1 \\
\hline R1.6 & 1 & 2 & \\
\hline R1.7 & 1 & & 1 \\
\hline R1.8 & 1 & & \\
\hline R1.9 & & 1 & \\
\hline$R 2.1$ & 1 & 7 & 5 \\
\hline $\mathrm{R} 2.2$ & 3 & 4 & \\
\hline RR1.1.4 & 6 & 1 & \\
\hline RR3.1.16 & 3 & & \\
\hline RR4.1.6 & 6 & & 2 \\
\hline RR5.1.3 & 4 & & \\
\hline RR1.19 & 1 & & \\
\hline RR7.2.2 & 2 & & \\
\hline RR8.1.9 & 1 & & \\
\hline RR10.2.1A & 1 & & \\
\hline RR10.2.1B & 1 & & \\
\hline Total & 76 & 97 & 16 \\
\hline Total Maps & 32 & 19 & 7 \\
\hline
\end{tabular}

Table 1 Data Type by Map Number

\subsubsection{Line Data}

The line data represents caribou movements by original map number as the identifier to the origin of the original data. The lines may represent several different attributes: animal description, activity, season, dates, place names and direction of route. As with the polygon data the route data is displayed by map number as it is the only attribute that contains data for all the maps. Line data maps have been 
created by activity in Chapter 4 which highlight how the use of selective data changes the map context. Lines that had direction on the original map have direction indicated in the digitized version of the map.

\subsubsection{Polygon Data}

The polygon data represents a variety of caribou activities including type, herd, hunting, calving, rutting. The attribute table for the data has information split into seven categroies such as animal description, activity, date, place name or season. The caribou map in Figure 10 is based on presence of caribou. The attribute tables include other descriptors that are used in Chapter 4 to create thematic specific maps to illustrate how the reduction in data reduces that information in the map, although they are accurate they do not fullfill the research objectives set forth of representing cummulative knowledge of the group of Elders and hunters.

\subsection{Vector to Raster Conversion}

In the vector format the data has limitations to the processes available in a GIS for analysis with the key drawback being the inability to use processes that will display the data cumulatively. As seen previously in Figure 10 the map is cluttered and not displayed in a way that any definable conclusion can be drawn from the data. The conversion of the data from vector to raster creates a continuous surface which will allow for great analytic functions in a GIS format. A raster surface allows for a value to be assigned to each cell to create a continuous surface, whereas in the vector format the attributes can have a value but all other areas are shown as no data (ESRI data Dictionary, (n.d.) Figure 8 illustrates the continuous surface of raster verses the segmented surface of vector data. 


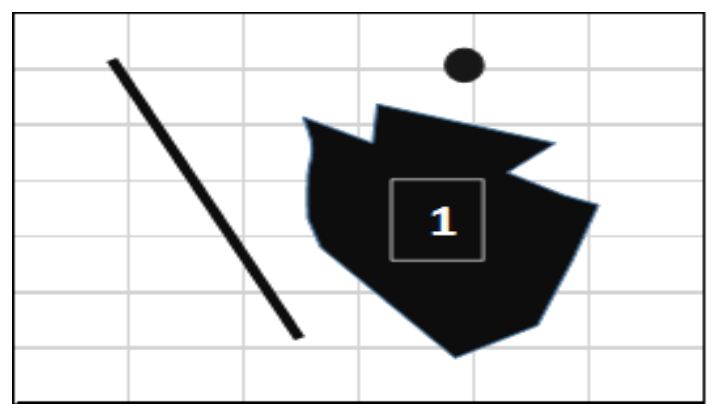

\begin{tabular}{|l|l|l|l|l|l|}
\hline $\mathbf{0}$ & $\mathbf{0}$ & $\mathbf{0}$ & $\mathbf{0}$ & $\mathbf{0}$ & $\mathbf{1}$ \\
\hline $\mathbf{0}$ & $\mathbf{0}$ & $\mathbf{0}$ & $\mathbf{0}$ & $\mathbf{1}$ & $\mathbf{1}$ \\
\hline $\mathbf{0}$ & $\mathbf{0}$ & $\mathbf{0}$ & $\mathbf{1}$ & $\mathbf{1}$ & $\mathbf{0}$ \\
\hline $\mathbf{0}$ & $\mathbf{0}$ & $\mathbf{1}$ & $\mathbf{1}$ & $\mathbf{0}$ & $\mathbf{0}$ \\
\hline $\mathbf{0}$ & $\mathbf{1}$ & $\mathbf{1}$ & $\mathbf{0}$ & $\mathbf{0}$ & $\mathbf{0}$ \\
\hline $\mathbf{1}$ & $\mathbf{1}$ & $\mathbf{0}$ & $\mathbf{0}$ & $\mathbf{0}$ & $\mathbf{0}$ \\
\hline $\mathbf{1}$ & $\mathbf{0}$ & $\mathbf{0}$ & $\mathbf{0}$ & $\mathbf{0}$ & $\mathbf{0}$ \\
\hline
\end{tabular}

Figure 7 Vector Data and Raster Data Comparison

Important factors in the conversion of the data is the extent of the layers and the cell size. Every layer converted must be consistent in these two factors. In this instance, the cell size was set at 500 metres. This was selected due to several factors: the size of the study area is large at more than 675,000 square kilometres and 500 metres is large enough to capture more than one element in a cell.

Additionally, the majority of the lines were drawn in a sweeping manner to indicate the general direction of the caribou or spatial indication or the area but they were not drawn as specific routes. This information is contained in the interview transcripts/ The research objective of cumulative knowledge was also taken into consideration. This size of a cell was believed to be large enough to capture multiple attribute that were drawn in roughly the same area. Cell sizes that are relatively small do not capture the multiple data aspect and large cells may contain large amounts of data creating hot spots that are not realistic (Cromley and Hanin, 2003). The extent of each file must also be consistent. In this case, the base map file of Nunavut / Northwest Territories was selected to ensure that all the data was within the raster converted boundaries. The process shown in Figure 9 indicates the steps required to convert all the line and polygon data from vector to raster. The single vector file with all the data was converted to 32 files by of caribou data by the extraction of data and using the original map number as the data reference and consistency throughout the study. The line and polygon vector data was extracted by map number to create a separate line and polygon file for each map. As stated previously, there are 19 maps with line data and 30 that have polygon data. Following this procedure, the separate polygon and line files were converted to raster files and saved by map number to ensure data integrity with raster in the file name. It 
is important to note that consistent naming of files is key to maintaining a database that is understandable and accurate.

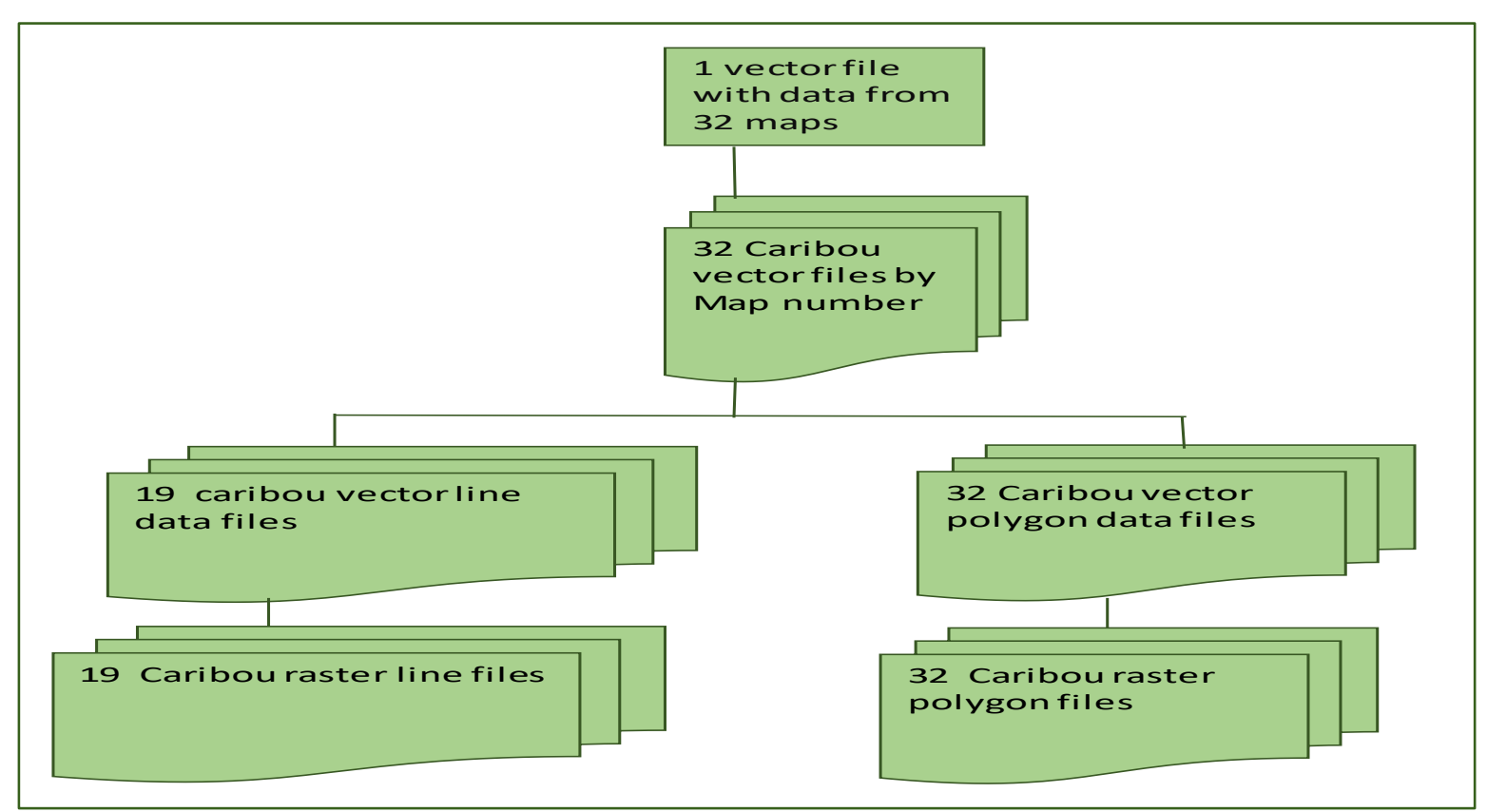

Figure 8 Vector to Raster Data Conversion Process

\subsection{Fuzzy Data / Euclidian Buffering}

Traditional knowledge is inherently complex and broad ranging, considering interrelations through all aspects of land-based experience, and it is these qualities that make it well suited to fuzzy models (Engler, et al., 2013; Dunn, 2007). The caribou information drawn on the maps does not represent fixed boundaries or exact routes as caribou are always on the move. The lines and polygons drawn are to indicate where caribou are found in the area or they come from a certain direction. This generalization between presence / no presence is well represented with a fuzzy model. The conversation to a raster format allows for the use of fuzzy modeling where Euclidian buffer is added to the data. The data that is in this buffer has diminishing degrees of membership to the attribute. The buffer is an area of a selected distance surrounding the attribute that is suitable for the data. In this instance, the distance of 20 kilometres was selected. As stated previously the terrain is very flat ranging from sea level to 40 metres with sightlines that are uninterrupted. It was deemed that this distance as feasible to observe caribou 
movements. Euclidean distance buffering measure the set distance in a two-dimension Cartesian plan. The distance is the selected measure between two points on a flat surface (Boruff, et al., 2012). This buffer compensates for the inherent imprecision in traditional knowledge. The process builds on the work flow outlined in Figure 11 where the final number of files from the original map are 19 line files and 30 polygon files. A buffer is added to each of the single raster line and polygon files where the result is 19 buffered raster line files and 30 buffered raster polygon files. The raster cells in the buffer values are determined by the distance from the attribute, either a line or polygon in this data set. The raster cells closest to the attribute have the highest value next to the value set for the attribute. In terms of membership, cells closest to the attribute have a higher degree of membership to the attribute than cells at the out edge of the buffer zone. In this data, the attribute has a value of 1 . The cells in the buffer decrease on a continuous scale from 0.99999 to 0.00001 at the 20-kilometre limit, beyond the buffered cells the value of the raster cell is zero as demonstrated in Figure 2.

The methodology uses an algebraic sum, where the sum is always greater than or equal to the largest fuzzy member value. This results in an output value with a maximum of 1 , which is the value of the line or polygon in the data (Atkinson, et al., 2005). Each fuzzy buffered layer was divided by the number of layers in either the line or the polygon fuzzy files, 19 and 32 respectively. This results in values that total 1 in each case when the layers are accumulated. The results are a caribou route and polygon raster shapefiles where every cell has a value from zero to a maximum of 1 . Cells where one or more authors draw data result in a value between 0.00009 and 1 . Therefore, a cell with the value of 1 in line buffered raster map would have all 19 maps with information in that cell. Similarly, in the polygon data all 30 maps would indicate data in the same cell. In this analysis, each of the maps and the attributes in them are of equal value as the Elders and Hunters drawing them did not indicate that any of the data had significance over other data. It is imperative to represent that data as accurately as possible therefore, a weighted method was not used to analyze the data. Lines and polygons and each map that contains them has been assigned the same value. 
The selection of the number of categories represented in the maps is an iterative process. Five categories were selected in the final process with the first category representing all the land where there is no caribou data. The data was then divided into four remaining groups in the route map that represented $1-10 \%, 10.01-25 \%, 25.01-50 \%$ and $50-75 \%$ hand drawn routes. These percentages indicate the percentage of the group of 32 participants who draw a route or line in the raster cell. The same process was repeated in the Caribou polygon map with five categories set at $0.99 \%$ which again represents the regions that are exempt of data and the following four categories: $1-10 \%, 10.1-20 \%, 20.01-40 \%$ and $40-67.46 \%$. The percentages again represent the percentage of map authors that drew data in that raster cell.

The methods of analyzing the data through the vector and raster format always a different approach to analyze the data. The vector data is strictly qualitative while the vector is a sum of the layers. While the analysis still qualitative there is a quantitative aspect. The transformation provides a dataset that represents the cumulative knowledge in the maps with the ability to sum the layers to arrive at a value that represents the number of maps that contain data in a specific cell. The use of the fuzzy method approach creates a continues surface which aligns with traditional knowledge where an element cannot be separated from the environment (Berkes, et al., 2009; McGregor, 2004; Duerden, et al., 1996; Pearce, et al., 2011; Martin, 2009). Traditional knowledge is nested within the physical environment in a continuous mode (Berkes, et al., 2009; McGregor, 2004; Martin, 2009). The processes used in this research enables the transformation of the caribou data from vector to raster and through the use a fuzzy methodology with the application of continuous buffers to produce maps that highlight the depth of the traditional caribou knowledge while remaining aligned with the spirit of participatory mapping where the outcome is supportive of the community priorities.

\subsubsection{Potential Spatial Analysis Methods}

Several spatial analyses methods were explored prior to selection of the fuzzy model to analyze the data. Kernal and line density, which calculates the density of an attribute in a given distance selected 
from the attribute. This method does not produce results with polygon data. Getis-ord did produce results for the data, however, the map did not have a continuous surface. Additionally, the "cold spot" terminology in this case was not appropriate. Local Morans-I was ruled out for the same reasons as Getisord. Kriging is not applicable in this case as the point data set is to small and most the data is line and polygon. The data was also distinguished by map number to understand the differences in the amount of data per contributor. The data on maps with several attributes was compared to maps with very few attributes looking similarities or difference in the location of the features. The fuzzy method was selected as the analysis that would produce the most comprehensive results based on the research objectives. 


\section{Chapter 4 Results}

Two types of data were used to create traditional caribou knowledge maps: vector and raster. Each of these data types produce maps with a varying degree of success in respect to the research question used to analyze the data. The research objectives are an analysis of vector based Boolean data and Fuzzy raster data to ascertain the ability of GIS techniques to produce maps that clear, concise, and an accurate depiction of the data as it was intended. The two types of data will highlight the strengths and weaknesses of both methods and answer the research questions of the need to disseminate the vector data to analyze that data and is a fuzzy methodology best suited to represent the data as continuous surface. The analysis will provide a greater understanding of type of data that represents traditional knowledge in the form in which it is drawn and represented in the original maps. The following chapter will discuss and analyze the results of the methods used to display the map information. The results are based solely on the data contained in the 32 maps and does not make overall assumptions regarding caribou or traditional knowledge in the study region.

\subsection{Vector Data}

All the caribou data in the vector format is contained in Figure 10, All Caribou Data. The map is cluttered and is difficult to understand the data shown as it contains 173 individual attributes. The layers in the map are arranged to provide an optimal outcome with the polygon below the line and point files. It is noted that this order of files creates a map with the greatest number of feature visible. The polygons are semi-transparent which makes the overlapping of data visible, however, it is not possible to know how many lines or polygons are in the same area or how many cannot be seen as the are beneath another larger polygon. 


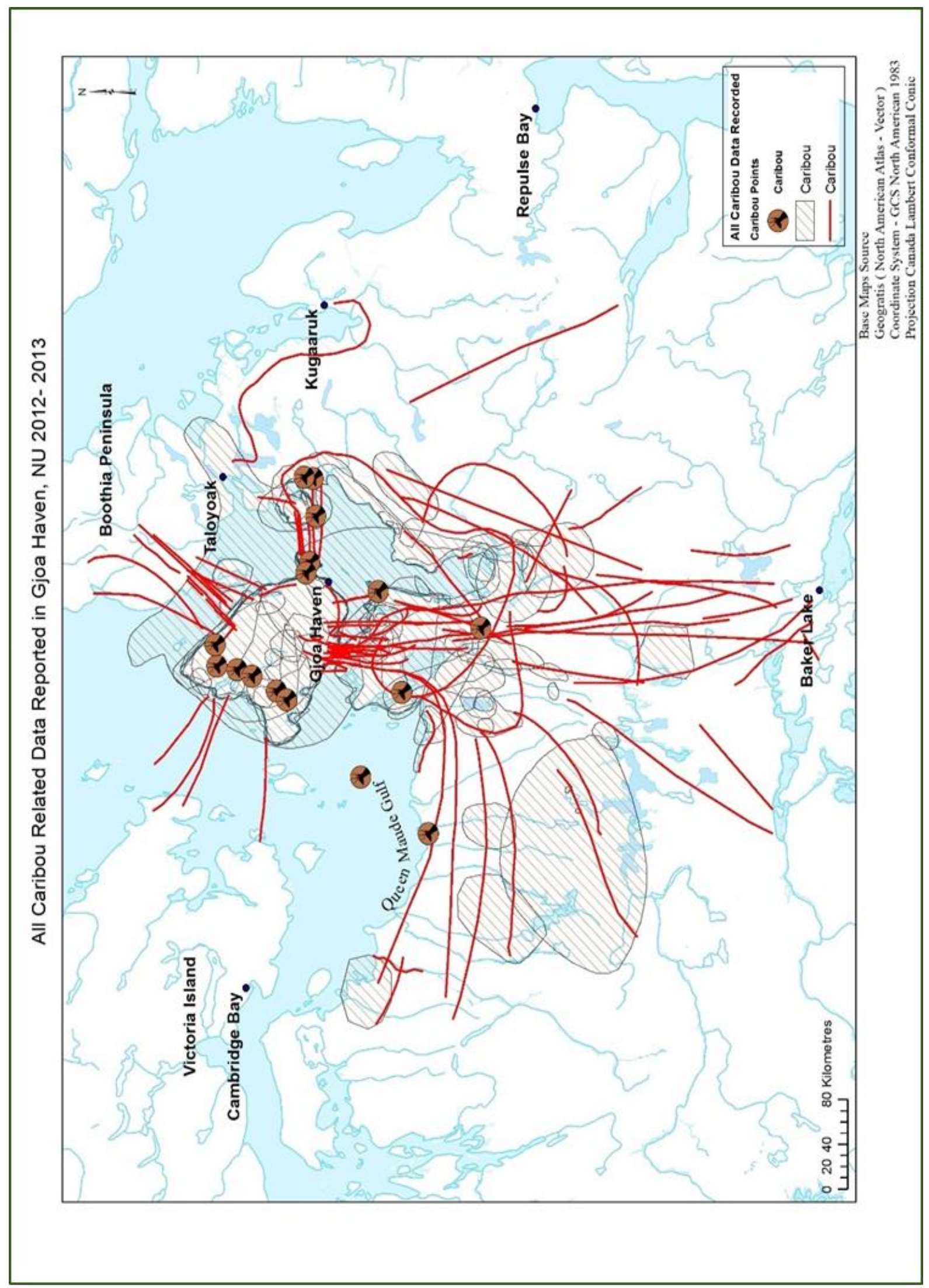

Figure 9 All Caribou Data. 
Vector data layers are displayed consecutively in top of each other. This causes the top most layer to block out the layer below where data is present as illustrated in Figure 10. This type of data does not provide a cumulative method where the number of layers in an area are identified and tallied. Figure 9 indicates the number of layers that are stacked upon each other to illustrate the effect that emerges in the collective map in the vector format. In this scenario, the red polygon is the forth in the series as the top layer. The layers beneath are not visible and one can only assume the number of layers beneath the top red layer as it varies from one to three. Each of the layers in the data is a different type

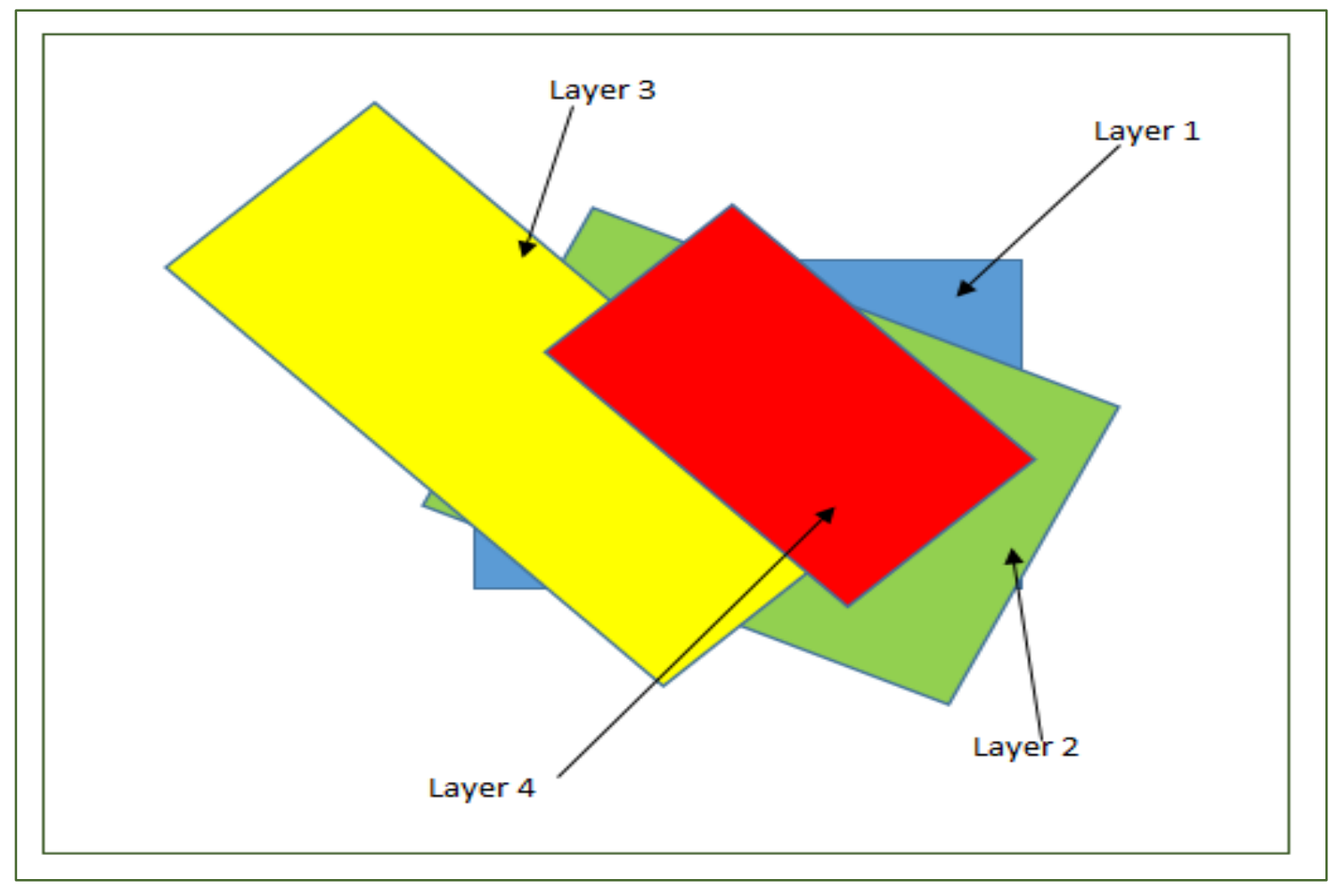

Figure 10 Layering Effect of Vector Data with Similar Coordinates.

and therefore, cannot be processed in this format to view a cumulative total as units must be in the same format to perform mathematical processes (Feizizadeh, et al., 2014; Atkinson, et al., 2005). 
The map in Figure 11 highlights the wealth of knowledge contained in the 32 maps used in the analysis in regard to caribou routes and areas. This vector based data map also showcases the shortcomings of the method as it relates to a large data set and the ability to treat the inherent vagueness of the traditional knowledge. The map illustrates the vast area of knowledge and connections to other communities in the region. The routes to Baker Lake to the south, Taloyoak and Kugaaruk to the east highlight the knowledge of caribou routes by the participants.

There is clustering of routes in three areas where the island is geographically closest to the mainland. The extent of the routes and areas of the TK covers an extensive 370,718,705 square kilometres which highlights the extent of travel for hunting in the region, yet it is this expense that may add to the inherent vagueness in this data. The map is cluttered with information and determining the amount of data in one geographic location is not possible as the map contains both lines and polygons. The layers are displayed with the polygon below the line data to enable the line to data to viewable. The polygon data is drawn with a hatch line and a darker outline which emphasizes the amount of data the is stacked on top of each other and visible. Based on these factors, only qualitative analysis is plausible as the map contains two types of data, both line and polygon. 


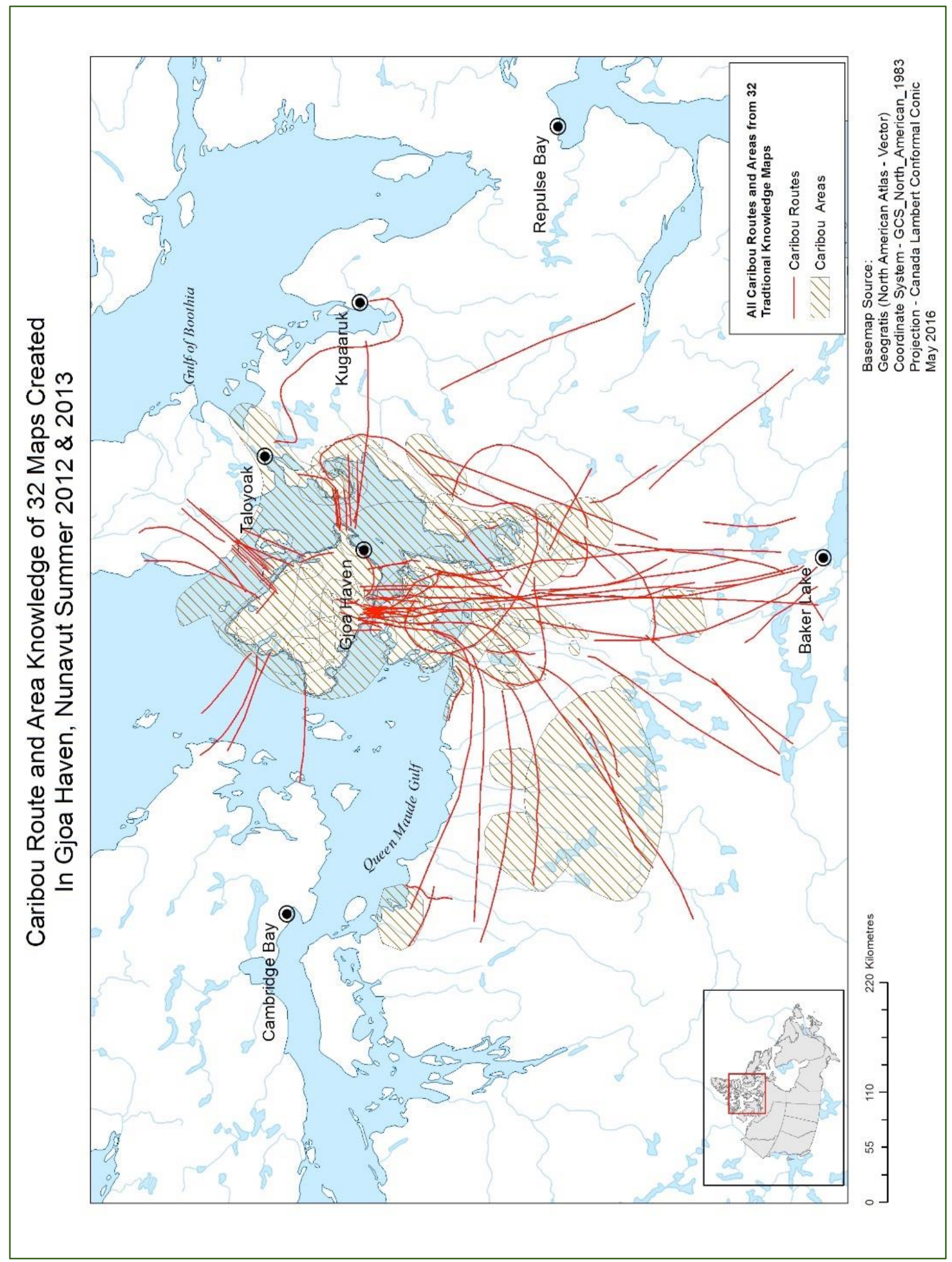

Figure 11 All Caribou Route and Area Knowledge on 32 TK Maps, Gjoa Haven, NU. 
The route and area data have different spatial patterning that is very evident with the routes for caribou on the land running towards or away from the island as direction is not indicated in this map due to the amount of data shown in this map. Adding directional arrows to the routes is additional information that adds to the clutter and readability of the map and does not aide in the explanation of the data in this instance. The direction is shown in a separate map where it is the only data and the directional arrows can be seen. The routes drawn either begin or stop at KWI. This may be a result of how the question was phrased, the participants where asked the direction the caribou come from or the direction they go. Whereas the data for the polygons is clustered on and around KWI with areas to the southwest in the Queen Maude Bird Sanctuary area. The separation of the data by line and polygon will reduce the amount of data and create an environment where analysis and spatial patterns emerge.

\subsubsection{Vector Route Data}

The data drawn on the maps is numerous with 19 of them containing line data for a total of 97 caribou routes. There are obvious clusters in the data in Figure 12 at three points on King William Island. These areas are within closest proximity to the Boothia Peninsula to the northeast and to the south of the island, east of the Queen Maude Bird Sanctuary. Each of the clusters is highlighted in Figure 12 Caribou Route Knowledge. The largest cluster are the routes that are on the south side of the island in an area which is very close to the mainland at a mere 3.8 kilometres. This distance leaves the heard crossing spring ice and possibly open water as land has the greatest amount of accessibility from them. Kendrick et al., 2008 states that caribou migration is affected by variations in weather such as warming, snow melt, snow depth. The data in a Baker Lake study indicates that caribou seek narrow water crossings. This coincides with the locations of the route data drawn by the participants. 


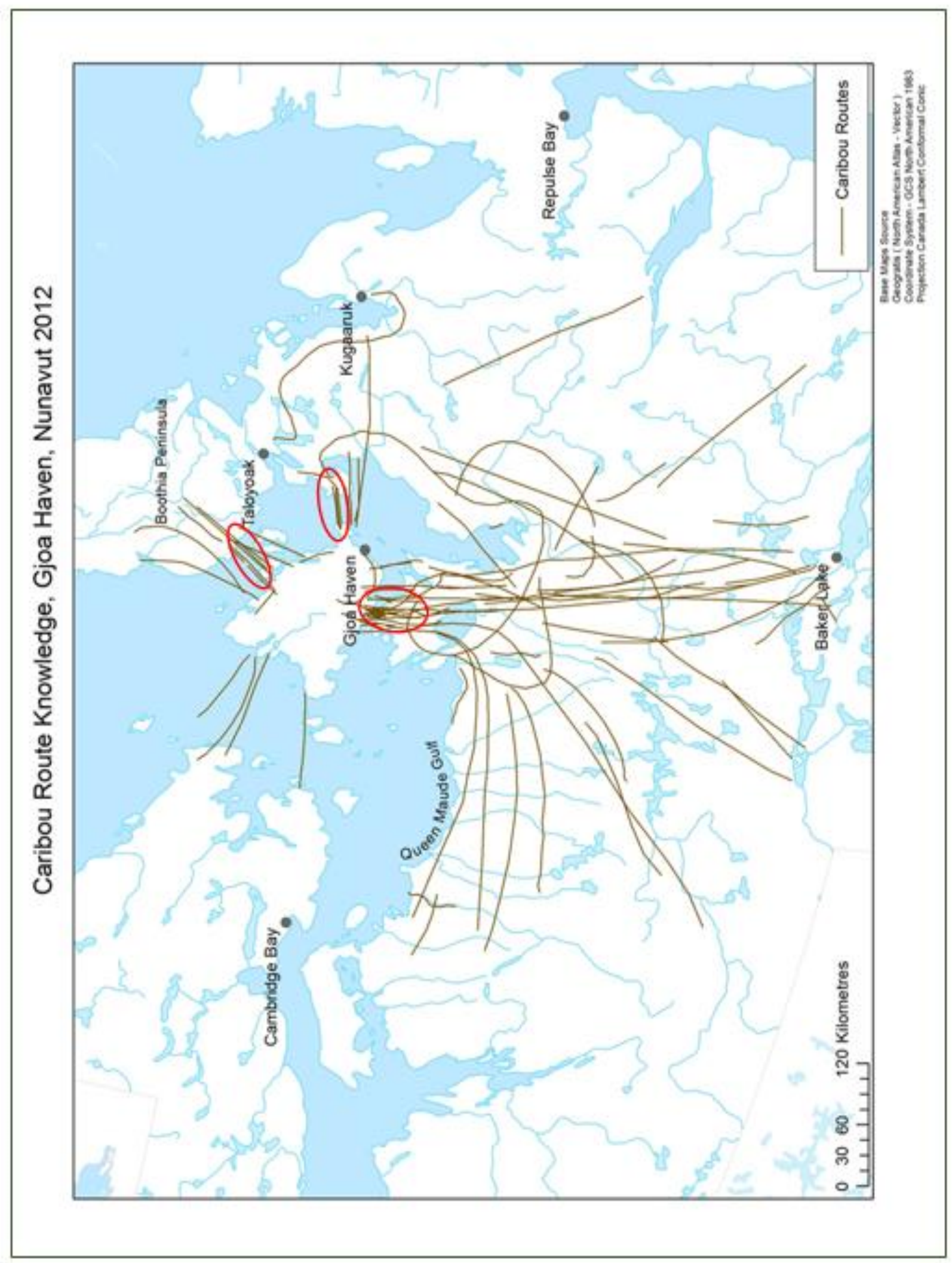

Figure 12 Caribou Route Knowledge 
The region with north-south cluster of routes which run from KWI towards Baker Lake are highlighted in red in Figure 13. These routes suggest the vast scope of the hunting region and the knowledge of the land by the individuals who participated in the mapping study as the area covered by the routes is approximately 434,553 square kilometres. There are also four routes drawn that show caribou movement between King William Island and Victoria Island to the west. The connection between these two islands are not noted in Northern Caribou Populations Trends 2010; Nunavut Caribou Strategy Framework, 2010; Caribou Valued Component 2004; or in papers written by Anne Gunn or Anne Kendrick. It is interesting to note that all lines were drawn either from the edge of the island away or from distances away towards the island. None of the routes lines are drawn on the island. Again, this may have been a response in the manner in which the question was phrased as to where the caribou come from and which direction do they go. The routes also suggest movement of the caribou through the Queen Maude Bird Sanctuary which is noted as a calving ground by Kendrick 2003; Gunn et al., 2013.

The data contained in the routes can be disseminated several ways, each of which explains the traditional knowledge of the Elders and Hunter who participated in the research. As stated previously there are two subspecies of caribou noted in the TEK: Barren-ground which are migratory herds that winter near the tree line and move north to calve and rut. (Gunn, et al., 2010; Gunn, et al., 2011, Kendrick and Manseau, 2008). The Barren ground belong to three main herds associated with the region: Beverly, Bathurst and Ahiak (Gunn, et al., 2013, Nunavut Caribou Strategy 2011). Based on animal description in the data only $19 \%$ of the authors noted the species or herd with $9 \%$ identifying each of Barren Ground and Peary which is seen in Figure 13. 


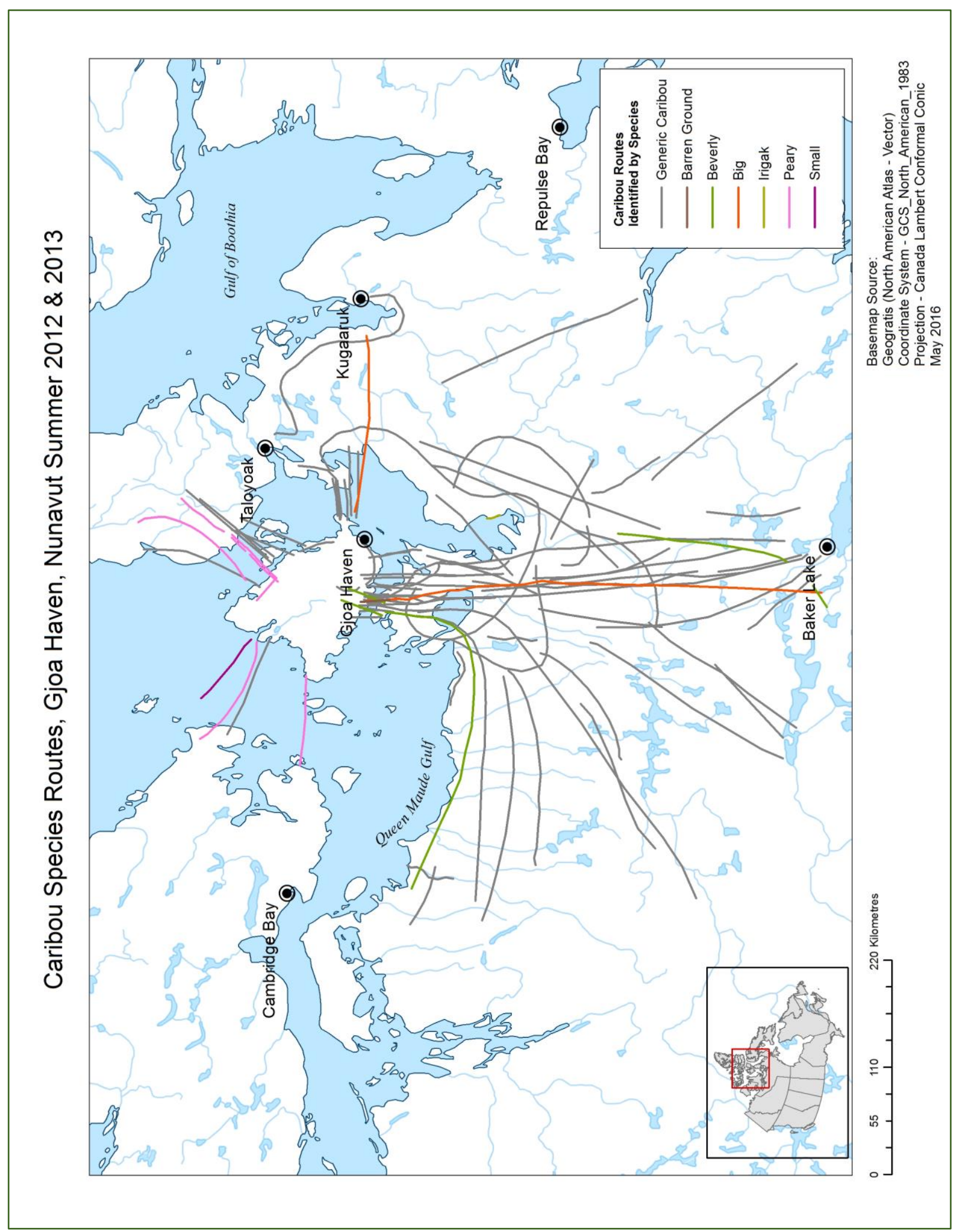

Figure 13 Caribou Species 
The data is displayed in the categories that the authors identified them as. They have used both sub-species and herd as the same type of distinguisher. Peary or small caribou routes are identified on the northern tip of the island to the Boothia Peninsula and to Victoria Island. The routes that are identified as Barren-ground are shown south of the island running to Baker Lake, from the east along the Queen Maude Gulf to the point of the mainland closest to the island. Additionally, a route to the east of Gjoa Haven to the peninsula is identified. The remaining $81 \%$ of the routes are unidentified as to the species or herd. All three of the previously discussed clusters contain unidentified routes as well as the routes that are the longest or run the farthest from the mainland to King William Island. 


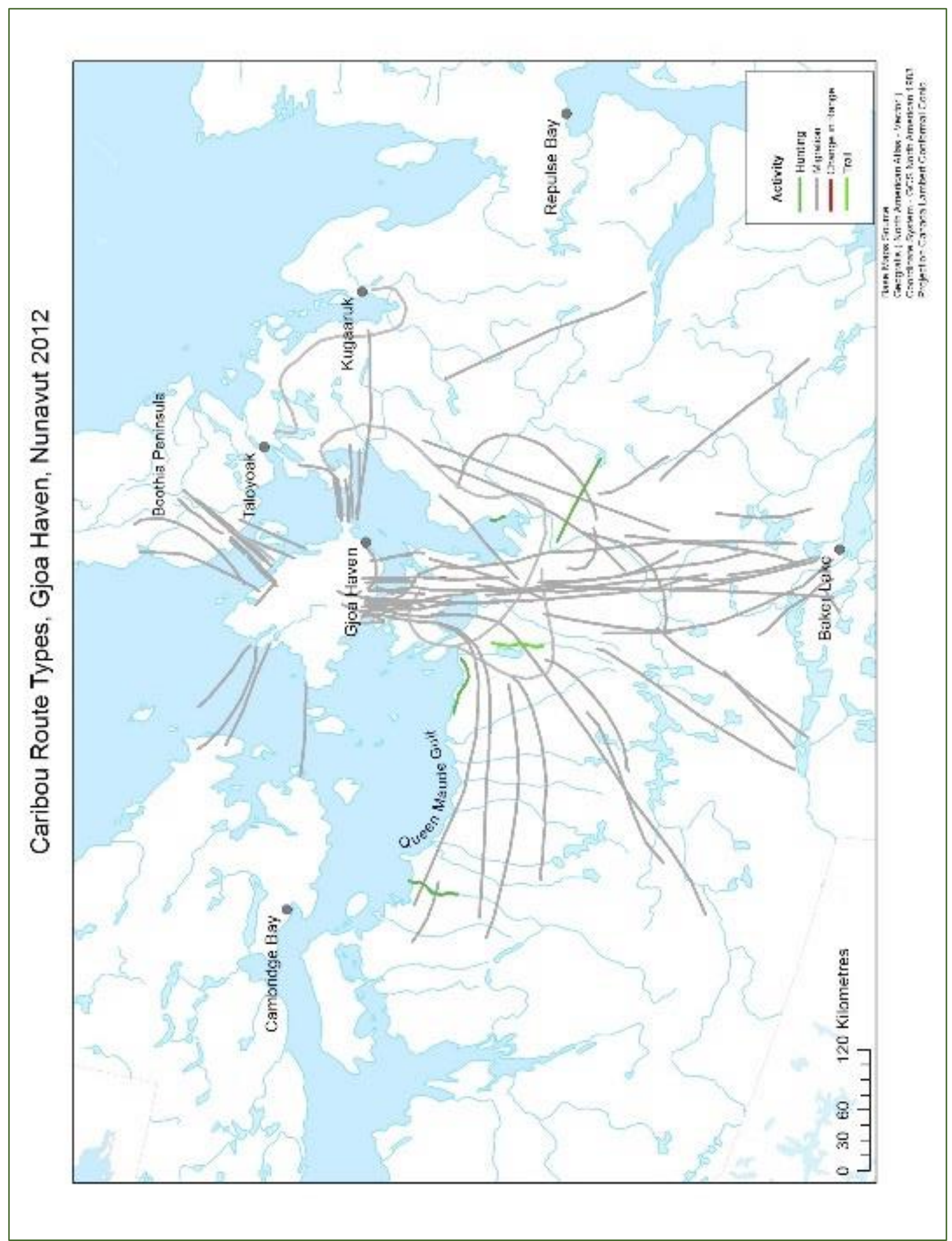

Figure 14 Caribou Route Types 
Through the use of GIS, the data can be displayed in a multitude of ways dependent on how it was created in the database. This data was created with an activity column in the attribute table of the file. $92 \%$ of the data in this activity category pertain to caribou migration or routes show in Figure 14, Caribou Route Types displays. In this same category, only $4 \%$ identified routes as hunting, which again can be attributed to the way the questions were asked during the interviews. All data has been included to analysis all caribou data included in the maps. The hunting routes are on the mainland, one following along the coast in the Queen Maude Bird Sanctuary region, one west of the sanctuary south-east of Cambridge Bay. The third route is along the coast in the Chantrey Inlet south of King Island where the Back Rivers flows into the sea. The forth route identified as hunting runs from the Back River in a southeast direction. One Elder noted a hunting route in the cluster south of KWI that denotes a "change in range" Another draw a route along the Eastern shore of McNaughton Lake is simply listed as a trail.

The direction of the route is important as it indicates the migration from the south in the spring and from the north back south in the fall (Kendrick, et al., 2008; Kendrick, 2013; Parlee, et al., 2005). The maps in Figure $15 \& 16$ indicate that caribou travel to and from the island with the map in Figure 16 showing KWI at a closer view. The routes drawn indicated that the caribou travel on and off the island at three main points where the island is closest to the mainland. The routes indicate that there is a convergence of caribou to the island which a contradiction to the literature where KWI is missing as noted by Ljubicic, et al. (2017). 


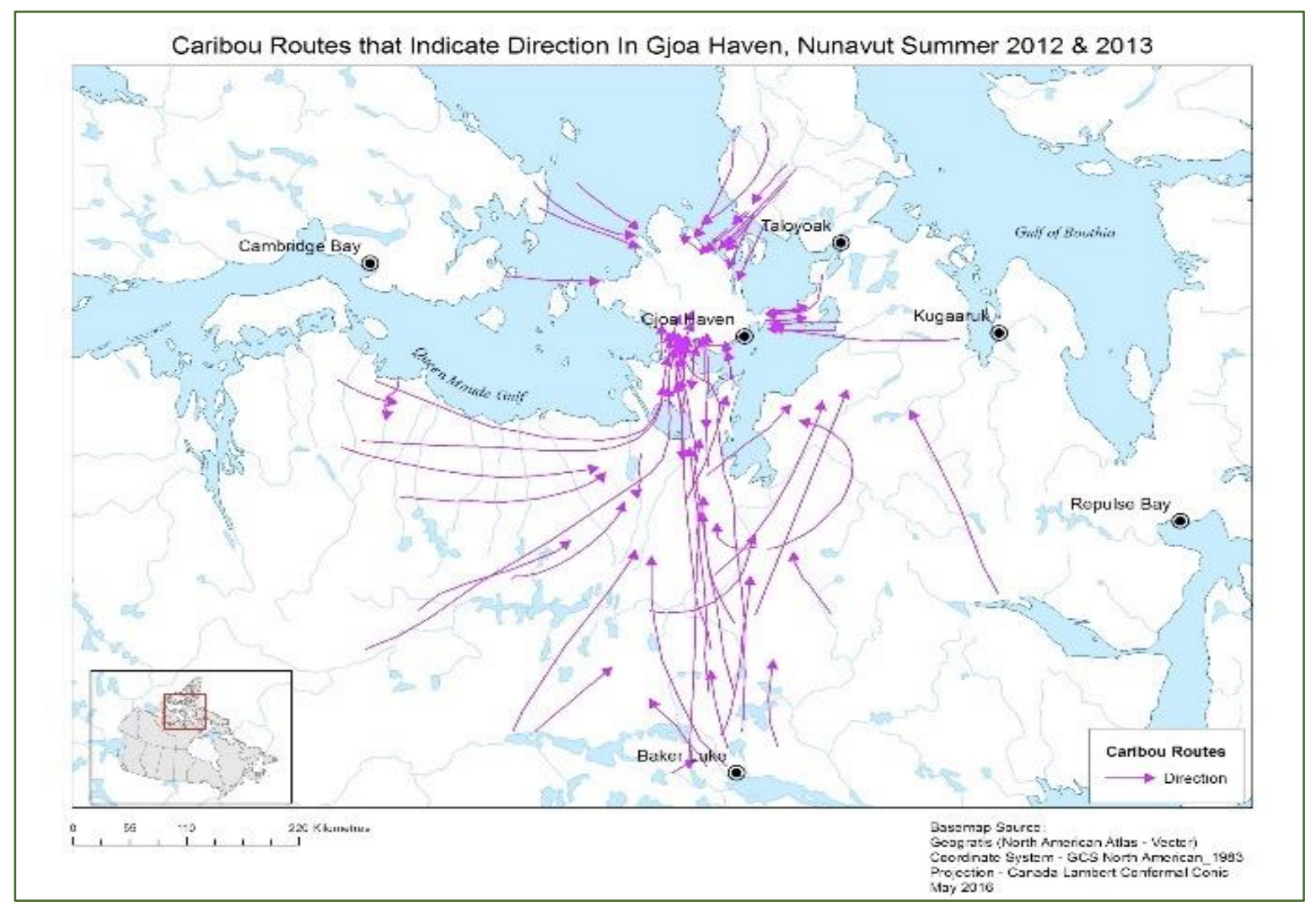

Figure 15 Caribou Routes Direction of Travel

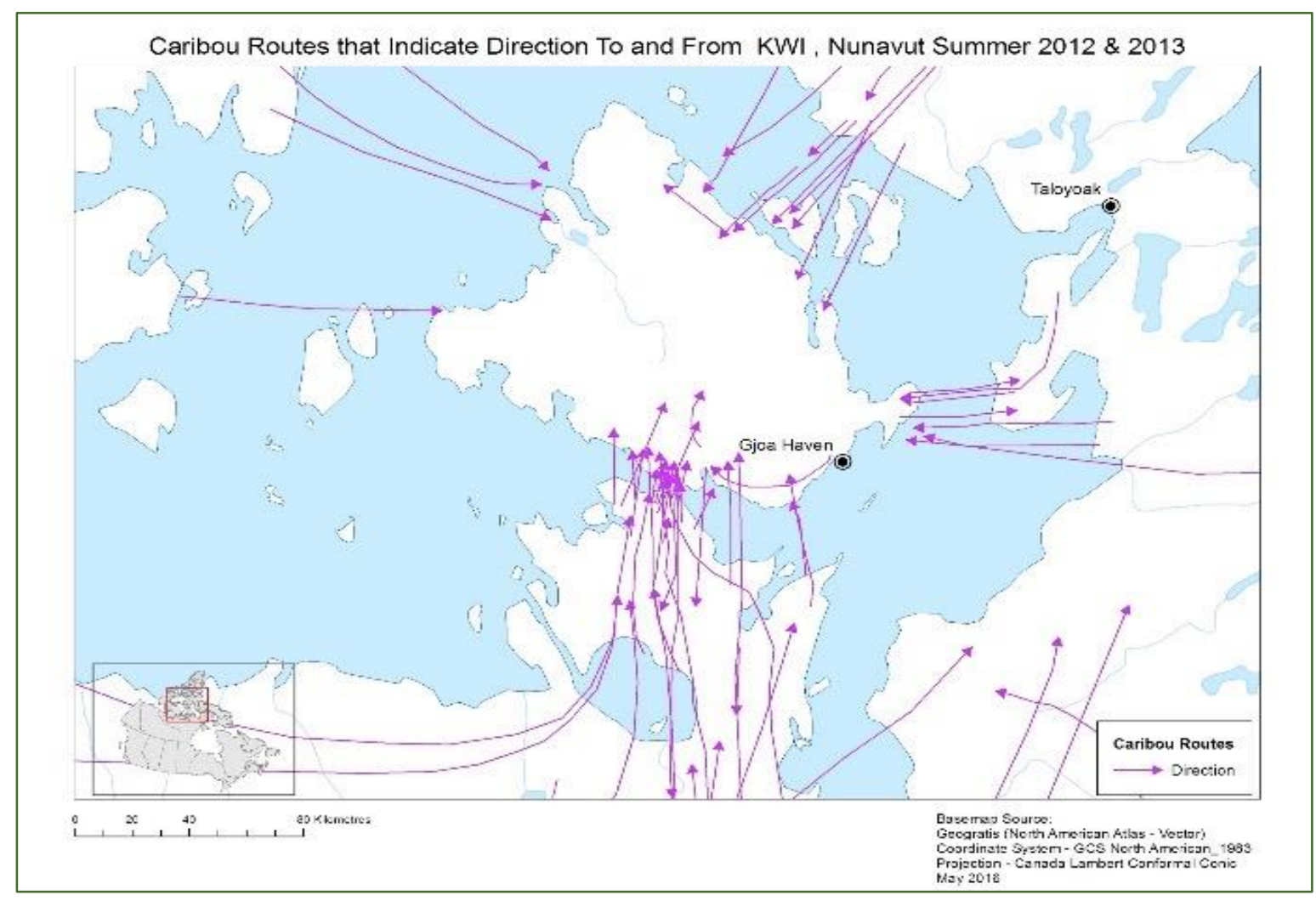

Figure 16 Zoomed in KWI Direction of Routes 
Evaluating the data in the season column of the attribute table also displays direction of travel with only $20 \%$ of the maps indicating a season. One map indicates summer as the season with the route following the coastline in the Queen Maude Gulf area. Three maps indicate fall with the lines clustered running south of KWI in the area that is closest to the mainland. The spring routes run north from Baker Lake, east to north-east and one line indicates the movement from the Boothia Peninsula towards King William Island as show in Figure 17, Seasonal Caribou Route Knowledge. Based on the information on the maps the participants placed more emphasis on spring migration towards the north than the fall migration south. 


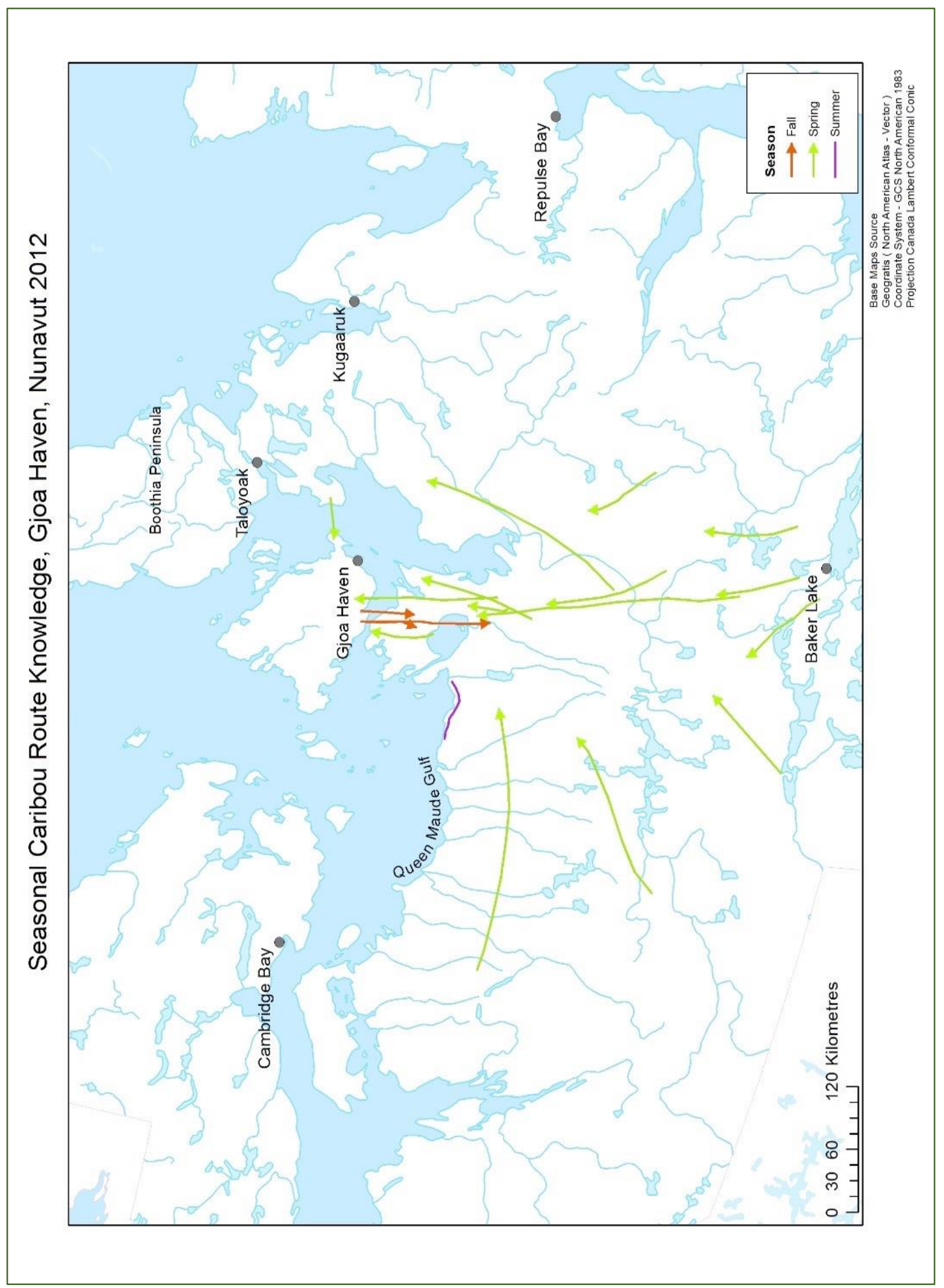

Figure 17 Seasonal Caribou Route Knowledge 
The vector based route data reveals patterns, spatial clustering, seasonality, the type of caribou and the type of caribou activity. The drawback to this format is the inability to analyze the data in a cumulative manner which would illustrate the number of caribou routes or areas that the Elders and Hunters have indicated in each of their maps. In vector route maps, there is evidence of clustering but the data requires further processes for a greater understanding of the collective knowledge.

\subsubsection{Vector Polygon Data}

The polygon data in a vector format illustrates that there is a concentration of knowledge pertaining to caribou on King William Island and the surrounding region in the study area. As with the route data there is a layering affect with the data which does not definitively indicate the number of Elders who drew polygons in a specific area. The Caribou Area map in Figure 18 has been created with hatched polygon that are transparent with a red outline to illustrate the overlapping polygons that demonstrate an accumulation of knowledge based on the original areas drawn. There is a total of 26 maps of the 32 in the dataset that contain caribou polygon data. Three additional files are included which are polygons that were drawn within a larger polygon for a total of 29 polygon layers. In order to represent all of the data these polygons were extracted and named for the map number and B to donate extracted data. The extraction of these smaller polygons is necessary in the raster process and has no affect in the vector process other than it allows for the movement of small polygons to the top all provide a clearer visual to all data. 


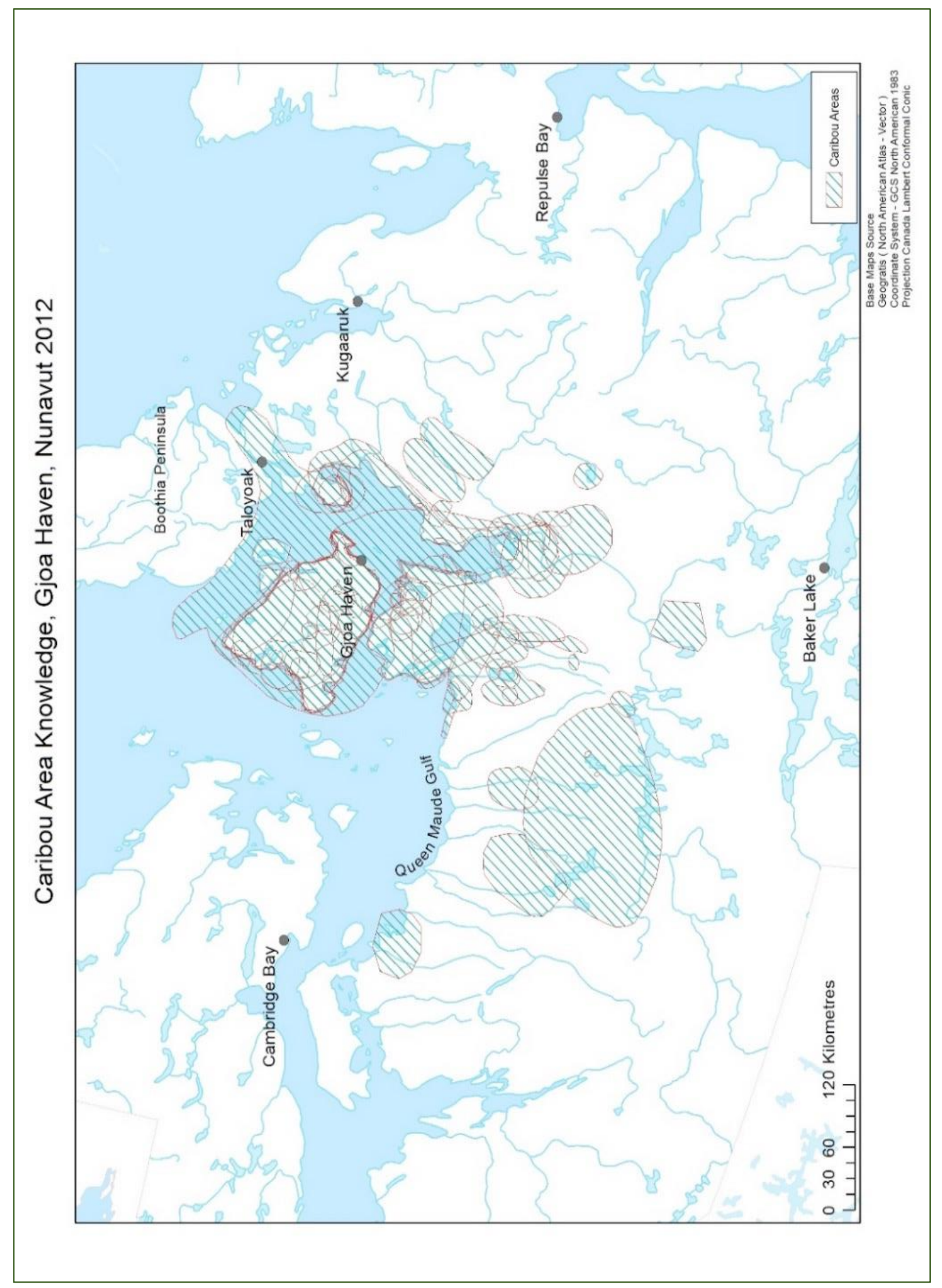

Figure 18 Caribou Area Knowledge 
Unlike the route data, $27 \%$ of the polygons are on King William Island or KWI included in the extent of the polygon. There is also a cluster of routes to the east of Gjoa Haven on the Boothia Peninsula. The region on the mainland to the south of the KWI accounts for $24 \%$ of the polygon data. The southern extent of polygon data is north of Baker Lake some 358 kilometres south of Gjoa Haven while the caribou route data has a southern extent is 470 kilometres from Gjoa Haven. There is an additional cluster of polygons in the region where the Back River flows into the sea in the Chantrey Inlet. The polygon that is the most western data along the coast south of Cambridge Bay is the same area that is noted in the hunting map data, this data was drawn by different authors reinforcing the sharing of knowledge as suggested by Kendrick, 2008; Kendrick, 2013; Wenzel, 2004; Russel, et al., 2000. 


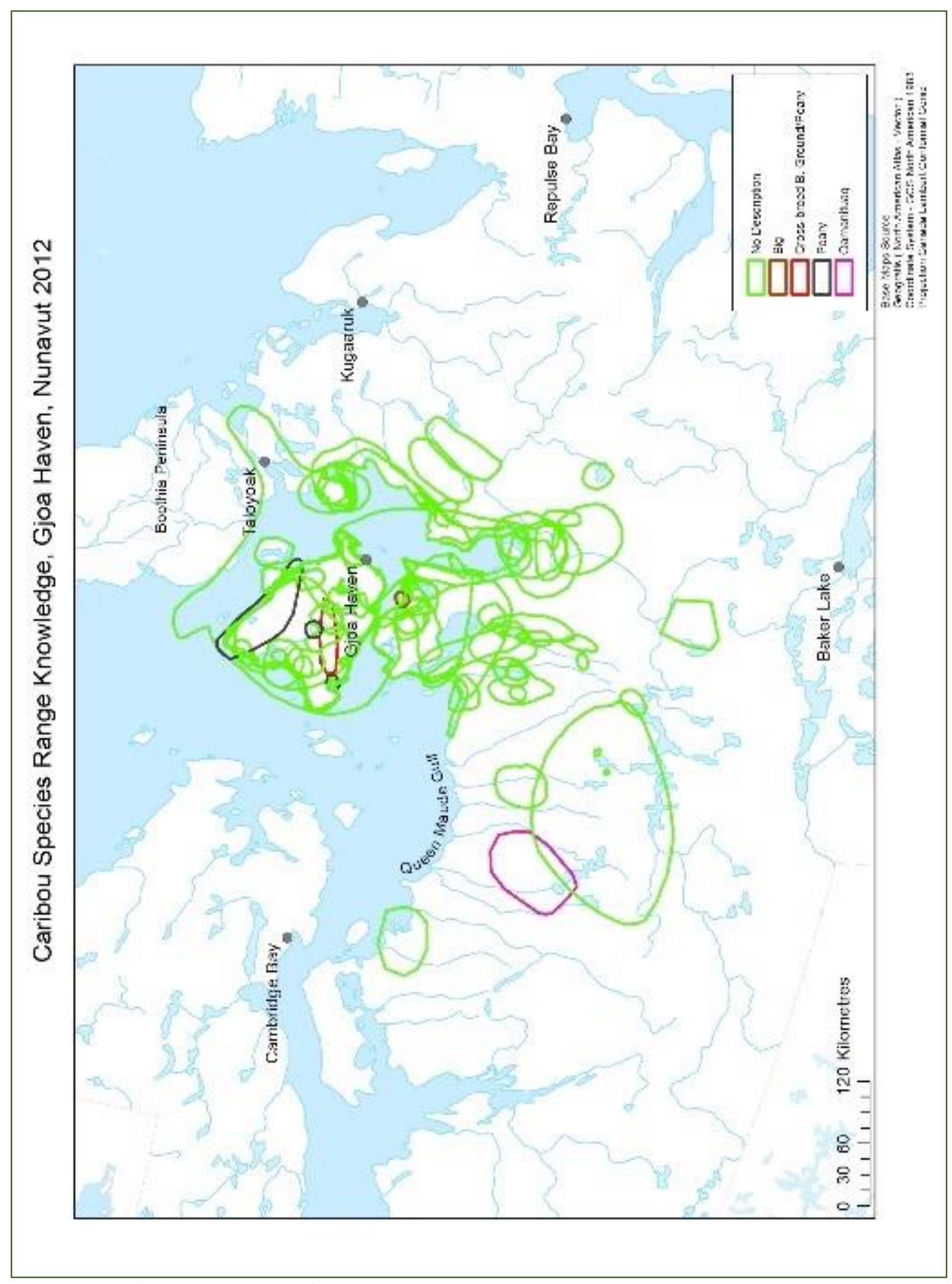

Figure 19 Caribou Areas by Species. 
The polygon data displayed by animal description in the attribute table indicates that only $8 \%$ of the authors identified species. Three identified Peary which are all located on the northern portion of King William Island as highlighted in Figure 19, Caribou Species. One small polygon is noted as "big" that is located on the mainland to the south of the island. There is also a region on KWI that is noted as a crossbreed Barron Ground-Peary. The author of R1.11 indicated a polygon on the mainland in the region of the Queen Maude Bird Sanctuary where he noted on the map "Qamanituaq" which translates to Baker Lake in Inuktitut. the author also noted " 25,000 herd", indicating it is a herd that originates in the Baker Lake region (Baker Lake.ca). 


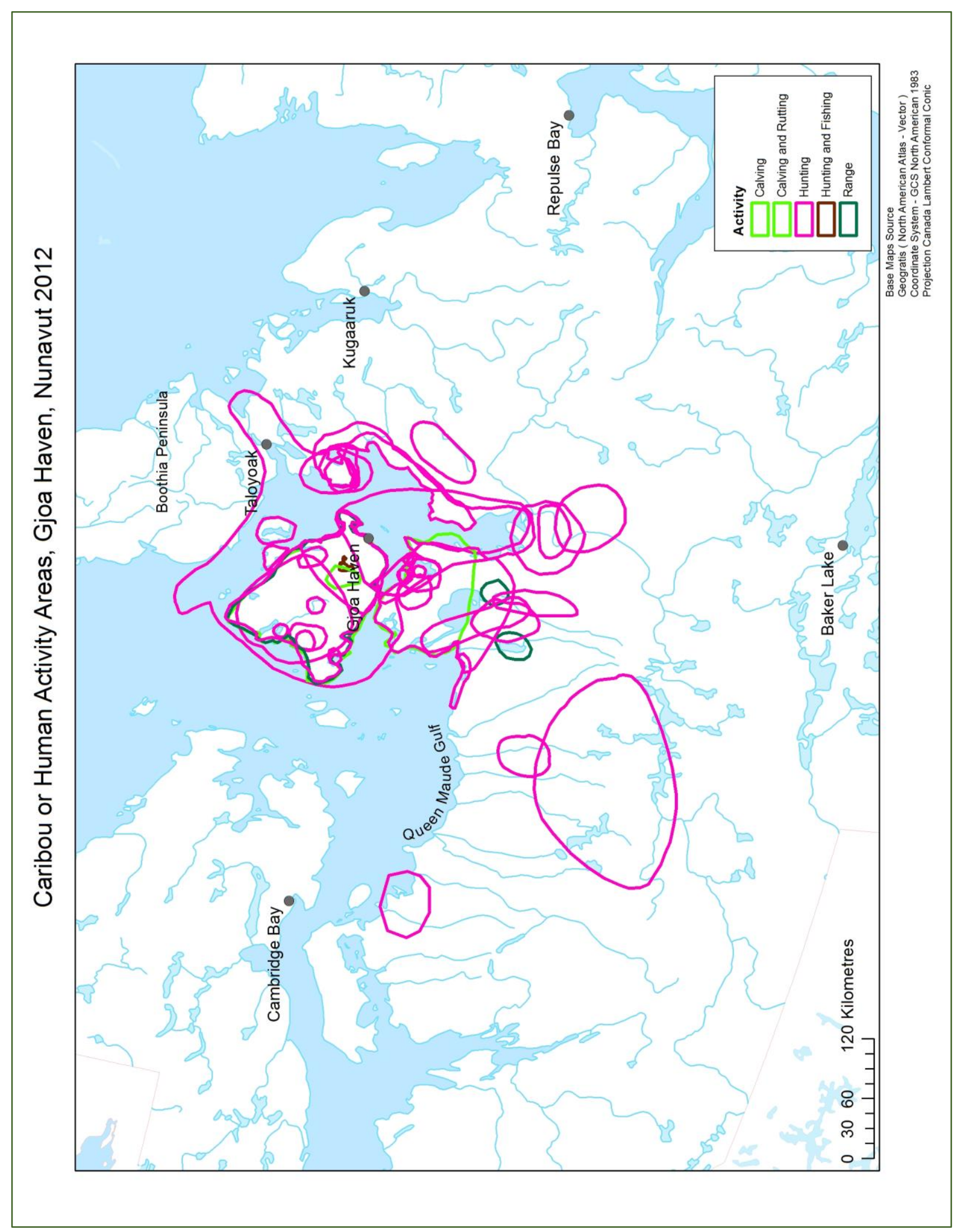

Figure 20 Caribou and Human Activity 
The activity column in the attribute table contains a wide variety of information. The data contains both human and animal activity as it displays both hunting, fishing, calving and rutting and range with $53 \%$ of the polygons listing data for this attribute as detailed in Figure 20 Caribou and Human Activity. Range relates to where caribou were in a different era based on the text on the map. Two of the polygons on the mainland note the 1960's while the third which roughly follows the outline of the KWI. The note for the data states that there was no caribou in the 1970's and 1980's but data contained in the maps indicates that the caribou have returned to the island.

A map of interest is the TK of caribou health with areas noted as "sick caribou" shown in Figure 21, Caribou Health. The number of authors who indicated sick or caribou are too few to interpret, but should be noted in the analysis. One polygon is located to the east of Gjoa Haven on the Boothia Peninsula which is the same region that there is a cluster of caribou routes and areas. The notes for this polygon state "sick and dead caribou". The two additional polygons are in the Chantrey Inlet Lowland where the Back River empties into the sea. The smallest of these two polygons is the furthest south notes "1994" but does not indicate if this was the only time that they hunter encountered unhealthy caribou or if this has occurred since 1994. The larger polygon simply notes that there are sick caribou and does not elaborate or provide a time frame. These locations are also noted as a hunting routes and in areas where there is a cluster of caribou polygons. 


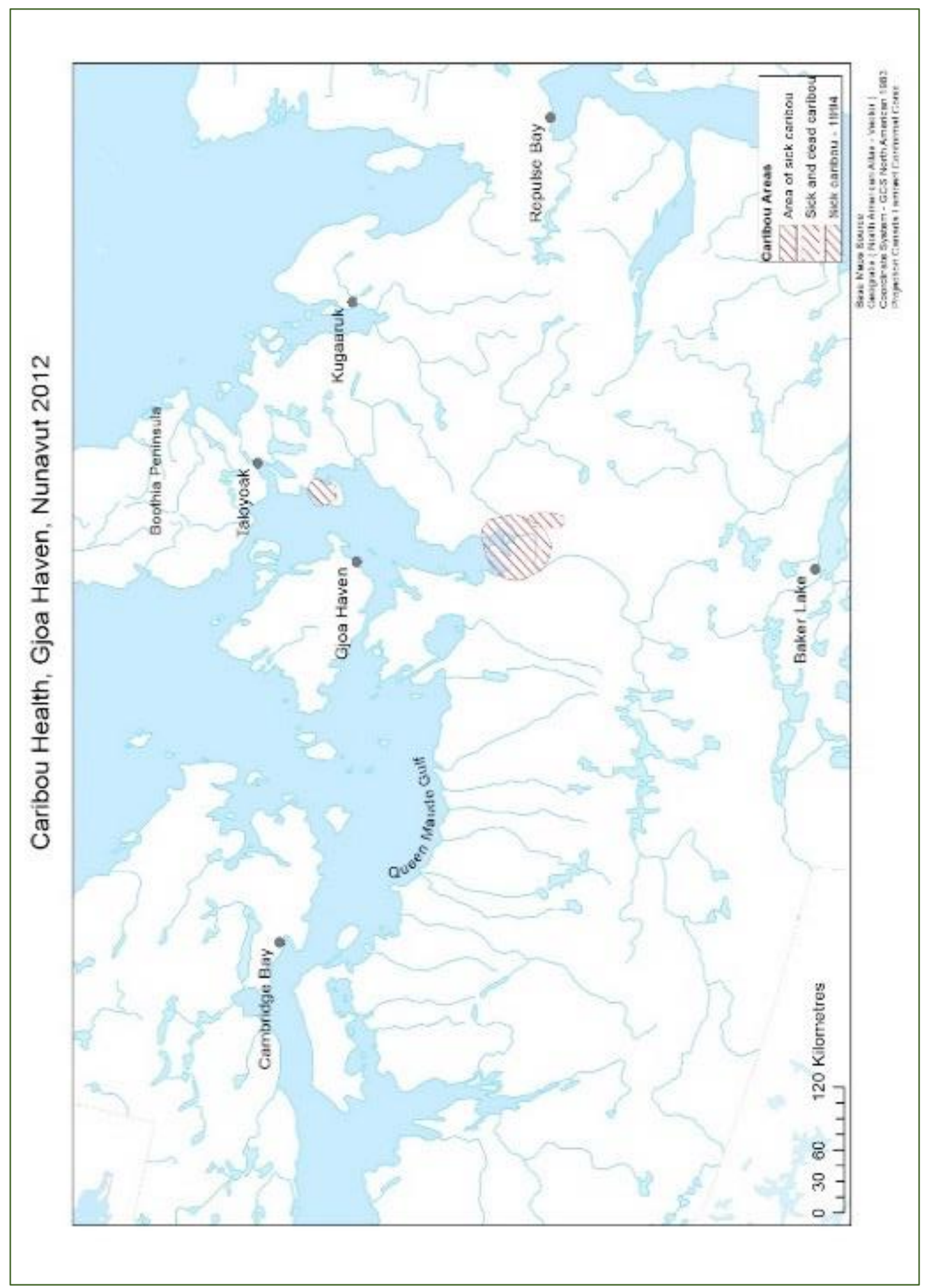

Figure 21 Caribou Health 
The time of year or season was given in the polygon data with $41 \%$ of the polygons labeled with a season as shown in Figure 22, Caribou Areas by Season. There are seven polygons that are labeled both summer and winter and one noted as summer and fall. The authors did not offer further explanation to multiple season notations on the maps. There is no definable pattern or location from the information in the maps that explains the variation in hunting locations. During the winter months' caribou are hunted on King William Island as well as the mainland south of the island. There are two large polygons that denote spring hunting in the region south of the island as far south as the outlet for the Back River in the Chantrey Inlet Lowlands. Summer hunting grounds are the entire island, a cluster to the east as well as small areas south on the mainland. There is one large polygon in the Queen Maude Bird Sanctuary and south to Garry Lake. One author noted a small polygon on KWI where he hunts in the summer and the fall. The data on seven of the maps suggests that caribou is hunted in the summer and winter on King William Island and areas to the south and south-west on the mainland 


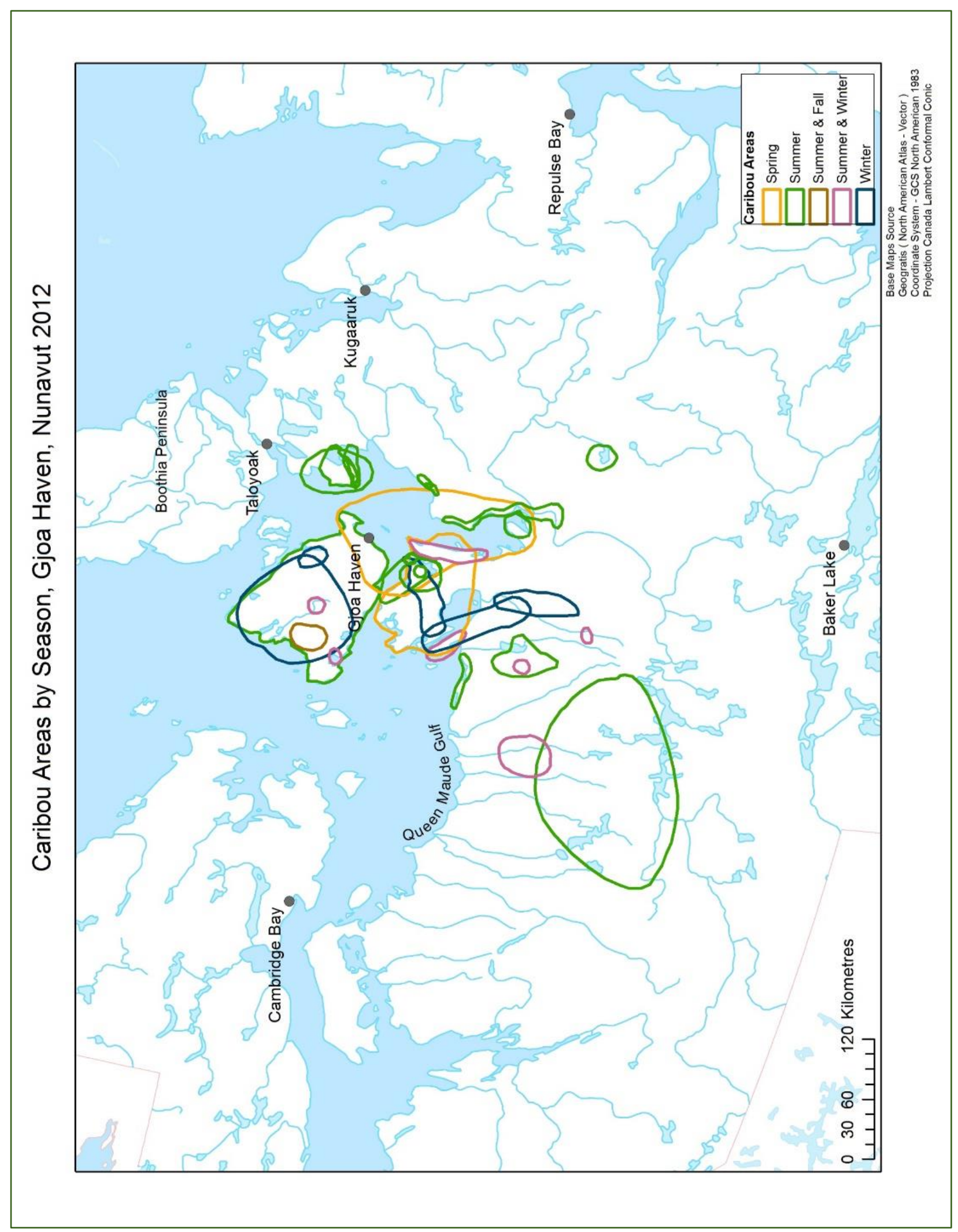

Figure 22 Caribou Areas by Season 
The historical caribou knowledge imbedded in TEK is shown by decade on the map featured in Figure 23, representing participants' interaction with caribou over time. The data set is not large enough to assess causation for changes in hunting locations, but rather it is a shared knowledge and reflects experiences and different hunting regions over their lifetime. There were only $23 \%$ of the participants that made note of time frames. The format they wrote in varied from a specific year or two, a decade, two decades, past, now, current and multiple which does not have an explanation. The data was categorized into decades if a specific year was noted or notes that did not contain a year but text that identified a time frame. Any linguistic clues that pertained to current times as well as current dates were change to "current". Those that noted hunting in current times were $18 \%$. The Elder that noted "past" did not elaborate on the time frame which is consistent with the author that labeled a polygon "Multiple". The polygons that are labeled as current also contain within them polygons dated 1950, 1980, 1960, 1960-70 and past. The only polygon that is not within the current polygon is a small one south west of the outlet of the Back River. The temporal TK data indicates that caribou is on King William Island and the numbers may fluctuate as indicated in the text on the maps. 


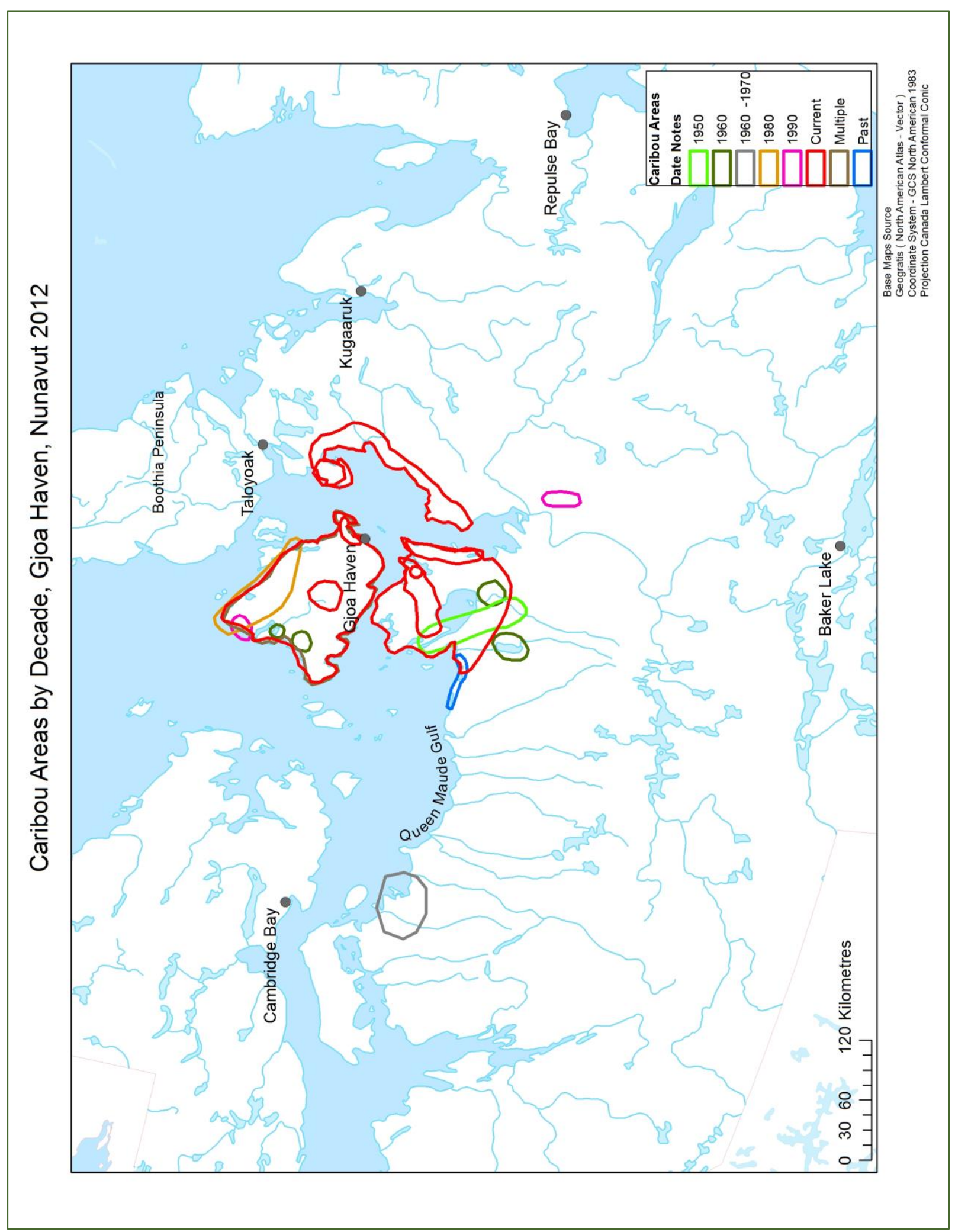

Figure 23 Caribou by Decade 
The analysis of point, line and polygon data provides insight pertaining to the collective caribou knowledge on the maps. Each of these maps details important information that is relative to the residents of Gjoa Haven and the surrounding communities whom they share this knowledge. The power of the knowledge in a visual format will aid in understanding the nuances of caribou in the region as the visualization of the TK aides in understanding the collective knowledge of the region. The data specific maps such as health are useful as a collection of TK to better understand the changes and management of herds. In this format, the data is fragmented and does not provide the cumulative power of the knowledge. Further data analysis in raster format will provide a measure that has greater significance than the vector based maps.

\subsection{Raster Data}

The raster based maps incorporate the power of cumulative analysis and the spatial scope of TK. TK is not generally location specific (i.e. as defined by finite boundaries) but rather knowledge that can contain information in the form of a story, weather, herd health and numbers or generalities about migration routes and timing it is well suited to a fuzzy methodology (Kendrick, 2005; Kendrick, 2013; Johnston, et al., 2015; Ford, et al., 2010; Caquard, 2011; Berkes, 1999; Berkes and Berkes, 2009; Wenzel, 2004). The maps in Figure 25 and Figure 26 illustrate the breadth of the caribou knowledge combined in the maps that are the basis for this research.

A fuzzy methodology is well suited to the variability of TK as it establishes continuous values within the buffer which denote the degree of membership the area surrounding the attribute has to the attribute for one or more of the caribou routes or the polygons (Berkes, et al, 2009; Dunn, 2007). As noted previously the 20 kilometre buffer was established based on the terrain, elevation and the probability of observing a caribou herd at that distance. This continuous surface data creates clear distinct patterns and highlights knowledge nodes or intersections that were apparent in the vector polygon and route maps but the data is a clearer visual representation of TK. It allows for the accumulation of the data as a single image rather than lines and polygons drawn in succession as in vector data. Additionally, the fuzzy 
method requires a mathematical process to create the surface, this formula provides a process that is repeatable. The data set includes every line and polygon that was identified as "caribou" in the original data. This methodology also highlights those lines or polygons that are unique or outside of the concentrations of knowledge that denote distinct experiences. The maps created have clear patterns without the clutter that effectively highlight the areas of shared knowledge. Both the route and area maps contain all the data from the original 32maps that pertains to caribou and is either a line of polygon attribute. As noted previously, the point data set is not large enough to preform analysis on.

\subsubsection{Raster Route Data}

The data contained in the route raster map is a duplicate of the data in the route vector map which consists of the 19 maps that comprise route data of the 32 maps as previously noted in Table 1 . The number of categories of data displayed in a GIS is an iterative process. The default in many GIS displays the data at five natural breaks in the data set which are not ideal for this information. The computer driven defaults do not include the nuances or the knowledge that comes from studying these maps. Judgement decisions are required to select a display method that best represents the data. However, it is imperative to ensure that the data is displayed in a manner the is culturally appropriate and understandable to Elders who many not speak English as a first language. The five categories selected in Figure 24 best represent the collective data with the first category of 0.00 meaning none of the participants indicated data in that area. The break points of the four groups that contain route data produce a surface that best highlights that collective knowledge on the original maps. The areas that are light green with a single yellow line in the centre are buffered routes with the yellow line as the route and the green represents the buffer. In areas where several lines are present as in the hotspots the buffers overlap creating a higher number which creates the area where a higher percentage of the participants drew routes. 


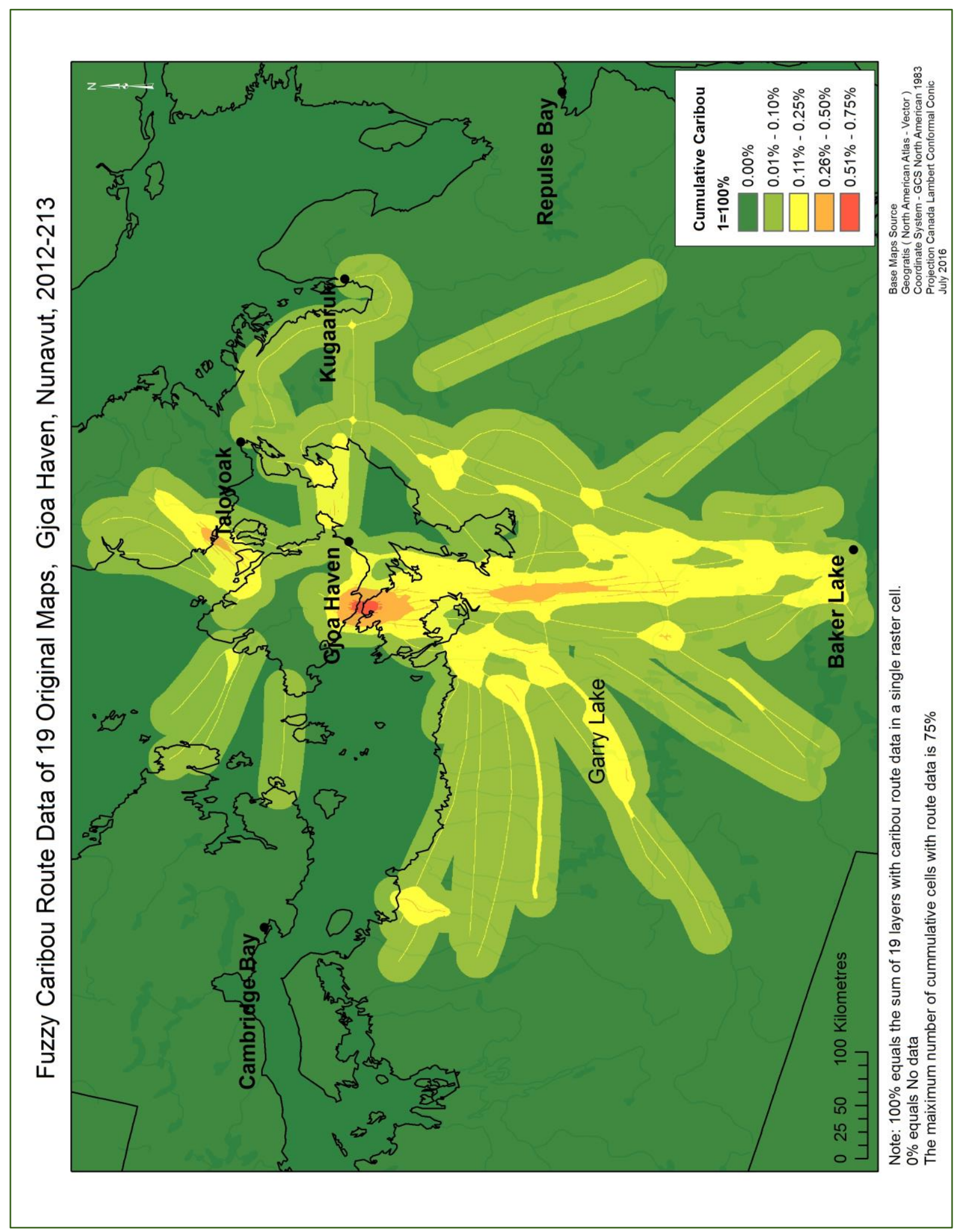

Figure 24 Fuzzy Caribou Route Data 
The route knowledge indicates the three clusters or knowledge intersection areas that were seen in the vector based map. The area south of King William Island which is only 3.8 kilometres from the mainland has the highest concentration of knowledge with $0.5-0.75$ of the authors drawing a route in the area. The proximity to of the land masses aligns with caribou research that suggest caribou cross water at the narrowest points to avoid swimming. This hot spot is also surrounded by an area where $0.26-0.50$ of the authors also drew a route, suggesting that participants indicated that this is an important area for caribou coming to the area and where they head in the fall migration returning to the south. The region south to Baker Lake which is mentioned in the transcripts as a cultural connection has a continuous route with at least $0.01-0.10$ of the participants drawing a route in the area. There is a zone that is 74 kilometres south of the main cluster at the coastline. This additional hotspot that is 112 kilometres in length and 19 kilometres at its widest point was not evident in the vector maps. Scattered throughout the region south of the island there are large areas indicated in yellow that show routes where up to $0.11-0.25$ of the participants indicated caribou routes. Given the vast area these maps cover multiple routes within the 20kilometre buffer highlight the precision of TK. There are single small line segments throughout the hotspot areas where up 0.25 drawn a route. The route to Garry Lake which is also noted in the polygon data indicates cumulative knowledge in the $0.11-0.25$ range. This is a large continuous range from the large hotspot south of KWI running in a south, south-west direction which is 64 kilometres at the widest point.

The second hotspot is east of Gjoa Haven and west of Kugaaruk. The area between KWI and the Boothia Peninsula indicates that $0.11-0.25$ of the participants drew routes in this region. This area does not have the accumulation of routes that it appeared to have in the vector map. The third hot spot to the east of Gjoa Haven on the Boothia reveals the travel route of caribou that is not noted in any of the literature. The hot spot that indicates route at the north end of KWI and the peninsula north of Taloyoak reinforces the traditional knowledge with more than 0.51 of the participants indicating that the caribou travels this route. Although co-management board herd maps do not show an abundance of caribou 
presence in this region the Elders in this study have drawn and spoke about hunting in the area. This is an area that hunters and Elders mention both Barren-Ground and Peary Caribou.

The data in a raster format provides greater clarity in respect to the routes in proximity to King William Island. This method provides a more representative indication of caribou movements, as caribou would not walk the same single route or line. The hotspot south of the island indicates a clear connection to the mainland with a portion of the highest grouping of $0.51-0.75$ of the lines are in this area. This highlights the importance of the crossing point as the caribou move onto the KWI. The area to the east of Gjoa Haven designates the hotspot on the Boothia Peninsula that is in close proximity to the island. This same affect is seen in the third region on the northern end of the island. These hotspots highlight the cumulative knowledge of the participants and the power of the visual perspective of knowledge.

\subsubsection{Raster Polygon Data}

The polygon data shown in Figure 25 is based on a greater number of the maps with 26 of the 32 original maps containing caribou data. As noted previously, 29 separate files were used to account for 3 maps in which a polygon was drawn within the boundaries of a larger polygon. As with the route raster

data the use of five categories for the raster polygon data is based on an iterative process that begins with the default with categories at the natural breaks in the data. Additionally, the same number of categories was used to ensure consistency in the analysis. The natural break for the lowest category is above one which does not accurately display the areas that did not contain any data in the original maps seen in Figure 26 


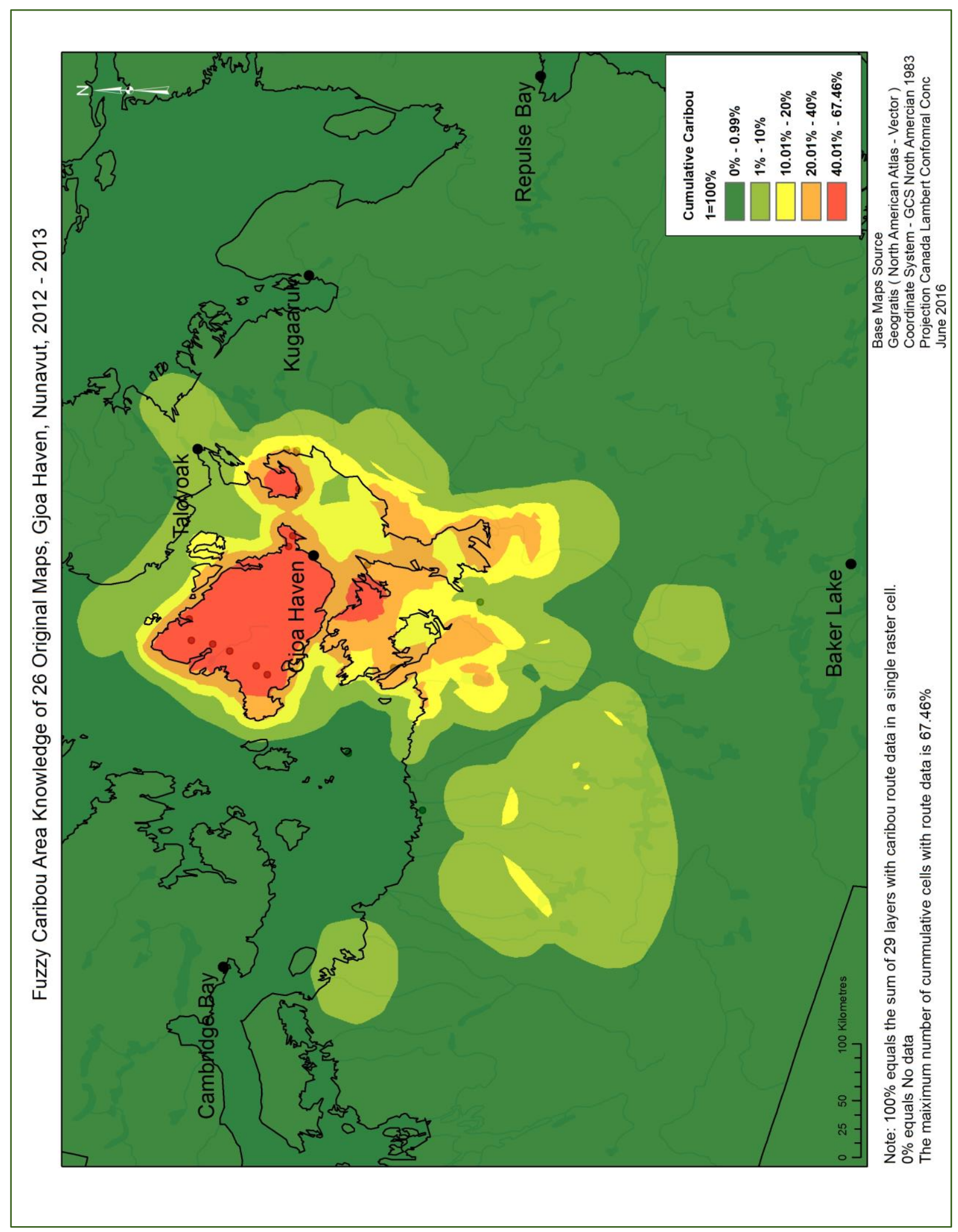

Figure 25 Fuzzy Caribou Area Knowledge 
The five category breaks that were selected create one category with no data and the next two at $10 \%$ intervals and the final two at $20 \%$ intervals. The selection of category breaks is an iterative process to find a solution that best represents the data to produce a map that emulates the data as it was drawn in the original maps. This five-category display is crisp and provides a clear visualization of the data. The data in the polygon raster map, Figure 26 is centred on King William Island. In comparison, the data in this map does not cover an area that is as large as the linear data in Figure 25. The closest polygon to Baker Lake is 120 kilometres north of the hamlet. The region with the highest percentage of polygons cumulatively is KWI, the hotspot to the east and the region to the south of the island. These red hotspots are areas where $41 \%-67 \%$ of the polygons are drawn. This is opposite of the route data drawn on the island which is very limited. The entire island is in the $41 \%-67 \%$ cumulative knowledge range except a small portion on the west coast closest to Victoria Island. The data appears to follow the shape of the island which may be triggered by the way it was recorded. There are maps where the author has followed the shoreline of the island to indicate that caribou is found in many places on the island. Hence, when the buffer is added the outline follows a similar shape. This accumulation of knowledge and the 20 Kilometre buffer creates the area in the $21 \%-40 \%$ range that surrounds the hot spots. The Chantrey Inlet Lowland area south of Gjoa Haven where the Back River flows into the sea is another region with cumulative knowledge at $21 \%-40 \%$. This region and the large area to the southwest in the Garry Lake area on the mainland south of KWI are distinct regions that have been noted as caribou areas and are not a result of the 20 kilometre ring buffer effect that is seen on KWI.

The hotspot to the east of Gjoa Haven on the Boothia Peninsula west of Kugaaruk was also noted as a location with multiple polygons. Furthermore, there is an area south of Cambridge Bay that indicates collective knowledge in the $01 \%-10 \%$ range which was also noted in the Cumulative Route map and in the vector maps. All the areas that indicate greater than $21 \%$ caribou presence are all within 50 kilometres of the shoreline or a large body of water. Without further discussion with the participants, knowledge of the terrain and plant phenology the reason for this is unknown. 
The fuzzy methodology produces a map that provides a clear visual of the cumulative knowledge of the participants. The hot spots and very distinct and pinpoint the areas. This map provides the Elders and Hunters a unique image of their collective knowledge of caribou in the region based on the questions in the interview.

\subsection{Comparative analysis of Hunting Data in Vector and Raster Fuzzy Formats}

The data for hunting in both the line and polygon datasets was extracted from 18 maps that specifically indicate hunting caribou and combined to create hunting maps using both vector data and raster data. It is noted that one of the polygons was labeled "hunting and fishing". In order to remain true to the data it has been included. The vector data map in Figure 26 illustrates the precise data georeferencing where the line and polygon is exactly where the map author drew the attribute on the Mylar map. The placement of the layers of data is imperative to the outcome. The linear data is placed above the polygon layer to ensure that the lines which are limited and in the same area as the polygons are visible. The vector data map indicates that the areas drawn pertaining to hunting are clustered on and near King William Island. The line data is limited to four lines which of two are completely within an area defined as hunting, one in the Back River area begins within a hunting area and continues in a south-easterly direction beyond the polygon. The forth line the indicates hunting abuts the polygon south of Cambridge Bay.

There is a clustering of polygons on the peninsula on the Boothia Peninsula to the east of Gjoa Haven and a secondary cluster south of Gjoa Haven on the mainland. There are several areas on KWI where more than one of the participants indicated an area they hunt for caribou. The number of polygons on the point of land on the Boothia Peninsula to the east of Gjoa Haven and the area to the south of KWI that is closest to the mainland are unknown in the vector map as noted previously. As stated previously the data in vector maps is not cumulative, it depicts clusters of polygons but the number of polygons in the clusters is unclear. Additionally, polygons in the hunting map dissect each other splitting the polygon where a portion has a higher collective value than another portion of the polygon. 


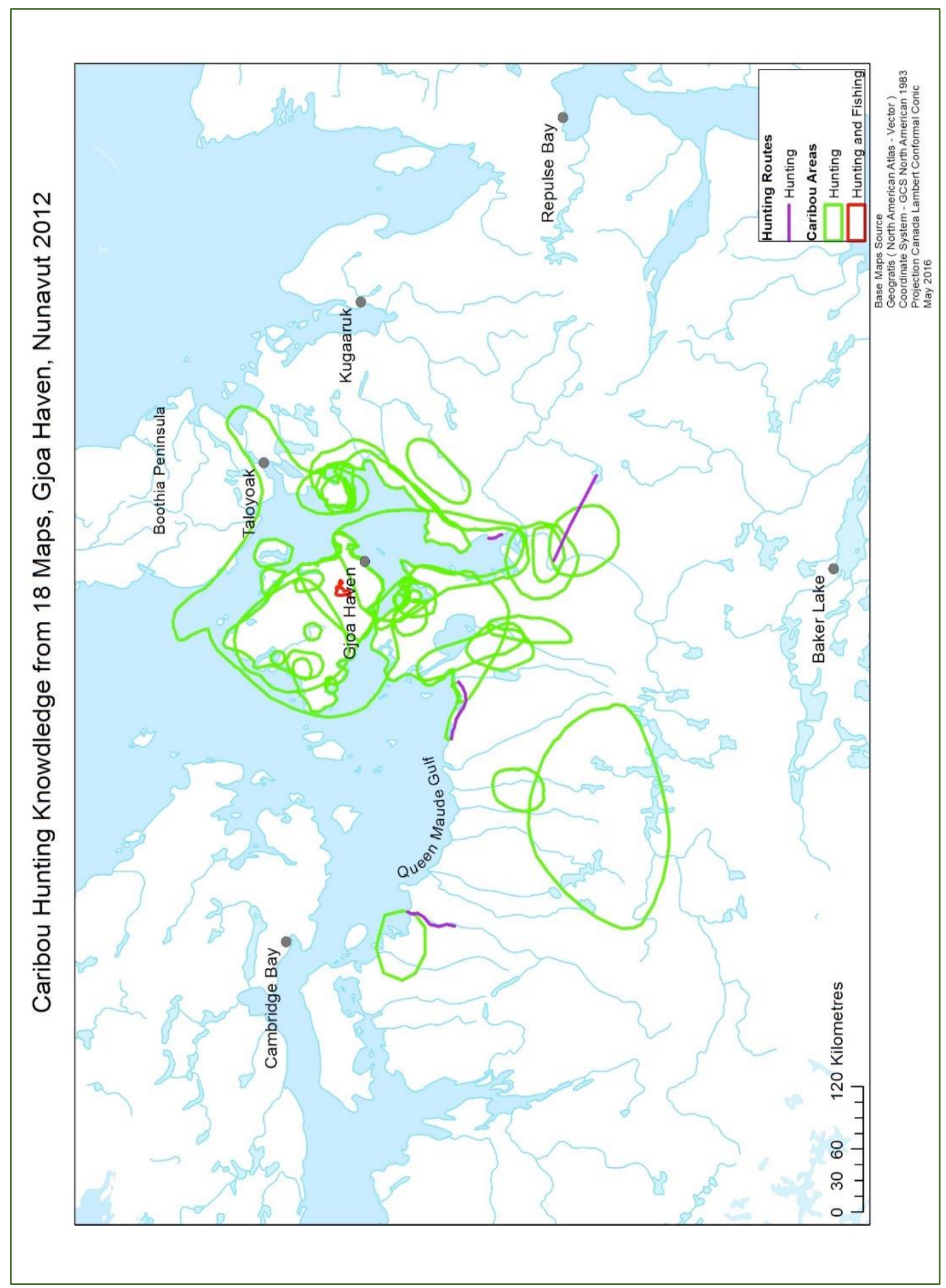

Figure 26 Vector Caribou Hunting Knowledge 


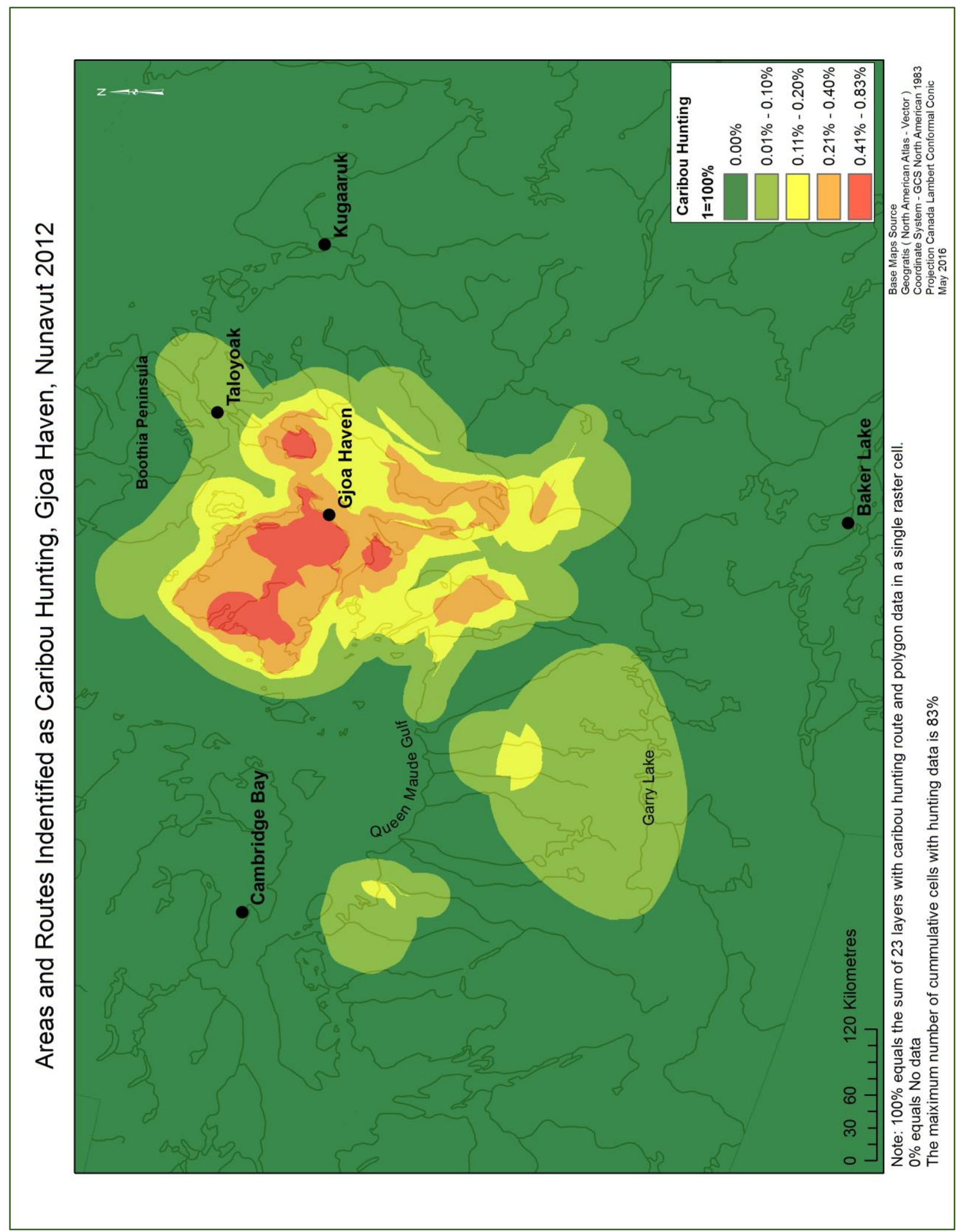

Figure 27 Cumulative Raster Caribou Hunting Knowledge 
The direct comparison of the two types of data and the use of the fuzzy methodology highlight the differences between these two methods. In comparison, the fuzzy method map in Figure 27 indicates distinct hotspots or knowledge nodes that are evident in the same areas as previously noted in the vector maps. However, there are clearly defined and less ubiquitous. In the vector map it appears as though all of KWI is a hotspot, however, the hotspots in the fuzzy map indicate distinct areas of KWI in the 0.41-1.00. This indicates that of the 18 maps that specify caribou routes or areas 7 to 18 of the Elders and Hunters drew caribou hunting knowledge in these areas. The hot spot that was noted east of Gjoa Haven on the Boothia Peninsula appears as a hotspot on the fuzzy map, while the area that is south of KWI indicates a tighter smaller hotspot that indicated in the vector map. The Chantrey Inlet and Back River area fall in the $20-40 \%$ range as does the remainder of KWI island except for a very small peninsula north of Gjoa Haven. The 20 kilometre buffer zone added to account for the inherent vagueness of the data has created two areas to the south-west that are not shown in the vector map. There is a large area in the $0.01-0.10$ range in the Garry Lake Region that corresponds with a polygon on the vector map with a small region in the 0.11-0.20 range that is within the large polygon which is visible in the vector map.

The fuzzy method provides a map where all participants data is given the same weight, the data is combined and displayed in an equitable manner. The contrast between these two methods of displaying data allows for the comparison of qualitative and quantitative methods. The fuzzy map provides a cleaner more precise depiction of the data.

The map in Figure 28 depicts a combination of raster based caribou hunting polygons and routes with the 20 kilometre buffer added to both. The fuzzy process is not included in this map. The ability to view the original vector data with the buffers added simultaneously highlights the buffers and provides for a clearer understanding of how the buffers can interact and create false values when the cumulative steps are added to the process. The black lines indicate the polygons and the four red lines are the hunting routes that were noted on the original maps. The two areas to the west of the major cluster of data on KWI and the area south clearly indicate the overlap of buffers, the large polygon in the Garry Lake region with a smaller polygon the intersects it to the north. In the area, south of Cambridge Bay a polygon and a line 
were both identified as hunting overlap and the buffers could have a tendency in both examples to increase the hotspot area.

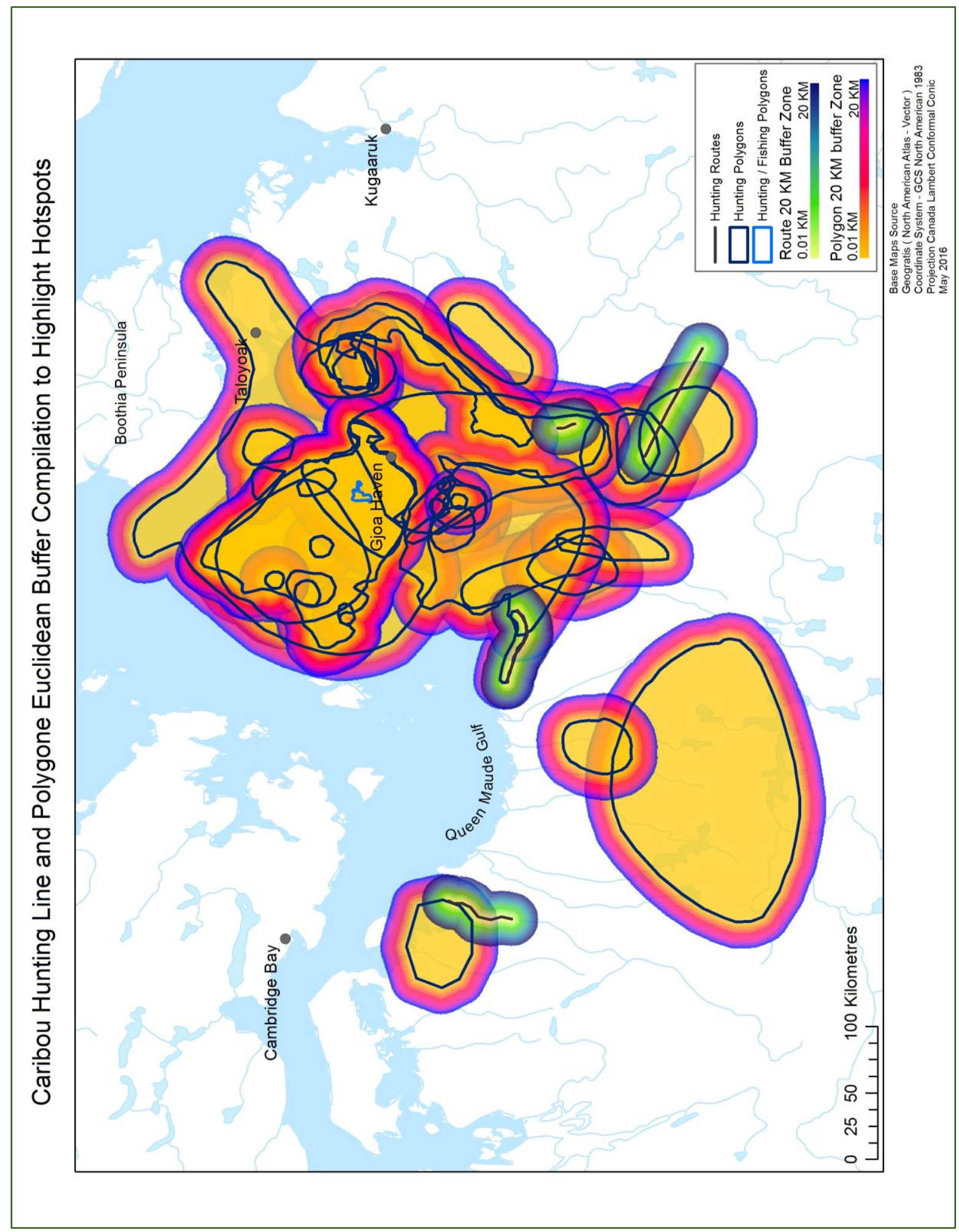

Figure 28 Caribou Hunting areas and routes with $20 \mathrm{Km}$ buffers 
It is important to note that the fuzzy concept does not enhance data from small datasets. For example, performing the conversion to raster, applying the buffer and running a fuzzy model would not enhance the linear or polygon data in the seasonal maps noted previously in Figures 18 and 23. The data in the linear map does not overlap, every line is clearly visible. Data in the polygon map does have significant overlap, yet the map in the original format clearly identifies geographic differences in seasonal information. It is important to note that the fuzzy method is not based on one attribute: it is both line and polygon data combined. The ability to combine linear and polygon data enhances the effectiveness of the process. Yet, a limitation is the ability to depict data that is varied as in the season data. The fuzzy method would not distinguish the seasonality of the data. Converting the layers to raster and applying the processes required in the fuzzy method would not provide any additional information. However, separating out of small datasets in a vector format to highlight them does enhance the clarity and provide the contributors additional information about their collective knowledge as seen in the Figure 18 seasonal routes and Figure 22 Sick Caribou

The large raster based data in the cumulative maps has greater detail and clarity when a fuzzy methodology is applied. These maps provide the Elders and Hunters a view of their collective knowledge which may not have been viewed in the encompassing way previously. These maps are a clearer indication that the collective knowledge of the 32 participants extends throughout their entire region. The vector based maps that are based on specific attributes in the dataset fulfill some of the key research priorities that were set out in the planning meeting of February 2010 in Gjoa Haven, Nunavut which lists: identifying different caribou herds on King William Island, caribou health and temporal changes. This research does not answer the impact of climate change, long term cycles of caribou abundance, increase in predators and changes in habitat due to climate change. These questions may be better suited to analysis through the use of remote sensing. 


\section{Chapter 5 Discussion}

The objective of this research is using traditional caribou knowledge parsed from 32 maps created by Inuit Elders and Hunters in Gjoa Haven, Nunavut during the summers of 2012 and 2011, to use GIS tools to create meaningful representations of the knowledge shared. The first objective was to use the data in a vector format to understand the ability to create maps that are accurate and display the TK as it was intended. The second objective was through the use of a fuzzy methodology create maps that are a collective continuous knowledge surface that is a closer representation of traditional caribou knowledge than vector based data.

The meld of TK and GIS highlights the compatibility of two different knowledge systems while simultaneously depicting the challenges of using traditional spatial knowledge in an appropriate context. The efficacy of a map is the ability to create maps that are meaningful and true to the TK drawn in the original maps (Bryan, 2011). The use of TK as a confident data source is significant to the Inuit as traditional knowledge has been the keystone to their survival in the Arctic (Duerden et al, 1996; Engler at al., 2013; Freeman et al 2005; McGregor 2004). Generations of knowledge of wildlife, environmental changes, and how to live in harmony with the land has been transferred from one generation to the next and western science is only beginning to understand the breadth and depth of it. Inuit society is dependent on caribou; they are vital to their culture, health, and societal traditions (Kendrick, 2003; Miller at al., 2009; Russell et al., 2000). However, caribou traditional knowledge does not appear to be the basis or used on par with western science in caribou management decisions.

The 32 Elders and Hunters who participated in the research drew maps based on semi-directed interviews of knowledge that was important to them based on the questions asked by the interviewer. The methodology adhered to during the interview process was an Indigenous research framework where the research questions are community driven and are based on respect, reciprocity and accountable relationships which ensures the Inuit guide the research (Ljubicic, ND; Crampton, 2001; Windsor, et al., 
2013; Peters, 2013). Participatory mapping aligns with the Indigenous research theory creating collaborative community driven research (Peters, 2013). The use of drawing as a means of communicating TK is a culturally appropriate medium (Pulsifer, et al., 2011). Additionally, the Indigenous framework in which the larger research project lead by Dr. Gita Ljubicic was conducted under creates collaborative work with a common goal of equal knowledge for all participants.

\subsection{Successes and challenges of Vector Data Maps}

This series of maps produced provide a collective understanding of the traditional knowledge of the participants in this study. The TK in the maps is communal knowledge that is shared between these Hunters and Elders. This series of maps as a whole synthesizes the data collected and creates images of knowledge and hotspots of knowledge where multiple authors data intersects. The vector maps generated from caribou areas and routes in Figure 15 highlights the knowledge that the participants have about caribou in their region. These maps indicate hunting and migration routes, hunting areas, calving grounds, areas of caribou abundance, temporal changes, caribou health and type of caribou. The data contained in the map overwhelms the visual aspect as it is cluttered, visually noisy and most importantly data in a vector format does not have the capacity for cumulative measures (Feizizaded, et al., 2014; Atkinson, et al., 2005). Additionally, the layering effect of data where the top-most layers' obscure that data below lead to the lack of clarity in the maps. While there are three areas where there are knowledge nodes the number of participants who indicated caribou data in an area is unknown. The data in this format does not provide an equitable view of the contained knowledge and may inadvertently convey a power imbalance due to a lack of clarity (Crampton, 2001). The richness and depth of the data as well as the abundance of knowledge the 32 participants is evident, yet when displayed in its entirety in this format the true collective knowledge is unknown. Further dissemination of the data is required to fully understand where caribou are located and to what degree this knowledge is shared among the Elders and Hunters 
There is a correlation to the decrease in data shown and clarity observed. The map in Figures 13 and 19 which display linear and polygon data separately allow for greater clarity. The linear data shows three clusters of data that indicate there is a shared knowledge base among the participants. These hotspots of caribou information may have been known among the Elders and Hunters of Gjoa Haven but the degree to which they exist was unknown. The line data also indicates familiarity of the Baker Lake herd as noted in text on several maps. There are ten lines that indicate caribou extending to the south-west which is noted by Gunn and Kendrick as areas that migratory Barren-ground caribou winter. These routes also indicate caribou in the area of the Queen Maude Bird Sanctuary which is noted as a calving ground. (Kendrick, 2003; Gunn, et al, 2013). Additionally, there is a connection to Victoria Island that shows four caribou routes which was not mentioned in any of the literature examined for the study. This may indicate that there are caribou routes that are not noted in government and co-management boards maps from the Nunavut Caribou Strategy or the BQCMB.

The further dissemination of the route data to indicate type of caribou demonstrates a disconnect between the way that caribou are identified by co-management boards, government and the TK of the participants. When indicating caribou $81 \%$ used "caribou" as the descriptor. Of those that did identify a species or herd only 9\% identified either Barren ground or Peary caribou. There is a clear distinction in the regions where Barren-ground and Peary caribou are located based on the TK data in the maps yet they are not named by sub-species or herd. The Peary caribou routes where identified on the northern portion of the KWI with connecting routes to Victoria Island and the Boothia Peninsula north of Taloyoak.

The direction of travel during migrations is an indication to the time of the year as Barren-ground caribou migrate to the southern reaches of the ranges in the winter months and move in a northerly direction in the spring (Kendrick, et al., 2008; Kendrick, 2013; Perlee, et al., 2005). The maps indicate the migration from the south and south-west towards King William Island but 20\% indicated the season with only three showing fall and a movement from the island to the mainland. These results may be attributed to the questions asked and the flow of the conversation with the person drawing the map. One participant 
indicated summer which was drawn in the Queen Maude flats regions that has been identified as calving grounds by Gunn and Kendrick is multiple research papers.

The caribou area maps which are represented through the use of polygons create the same clutter and visual noise that the line data maps create, but have a greater amount of layered data. The participants clearly indicate that caribou are on KWI although the island is not included in most barren ground caribou maps. This reinforces the inherent social and political statements about the data that is and is not included in maps (Crampton, 2001; Engler, at al., 2013). Displaying the data by caribou species and range the map data has five areas that specify the type of caribou which is only $8 \%$ of the data, leaving the remaining 92\% noted as "caribou". The polygon noted as "Qamamituaq" is Inuktitut for Baker Lake and may indicate a connection to the Bake Lake herd. This map also places Peary caribou on the northern portion of the island which aligns the routes identified previously. The overlap of caribou areas displayed in the polygon maps reinforces the sharing of knowledge as suggested by Ljubicic and Grimwood, 2010; Kendrick, 2008; Kendrick, 2013; Wenzel 2004; Russel et al., 2000. Additionally, the number of polygons drawn in the same area may be an indication of the transfer of information that is imperative to survival in hunter-gathered societies, it is an aspect of social processes that are critical to life in the Arctic (Engler, et al., 2013; Pulsifer, et al., 2011; Leduc, 2006).

The activity related to caribou was overwhelmingly noted as hunting which is crucial to the health and sharing of resources in the community (Mason, et al., 2012; Engler, et al., 2013). They have indicated that caribou are found on the island on a year-round basis and include Barren ground and Peary. Of importance are the areas notes as "sick caribou" as both are in regions noted as hot spots for caribou hunting. The map in Figure 18 which indicates seasonality highlights the lack of knowledge about caribou in the region by the Nunavut government and the co-management boards as the data on the map suggests that caribou are located on the island year-round

The data contained in the maps dates to 1950's and is rich with information that could enable comanagement boards the ability to map and understand the actual extent of herds and the temporal fluctuations. While the data is limited in respect to the temporal variations drawn on the map there are 
areas that indicate caribou in the 1960's, 1980's,1990's, and current times. The data on the mainland dates to 1950's with some noting "past" and the area south of Cambridge Bay listing several dates. This longterm temporal data dating back over sixty years reinforces the need for the inclusion of traditional knowledge to understand the fluctuations in caribou populations.

The power of these maps is in the clarity of the data specific maps that indicate the cumulative knowledge of the participants. The knowledge in these maps highlights the depth of the TK and the importance to the cultural integrity of the Inuit community. The use of GIS to display vector based data allows for the visualization of the collective mental maps to highlight the shared knowledge which is the cornerstone of TK (McGregor, 2004; Duerden, et al., 1996; Freeman, et al., 2000, Pearce, et al., 2011). The vector based theme specific maps depict the crisp lines drawn and areas with clear borders creating a binary presence / no presence depiction of the caribou TK drawn by the participants. However, the maps that include all the data do not produce information that aides in understanding the spatial distribution of caribou in the KWI study area.

\subsection{Successes and challenges of Raster Data Fuzzy Method Maps}

The results of the cumulative analysis using raster data and a fuzzy methodology highlight the depth of shared knowledge contained in the 32 maps. The cumulative maps are mathematical equations that represent the traditional knowledge which can provide the community with potential for a greater influence TK in their lands (McGregor, 2004).

Traditional knowledge is inherently incorporates degrees variability over time and space, and thus it is well suited to a fuzzy methodology (Dunn, 2007; Jiang, et al., 2000; Berkes and Berkes, 2009; Berkes, et al., 2009). Additionally, this methodology allows for the use qualitative and well as quantitative data (Berks, et al., 2009). Fuzzy methodology accounts for the excluded middle of standard

binary data which must be true or false. Traditional knowledge is a continuum between true and false with varying degrees of correctness (Berkes, et al., 2009). The use of linguistic cues in TK such as; near here, close by, and this area allows for the inclusion of all the data independent of where it lies on the 
continuum. The data that falls between true and false is represented in the buffered area surrounding the data with data that is closer to the original line or polygon having a higher degree of membership to the feature than those that fall at the outer edges of the buffered zone. Membership relates to possibility, that is the higher the number is to 1 the closer it is to the feature and the higher the possibility that the feature lies within the buffered area.

The cumulative line data using fuzzy methodology creates a map that is very clear and succinct. Maps must be clearly understandable and relative to the participants to be of value. The simplicity of this map is created through the selection of only five categories, one representing no caribou routes and the remaining four categories representing between $1 \%$ with $75 \%$ or 14 of the 19 participants drawing a caribou route in the same place on the maps (Forsyth, 1996). The knowledge nodes are clear with a number of participants that draw a line to represent caribou in that area. The region south of the island and in a line towards Baker Lake is a reoccurring theme a connection to the Bake Lake herd. Only one area directly south of the KWI on the shoreline of the mainland falls in the top category of $51 \%-75 \%$, whereas in the vector maps there were three areas that appeared to be hot spots. The area to the east of Garry Lake indicates that it is also an area of high cumulative knowledge as well as the expected area south of KWI and the area north of Taloyoak. These areas emerge as the buffers allow for the variability of TK as suggested by (Dunn, 2007; Jiang et al., 2000; Berkes and Berkes, 2009; Berkes et al., 2009).

The caribou polygon areas indicate that KWI in its entirety except for a small portion in the north-west is a knowledge node or hotspot for caribou with between $41 \%$ - $67 \%$ range of the participants indicating that caribou is present on the island. As with the route data map the categories were simplified to five, with one indicating zero caribou and the remaining four representing between $1 \%$ - and $67 \%$ of the participants drawing a caribou area on the island. An area to the on the mainland south of KWI on the Adelaide Peninsula and west of the route hotspot on the mainland is also in the highest category. The third area with the highest number of caribou presence is the peninsula on land west of Gjoa Haven on the Boothia which was noted as a knowledge node in both the line and are vector maps. The knowledge of caribou presence in an area covers less area than that data drawn for caribou routes, with the hot spot of 
knowledge concentrated on the island, in the Chantrey Inlet Lowland and along the coast of the mainland south of KWI. An area of caribou presence is noted in the Garry Lake region with two mid-level spots. This area is also in the region of the Queen Maude lowlands which is noted as a calving ground for Barron ground caribou by both Gunn and Kendrick is several journal articles.

The power of the cumulative ability of raster based fuzzy methodology allows for the creation of clean succinct maps that are easily understand (Zadeh, 1973) and produce a bold statement about the knowledge of caribou on King William Island by the participants of this study. The lack of political boundaries on the maps reduces the political power and increases a balance between the knowledge holder and the state (Middleton, 2010; Crampton, 2001; Robbins, 2003).

\subsection{Caribou Hunting}

The series of maps created from caribou data that specified hunting as the activity related to the data can be of importance to the community as the social, cultural and traditional knowledge related to caribou is significant. (Kendrick, 2003; Kendrick, 2013; Miller, et al., 2009; Russell, et al., 2000;

Johnson, et al., 2015). The development of the data from vector line and polygon to raster using a fuzzy inference and finally a map displaying both sets of data highlights the shared knowledge that exists among the participants of the research group. With only four lines that indicated hunting the overall visual is the hunting areas in both the vector and cumulative maps. The final combined map better illustrates the knowledge nodes with the ability to see the overlapping hunting areas. The TK of hunting areas is very concentrated around KWI, the area between the clusters on the mainland south of the island and the large area to the east in the Garry Lake region illustrates the shared knowledge that can be concentrated in very specific areas highlighting the special aspect of TK (Engler, et al., 2013; Duerden, et al., 1996; Laidler, 2003). This spatial knowledge is based in generational observations about the environment and the interconnected nature of TK (McGregor, 2004; Leduc, 2006, Pulsifer, et al., 2011). 


\subsection{Observed Differences between Caribou TK in Maps and Caribou Management}

Dissemination of the route data demonstrates a disconnect between the way caribou are identified by co-management boards, government and the TK of the participants. The data in the maps overwhelmingly notes Big and Small as the descriptors for caribou, however, co-management boards such as the BQMB, and the Nunavut Caribou Strategy identify caribou by specific herd. This discrepancy may be counter intuitive to TK where caribou are identified as "big" which refers to Barren ground and "small" which identifies Peary. This breakdown into specific herds is problematic as there is a lack of information that pertains to the dynamics of herds over time and populations fluctuate (Kendrick, et al., 2008; Gunn, et al., 2011; Russell, 2000, Sharma, et al., 2009; Lenart, et al., 2002). Pearce suggests in a 2015 paper that traditional knowledge and the sharing of information about the health of caribou may be more accurate than western science based data. These discrepancies in knowledge of caribou presence, health and type on KWI between the co-management boards and the participants of this research highlight the need to include traditional knowledge, it values and principles at the start of a research project.

The management of caribou is complex as herds range over thousands of kilometers crossing jurisdictional boundaries, several levels of government and multiple stakeholders (Kendrick, et al., 2008). The cost of herd counts prohibits the ability conduct counts at intervals less than every six years for most agencies (Kendrick and Manseau, 2008). This lack of scientific data necessitates the input of TEK to understand the nuances in herd numbers, behaviors and fluctuations in respect to timing of calving, health and general abundance

\subsection{Overall Observations}

Each of the maps created based on the traditional knowledge of participants has merit and offers an understanding of the data. These maps underscore the importance of TK and role it has in the management of caribou for the Inuit on King William Island. The collective knowledge of the group suggests that there are Barren-ground and Peary caribou on the island year-round and the maps highlight 
the specific areas that are of key importance to the participants. There are clear hunting grounds on KWI and the mainland with connections as far as 500 kilometres from Gjoa Haven in Baker Lake. The literature researched on traditional knowledge for this thesis is clear on the importance of the inclusion of TK. The interconnectedness of the environment from a traditional knowledge standpoint necessitates the inclusion of TK on all aspects of life (WIPO, 2002; Berkes, et al., 207; McGregor, 2004; Wenzel, 1991; Berkes, 2008). The qualitative data on the maps includes information that is significant and would be omitted if the study was based strictly on quantitative data. The maps highlight the melding of TK and western science to better understand the traditional knowledge of the participants as it relates to the presence of caribou on King William Island. The equitable use of two knowledge systems is not only necessary to facilitate the requirements of the Nunavut Land Claims Agreement, 1993 it also highlights the breadth and depth of the knowledge of the Elders and Hunters who participated and provides temporal data that may aide in the understanding of changes that have occurred in the past and may occur in the future.

There are advantages and disadvantages in the use of both vector and raster fuzzy data maps. The maps can be viewed with varying degrees of reliability dependent on the purpose of the map. The vector maps which include all caribou data emphasizes the amount of knowledge that these 32 individuals embody, however, the maps do not convey data that is quantifiable. When separated into linear and polygon data the maps begin to explain the patterns that emerge and possible insight into how the questions were phrased with the routes and polygons producing different results as to where caribou are located. The further dissemination of the vector data reveals distinct directional and seasonal patterns that are not evident in the large data set. A smaller dataset provides a more concise map when using vector data in this instance. Additionally, the vector data has the ability to display and categorize data as noted in Figure 23 Seasonal data. The ability to code data with a different colour or line type creates maps that provide the user with options as to how to distinguish between different data in the set to highlight the amount or types. 
The fuzzy membership raster based maps provide a clearer visual image of the data in a large dataset. The visual images in the linear and polygon fuzzy maps in Figures 25 and 26 highlight very distinct hotspots. The homogenization of the data to a raster set that has the same size raster cell and extent allows for patterns to emerge. The continuous surface of a fuzzy model speaks to the continuity of the land and all the elements that embodies traditional knowledge. The separation of data into distinct separate lines and polygons as it was originally drawn dissects that land into separate entities while continuous surface which is a truer reflection of natural patterns. The fuzzy buffer zone emulates a distance decay with the numbers diminishing as you move toward the outer edges. As with a caribou herd that would be dense in numbers in the centre and decrease towards the edges of the herd. The knowledge nodes in the linear map are very distinct. The fuzzy model represents the data as equal with all the layers having the same weight in this instance. The fuzzy polygon map reinforces the differences noted in the vector maps between caribou routes and areas. However, the areas have greater definition in the fuzzy map. There is a loss of data distinction in the fuzzy model with the homogenization as there is a loss of the ability to extract or highlight specific data traits such as type of caribou, seasonality, and direction or travel. Yet, when observing the presence of caribou based on the data contained in the original maps the fuzzy model provides a surface that an effective means of conveying the collective extent of regional knowledge of caribou. Working within the spirit of the Indigenous research paradigm was a significant commitment in the overall research project led by Dr. Ljubicic. This thesis contributes one aspect of this, which is an effort to explore more appropriate representations of collective traditional knowledge, with the goal of having more representative community contributions to be considered along scientific inquiry to support community based collaborative management strategies (Crampton, 2011; Parlee at al., 2005; Cutts et al., 2011).

\subsection{Limitations}

\subsubsection{Data Limitations}


The study was limited by a small dataset. Additionally, the point data set was not large enough to analyze and would have been interesting to understand specific points. Furthermore, some of the nuances in the data may have been better understood if there was knowledge of the oral portion of the interview that accompanied the maps. The data in the fuzzy methods used an equal weighting as the importance of specific data is unknown. There may be routes that caribou migrate through that may have greater importance than others due to the number of caribou in the herds. This may also apply to the polygon data. There may be hunting areas identified as areas that have a higher yield than others. Important routes and polygons that would be weighted and classified giving them a higher degree to membership in the set.

\subsubsection{Interview Limitations}

Project information and methods overview was supplied by Dr. Ljubicic for the larger project, however, the document does not contain the specific questions in the conversation as each interview took on a different tone and direction dependent on the participant. This knowledge may have added to the context of the maps and there may have been a greater understanding of the data on each map had this information been available.

The interviews aimed for a conversational flow, and for respect of Inuit customs where it is considered rude to interrupt an Elder (Ljubicic, Personal Communication). So, there is variability in the coverage of interviews, and what is drawn on maps, according to what was most important to the individual being interviewed. Greater consistency may have been achieved through additional follow-up interview or workshops with the same interview team. The rapport they have with the Elders and Hunters may facilitate a closer relationship where trust has already been established and the Elders may see a twoway conversation as respectful communication. The research was focused on caribou and the inclusion of the other data contained in the maps may have led to interesting observations about caribou and the interplay between other animal species. Additionally, the cultural notes on the map have strengthened the interpretation of connections to Baker Lake and other communities. 


\subsubsection{Results Limitations}

The processes used in the both the vector and fuzzy method maps is successful in that both processes produced maps The first objective seeks to understand the ability of the maps produced to accurately depict the TK as it was intended. The maps successfully depict the knowledge within them. Maps created using a single theme from the data provide insight into the depth of the TK of the participants, however, the degree to which this satisfies in Inuit perspective remains unknown The second objective was through the use of a fuzzy model creates collective knowledge surfaces that accurately represents the shared knowledge of the 32 participants. As with the vector maps the success of how the participants were able to understand and decipher that data as it was displayed is unknown. This information would add to the ability to accurately gauge the success of the methods used.. In order to achieve this, further verification workshops and discussions would be needed to understand Inuit perspectives on the different approaches to representing their knowledge - what they like and what they would want done differently.

The final community results summary report created to share results in Gjoa Haven (Ljubicic et al., 2016) summarizes the project background, provides an overview of methodology, and describes caribou knowledge of the participants. As part of the photos throughout the report, community members are shown looking at the maps (caribou linear raster map, and two vector maps that are not distinguishable) that were posted during a community celebration in February 2016. However, the report does not speak to the success or failure of the maps to portray the vector data or the raster maps to express the cumulative caribou knowledge of the participants, as more extensive consultations would be needed to ensure Inuit perspectives on this are effectively represented (Ljubicic, personal communication, 2017). Nevertheless, emerging from this thesis are a few recommendations that are suggested as ways to improve the representation of TK in future mapping work (Table 2). 


\begin{tabular}{|l|l|}
\hline \multicolumn{1}{|c|}{$\begin{array}{c}\text { Recommendations for Improving the } \\
\text { translation of TK into a GIS platform }\end{array}$} & \multicolumn{1}{c|}{ Rationale } \\
\hline $\begin{array}{l}\text { Involvement of a GIS analyst / cartographer from } \\
\text { the onset of the project }\end{array}$ & $\begin{array}{l}\text { Clarify the questions that have a spatial context to } \\
\text { parse out a greater amount of spatially connected } \\
\text { data from the study. This provides the analyst the } \\
\text { information to engage in additional spatial } \\
\text { analysis such as weighted models. } \\
\text { Allows the GIS maps to be an integral part of the } \\
\text { research to create consistency in the overall } \\
\text { framework. } \\
\text { The GIS person should be aware of the } \\
\text { community's thoughts about the maps created. } \\
\text { The ability to be involved in an iterative process } \\
\text { for the production of maps that satisfy the } \\
\text { community priorities, would better support the } \\
\text { integrity of the research. }\end{array}$ \\
\hline $\begin{array}{l}\text { Consider the habitat of the region as an integral } \\
\text { portion of the data when wildlife is a focus of the } \\
\text { research }\end{array}$ & $\begin{array}{l}\text { Allows for observations about environmental } \\
\text { influences that may affect the data. }\end{array}$ \\
\hline $\begin{array}{l}\text { Team including GIS analyst comprise a best } \\
\text { practices document }\end{array}$ & $\begin{array}{l}\text { Creates a basis for continued spatial work with } \\
\text { continuity to the mapping process where } \\
\text { appropriate. }\end{array}$ \\
\hline
\end{tabular}

Table 2 Recommendation for improving the translation of TK to a GIS platform.

\subsection{Further Research}

This research is based on the experiences of 32 participants and the knowledge they have shared about caribou presence on King William Island. The closest community to Gjoa Haven is Taloyoak on the Boothia Peninsula, and there may be shared knowledge of caribou with those in Gjoa Haven. Additional data that substantiates the knowledge of caribou in the region would aide in the inclusion of TK in the management of caribou in Nunavut. Additional studies based on the same methodology may be a catalyst to change in the way in which caribou are managed and harvested. A greater understanding of the depth of TK and cultural links to other communities may move traditional knowledge from an "add-on" to biological science to the forefront of herd management.

Additional research that would meld the geography of the landscape with the TK would enhance the data. The use of remote sensing to verify land cover types, and changes over time, would aide in understanding the presence of caribou in specific areas. The classification of vegetation with remote sensing would also indicate areas that are suitable for caribou migration, calving and grazing. This 
information coupled with elevation would provide more in-depth knowledge of the study area leading to a greater understand of the depth and breadth environmental knowledge contained in the traditional knowledge of the Elders and Hunters who participated in the research group. 


\section{References}

Agrawal A., (1995). Dismantling the divide between Indigenous and scientific knowledge. Development and change. 26(3), 13-439

Atkinson, D., Deadman, P., Dudycha, D., Traynor, S. (2005) Multi-criteria evaluation and least cost path Analysis for an Arctic all-weather road. Applied Geography, 25, 287-307

Baker Lake - Qamani'Tuaq. Retrieved November 4, 2016 http://bakerlake.ca/en/home/

Berkes, F. (1999). Sacred Ecology: Traditional ecological knowledge and resource management. Philadelphia. PA: Taylor and Francis.

Berkes, F., Berkes, M. (2007). Collaborative integrated management in Canada's North: The role of local traditional knowledge and community-based monitoring. Coastal Management, 35 (1), 143-162.

Berkes F., Berkes, M. (2009). Ecological complexity, fuzzy logic, and holism in Indigenous knowledge. Futures, 41, 6-12.

Berkes F., (2009). Indigenous ways of knowing and the study of environmental change. Journal of the Royal Society of New Zealand, 39(4), 151-156

Beverly Qamanirjauq Management Board- Document Library. Retrieved March 15, 2016 http://Arctic-caribou.com/library/

Bojorquez-Tapia, LA., Juarez, L., Cruz Bello, G. (2002). Integrating fuzzy logic, optimization and GIS for ecological impact assessments. Environmental Management, 30, 418-433.

Bryan, J. (2011). Walking the line: Participatory mapping, Indigenous rights, and neoliberism. Geoforum, 42, 40-50.

Burrough P., McDonnell, R. (1998). Principles of Geographical Information Systems. New York, NY: Oxford University Press

Buroff, B., Nathan, A., Nijenstein S. (2012). Using GPS technology to (re)-examine operational definitions of 'neighbourhood' in place-based health research. International Journal of Health Geographics, 11(22),

Caquard, S. (2011). Cartography I: Mapping narrative cartography. Progress in Human Geography, 37 (1), 135-144

Caquard, S. (2011). Walking the line: Participatory mapping, Indigenous rights and neoliberalism. Geoforum, 42, 40-50.

Caribou Forever- Our Heritage, Our Responsibility. A Barren-ground caribou management strategy for the Northwest Territories 2011-2015. (2011) Northwest Territories Environment and Natural Resources.

Crampton, J. (2001). Maps as social constructions: power, communication and visualization. Progress in Human Geography, 25(2), 235-252.

Cromley, G., Hanink, D. (2003) Scale-independent land-use allocation modeling in raster GIS. Cartography and Geographic Information Science, 30(4), 343-351

Cutts, B., White, D., Kinzig. (2007). Participatory geographic information systems for the co-production of Science and policy in an emerging boundary organization. Environmental Science and Policy, 48 (8), 977-985.

Duerden, F., Kuhn, R. (1996). The application of Geographic Information Systems by First Nations and government in Northern Canada. Cartigraphica ,33 (2),49-64

Dunn, C. (2007). Participatory GIS, A peoples GIS. Progress in Human Geography, 32(5), 616-637.

Eisner, W., Cuomo, C., Hinkle, K., Jelacic, J., Kim, C., Alba, D. (2012). Producing an Indigenous Knowledge web GIS in Arctic Alaska communities: Challenges, successes, and lessons learned. Transactions in GIS, 16 (1), 17-37.

Engler, N., Scasse, T, Taylor, F. (2013). Mapping traditional knowledge: Digital cartography in the Canadian North. Cartigraphica, 48 (3), 189-199. 
ESRI Data Dictionary, (n.d) Retrieved May, 3, 2016 http://support.esri.com/other-resources/gisdictionary/term/data\%20dictionary

Feirizadeh, B., Roodposhti, M., Jankowski, P. Blaschke, T. (2014). A GIS-based neuro-fuzzy procedure for Integrating knowledge and data in landslide susceptibility mapping. Computers and Geoscience,73, 208-221.

Feizizadeh, B., Roodposhti, M., Jankowski, P., Blaschke, T. (2014). A GIS-based extended fuzzy multicriteria evaluation for landslide susceptibility mapping. Computers and Geoscience, 73, 208221.

Ford J., Smit B., Wandel, J., Allurut, M., Shappa, A., Ittusarjuats, H., Qrunnuts, K. (2008). Climate change in the Arctic: current and future vulnerability I two Inuit communities in Canada. The Geographical Journal, 174(1), 45-62.

Ford, J., Pearce, T., Duerden, F., Furgal, C., Smit, B. (2010). Climate change policy responses for Canada's Inuit population: The importance of and opportunities for adaptation. Global Environmental Change, 20, 177-191.

Forsyth, T. (1996). Science, myth and knowledge and data in landslide susceptibility mapping. Geoforum, 27(3), 375-392.

Freeman, M. (1976) Inuit land use and occupancy project, Vol. 3: Land use atlas. Ottawa, Canada: Department of Indian and Northern Affairs.

Freeman, M., Hudson, R., Foote, L. (2005). Conversation hunting: people and wildlife in Canada's north. Canadian Circumpolar Institute ,56, CCI Press./roald-amundsen-gjoa.htm

Freeman M. (1992) The nature of traditional ecological knowledge. Northern Perspectives. 20 (1), 9-12

Freund Thomason (2012)

Gjoa Haven, Nunavut: Roald Amundsen. (2010) Retrieved from http://www.gjoahaven.com

Goodchild, M. (2000). The current status of GIS and spatial analysis. Journal of Geographical systems, 2, 5-10.

Grimwood, B., Doubleday, N., Ljubicic, G., Donaldson, S., Blangy, S. (2012). Engaged acclimatization: Towards responsible community-based participatory research in Nunavut. The Canadian Geographer, 56(2), 211-230.

Gunn, A., Russell, D., Eamer, J. (2011). Northern Population trends in Canada. Canadian Biodiversity: Ecosystems and Trends 2010. Technical Thematic Report. Councils of Resource Ministers, Ottawa Ontario.

Hou, Y., Zurdada, J., Karwowski, W., Marras, W., Davis, S. (2007). Identification of key variables using Fuzzy average with fuzzy cluster distribution. IEEE Transactions of Fuzzy Systems, 15(40), 673685.

Jardine, C., Furgal C. (2010). Knowledge translation with Northern Aboriginal Communities: A case study. Canadian Journal of Nursing Research, 42(1), 119-127.

Jiang, H., Eastman, J. (2000). Application of fuzzy measures in multi-criteria evaluation in GIS. Geographical Information Science, 14(2), 173-184.

Johnson, C., Russell, D. (2014). Long-term distribution responses of a migratory caribou herd to human disturbance. Biological Conservation, 177, 52-63

Johnson, N., Alessa, L., Behe, C., Danielsen, F., Gearheard, S., Gofman-Wallingford, V., Kliskey, A., Krummel, E., Lynch, A., Mustonen, T., Pulsifer, P., Svoboda, M. (2015). The contributions of Community-based monitoring and traditional knowledge to Arctic observing networks: Reflections on the state of the field. Arctic, 68(1)1-13.

Kendrick, A. (2003). The flux of trust: caribou co-management in Northern Canada. Environments, 32(1), 43-59.

Kendrick, A. (2005). Mapping Traditional knowledge: Digital cartography in the Canadian North. Cartographica, 48, 189-199

Kendrick, A., Manseau M. (2008). Representing traditional knowledge: Resource management and Inuit Knowledge of Barren-ground caribou. Society and Natura Resources, 21, 404-418.

Kendrick, A. (2013). Canadian Inuit: Sustainable use and management in Northern Canada. International 
Journal of Environmental Studies, I70(3), 414-428.

Kendrick, A. (2013) Canadian Inuit sustainable use and management of Arctic Species. International Journal of Environmental Studies, 70(3), 414-428

Laidler, G. (2003) Climate Variability and climate change: Potential implications for Hudson Bay Coastal Communities. Polar Geography, 27(1), 38-58.

Laidler, G. (2007) Ice through Inuit eyes: Characterizing the importance of sea ice processes, use, and Change around three Nunavut communities. Doctoral dissertation, University of Toronto. (Retrieved from ProQuest ISBN:978-0-494-27962-5

Laidler, G., Grimwood, B. (2010) Report on the results of a research planning workshop in Gjoa Haven: Qanuttumik takuvit? Workshop held February 17-19, Gjoa Haven, Nunavut. Available at URL: http://www.straightupnorth.ca/Sikuliriji/GH-SummReports.html.

Leduc, T. (2006). Inuit economic adaptations for a changing global climate. Ecological Economics, 27-35

Lenart, E., Bowyer, T., VanHoef, J., Ruess, R. (2002). Climate change and caribou: effects of summer weather on forage. Canadian Journal of Zoology, 80(4|), 664-678.

Ljubicic, G., Oberndorfer, E., Smith, G. (2017) The curious case of King William Island, Nunavut: An Island overlooked in caribou research. InfoNorth essay in Arctic, 70 (1), 107-117.

Ljubicic, G., Robertson, S., Mearns, R., Okpakok, S. (2016) Connecting Inuit Elders and Youth: Learning about caribou, community, and well-being in Gjoa Haven, Nunavut (2011-2016). Available at URL: http://www.straightupnorth.ca/Sikuliriji/GH-SummReports.html.

Louise, R. (2007). Can you hear us now? Voices from the margin: Using Indigenous methodologies in geographic research. Geographical Research 41, 130-139.

Martin, K. (2009). “Are we also here for that?”: Inuit Qaujimajatuqangit - traditional knowledge, or Critical thinking. The Canadian Journal of Native Studies, 29 1/2, 183-202

Mason, M., Anderson, R., Leo-Paul, D. (2012). Inuit culture and opportunity for commercial caribou Harvests in the bio economy. Journal of Enterprising Communities, 6(3), 194-212

Matsakis, P., Wedling, L., Ni, J. (N.D.) University of Guelph, Ontario, Canada, University of Paris Descartes, Paris, France

McGregor, D. (2004) Coming full circle: Indigenous knowledge, environment and our future. American Indian Quarterly, 28 (3/4), 385-410.

Middleton, E. (2010). Seeking spatial representation: Reflections on a participatory ethnohistorical GIS Mapping of Maidu allotment lands. Ethnohistory, 57 (3), 363-387.

Miller, F., Barry, S. (2009). Long-term control of Peary Caribou Numbers by Unpredictable Exceptionally Severe Snow or Ice Conditions in Non-Equilibrium Grazing systems. Arctic, 62(2), 175-189

Natural Resources Canada. (2004) Treaty and Comprehensive Land Claims in Canada.

Nunavut Caribou Strategy Report, 2011. Government of Nunavut Retrieved August 30, 2016 http://www.nunavut.ca/files/04\%20GN\%20Caribou\%20Strategy.pdf

Nunavut Lands Claim Agreement, 1993. Article 5: Wildlife. Nunavut Tunngavik Inc., Department of Communications, Iqaluit, Nunavut. ISBN 0-9734066-1-5

Nunavut Tourism, Gjoa Haven (n.d.) Community History. Retrieved from http://nunavuttourism.com/regions-communities/gjoa-haven

Olson, R., Hackett, J., DeRoy, S. (2016). Mapping the Digital Terrain: Towards Indigenous Geographic Information and Spatial Data Quality Indicators for Indigenous Knowledge and Traditional Land-Use Data Collection. The Cartographic Journal, 2016, 1-8

Ostrom, E., Gardener, R., Walker, J. (1994). Rules, games and Common-pool resources. University of Michigan Press, Ann Arbor, MI.

Parlee, B., Manseau, M., Lutsle K'e Dene First Nations. (2005). Using traditional knowledge to adapt to Ecological change: Deneesqhne monitoring of caribou movements. Arctic, 58(1), 26-37

Pearce, T., Ford, J., Wilcox, A., Smit, B. (2015). Inuit ecological knowledge (TEK), subsistence hunting and Adaptation to climate change in the Canadian Arctic. Arctic 68(2), 233- 245. 
Pearce, T., Wright, H., Notaina, R., Kudiak, A, Smit, B., Ford, J., Furgal, C. (2011) Transmission of environmental knowledge and land skills among Inuit men in Ululhatok, Northwest Territories, Canada. Human Ecology, 39, 271-288.

Peters, W. (2013) Use of Indigenous / Indigenist research methodologies. Seven Generations Center of Excellence in Native Behavioral Health, University of North Dakota.

Pulsifer, P., Laidler, G., Taylor, F., Hayes, A. (2011). Towards an Indigenous data management program: Reflections on experiences developing an atlas of sea ice knowledge and use. The Canadian Geographer, 55 (1), 108-124.

Robbins, P. (2000). The practical politics of knowing: State environmental knowledge and local political economy. Economic Geography, 76(2), 125-144

Robbins, P. (2003). Beyond ground truth: GIS and the environmental knowledge of herders, professional foresters, and other traditional communities. Human Ecology, 32 (2), 233-253

Robinson, C., MacLean, K., Bock, E. (2016). Participatory mapping to negotiate Indigenous knowledge Used to assess environmental risk. Sustainability Science, 11, 115-126

Russell, D. Kofinas, G., Griffith, B. (2000). Need and opportunity for a North American caribou knowledge Cooperative. Polar Research, 19(1), 117-129.

Saati, S., Hatami-Marbini, A., Tavana, M., Agrell, P. (2013). A fuzzy data envelopment for clustering operations units with imprecise data. International Journal of Uncertainty, Fuzziness and Knowledge-based systems, 21(1) 29-54.

Shad, R., Shad, A., Mesgari, M., Aghamohammadi, H., Molael, D. (2009). Fuzzy topological simulation for deducing in GIS. Applied Geomatics, 1, 121-129

Sharma, S., Couturier, S., Cote, D. (2009). Impacts of climate change on the seasonal distribution of migratory caribou. Global Change Biology, 15, 2549-2562.

Sletto, B. (2009). "We drew what we imagined" Participatory mapping, performance, and the art of landscape making. Current Anthropology, 50(4), 443-476.

Store R., Jokimaki J. (2003). A GIS baes multi-scale approach to habitat suitability modeling. Ecological Modelling, 169, 1-15.

Stewart, A., Keith, D., Scottie, J. (2001). Caribou crossings and cultural meanings: Placing traditional Knowledge and archaeology in context in an Inuit landscape. Journal of Archaeological Method and Theory, 11(3), 183-211.

Sui, D. (1992) A fuzzy GIS modeling for urban land evaluation. Environment and Urban Systems, 16, 101-115.

Statistics Canada, Nunavut Community Population Counts 2016 censuses. Retrieved from http://www.stats.gov.nu.ca/en/Population\%20estimate.aspx

Thorp, N., Eyegetok, N., Hakongak, and the Kitikmeot Elders. (2002). Inuit Qaujimajatuqangit, climate, and caribou in Kitikmeot region of Nunavut, Canada. In the earth is faster now: Indigenous observations of Arctic environmental change. Fairbanks Arctic Research Consortium of the United States

Tong, X., Wang, Z. (2012). Fuzzy acceptance sampling plans for inspection of geospatial data with Ambiguity in quality characteristics. Computers and Geoscience, 48, 256-266.

Turnbull, D. (1997). Reframing science and other local knowledge traditions. Futures, 29(6), 551-562

Vahidnia, M., Alesheikh, A., Alimohammadi, A., Hosseimali, F. (2010). A GIS based neuro-fuzzy procedure for integrating knowledge and data in landslide susceptibility mapping. Computers and Geosciences, 36, 1101-1114.

Vaijhaha, S. (2005, July). Integrating GIS and participatory mapping in community development planning, Paper presented at ESRI International Conference, Sustainable Development and Humanitarian Affairs Tract, San Diego, CA

Veland, S., Lynch, A., Bischoff-Mattson, Z., Joachim. (2014). All strings attached: Negotiating relationships of geographic science. Geographical Research, 52 (3), 296-308

Vors, L., Boyce, M. (2009) Global declines of caribou and reindeer. Global Change Biology, 15(11), 2626- 2633.

Wenzel, G. (1999). Traditional ecological knowledge and Inuit: Reflections on TEK research and ethics. 
Arctic, 52(2), 113-124.

Wenzel, G. (2004). From TEK to IQ: Inuit quajimajatuqangit and Inuit cultural ecology. Arctic Anthropology, 41(2), 238-250.

Wilson, S. (2003). Progressing towards an Indigenous research paradigm in Canada and Australia. Canadian Journal of Native Education, 27(2), 161-178

Wilson, S. (2007). Guest Editorial: What is an Indigenous research paradigm? Canadian Journal of Native Education, 30(2), 193-195

Windsor, L. (2013). Using concept mapping in community-based participatory research: A mixed methods Approach. Journal of Mixed Methods Research, 7(3), 135-144

WIPO, 2002

Working together for caribou. Nunavut Caribou Strategy (March 2010). Department of environment, Nunavut

Zadeh, L. (1973) Outline of a new approach to the analysis of complex systems and decision processes. IEEE Transactions on Systems, Man and Cybernetics, 1 